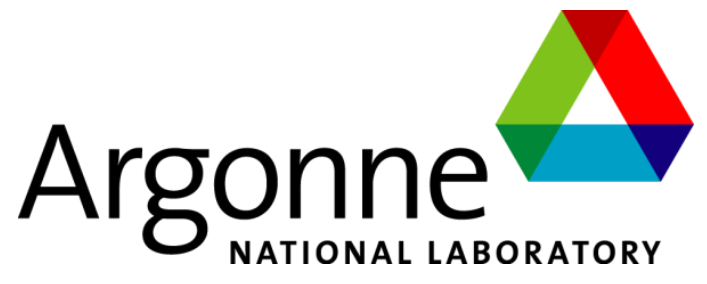

ANL-19 /15

\title{
Computational Assessment of Hydrodynamic Loads on Rockeries for River Bank Protection
}

Nuclear Science and Engineering Division 


\title{
About Argonne National Laboratory
}

Argonne is a U.S. Department of Energy laboratory managed by UChicago Argonne, LLC under contract DE-AC02-06CH11357. The Laboratory's main facility is outside Chicago, at 9700 South Cass Avenue, Argonne, Illinois 60439. For information about Argonne and its pioneering science and technology programs, see www.anl.gov.

\section{DOCUMENT AVAILABILITY}

Online Access: U.S. Department of Energy (DOE) reports produced after 1991 and a growing number of pre-1991 documents are available free at OSTI.GOV (http://www.osti.gov/), a service of the U.S. Dept. of Energy's Office of Scientific and Technical Information

\author{
National Technical Information Service (NTIS): \\ U.S. Department of Commerce \\ National Technical Information Service \\ 5301 Shawnee Rd \\ Alexandra, VA 22312 \\ www.ntis.gov \\ Phone: (800) 553-NTIS (6847) or (703) 605-6000 \\ Fax: (703) 605-6900 \\ Email: orders@ntis.gov
}

Reports not in digital format may be purchased by the public from the

\author{
Reports not in digital format are available to DOE and DOE contractors from the \\ Office of Scientific and Technical Information (OSTI): \\ U.S. Department of Energy \\ Office of Scientific and Technical Information \\ P.O. Box 62 \\ Oak Ridge, TN 37831-0062 \\ www.osti.gov \\ Phone: (865) 576-8401 \\ Fax: (865) 576-5728 \\ Email: reports@osti.gov
}

Disclaimer

This report was prepared as an account of work sponsored by an agency of the United States Government. Neither the United States Government nor any agency thereof, nor UChicago Argonne, LLC, nor any of their employees or officers, makes any warranty, express or implied, or assumes any legal liability or responsibility for the accuracy, completeness, or usefulness of any information, apparatus, product, or process disclosed, or represents that its use would not infringe privately owned rights. Reference herein to any specific commercial product, process, or service by trade name, trademark, manufacturer, or otherwise, does not necessarily constitute or imply its endorsement, recommendation, or favoring by the United States Government or any agency thereof. The views and opinions of document authors expressed herein do not necessarily state or reflect those of the United States Government or any agency thereof, Argonne National Laboratory, or UChicago Argonne, LLC. 


\section{Computational Assessment of Hydrodynamic Loads on Rockeries for River Bank Protection}

prepared by

M.A. Sitek, S.A. Lottes, and C. Bojanowski

Nuclear Science and Engineering Division

May 2019 
Table of Contents

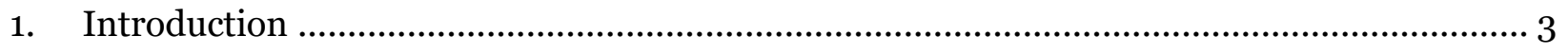

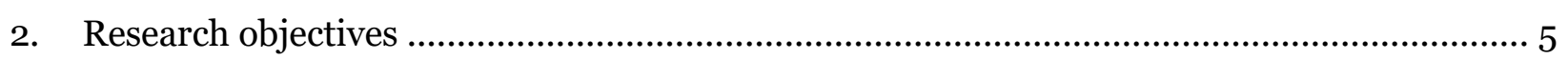

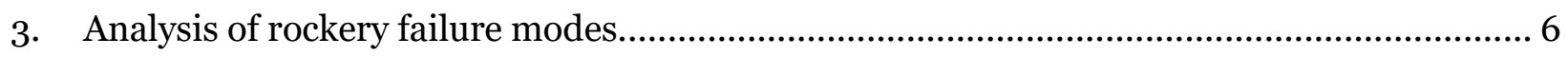

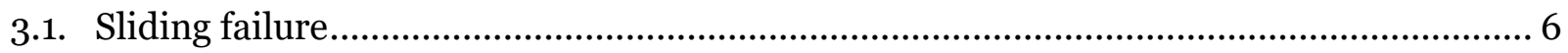

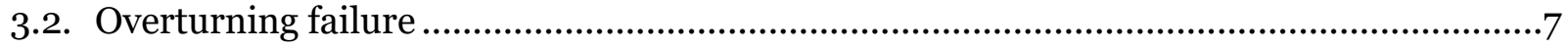

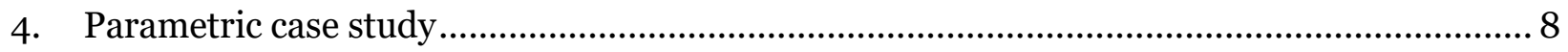

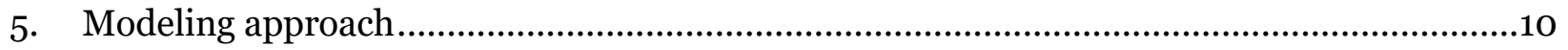

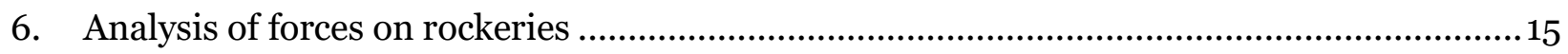

6.1. Static and dynamic forces acting on a rockery ............................................................ 15

6.1.1. Influence of the backfill ..............................................................................18

6.1.2. Influence of the rockery face batter and base width ...........................................19

6.1.3. Influence of the channel width ..................................................................20

6.1.4. Overtopping of a rockery structure ............................................................... 35

6.2. Numerical example of rockery failure criteria. Straight channel ................................. 37

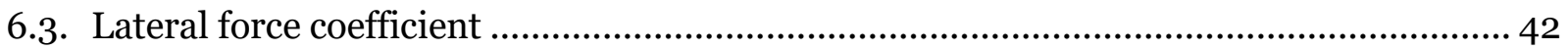

6.4. Selection of representative set of rocks for further analysis....................................... 47

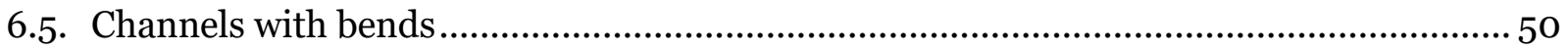

6.6. Numerical example of rockery failure criteria. Channel with a bend............................ 60

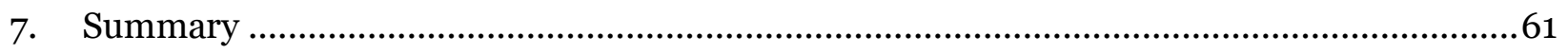

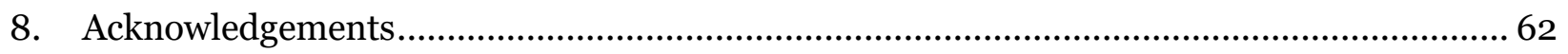

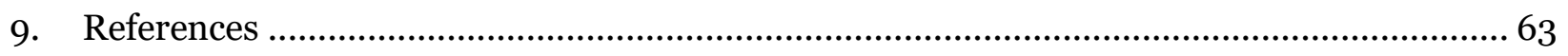




\section{List of Figures}

Figure 1-1: Example dry-stack rockeries built as retaining structures. Photo source: CFL staff from the "Beaver to Junction Project" in south-western Utah; project designed by CH2MHill ... 4

Figure 3-1: Forces acting on a rockery in water environment ........................................... 6

Figure 3-2: The distances between the point of rotation and forces .........................................

Figure 4-1: The studied parameters and adopted values................................................... 9

Figure 4-2: Channels with sharp bends with marked angle of the bend ................................... 9

Figure 5-1: An example computational model of a straight channel...................................... 11

Figure 5-2: An example computational model of a channel with a sharp bend ......................... 11

Figure 5-3: The adopted boundary conditions in CFD models of straight channels ...................12

Figure 5-4: Mean flow velocity vs. channel width ...............................................................13

Figure 5-5: Volume flow rate vs. channel width ...............................................................13

Figure 5-6: Cross-sections through CFD domains (a) without backfill, (b) with backfill .............14

Figure 6-1: Forces computed for each of the rocks ...............................................................15

Figure 6-2: Pressure distribution on rocks, (a) front side of the rockery (water side), (b) back side of the rockery (backfill side) in the base test case. .......................................................16

Figure 6-3: Hydrodynamic forces for separate rocks in the base test case ...............................17

Figure 6-4: Hydrodynamic forces vs. buoyancy of the rocks in the base test case......................17

Figure 6-5: Ratio of the hydrodynamic force to weight for separate rocks in the base test case ...18

Figure 6-6: Vertical distribution of hydrodynamic forces per unit length of rockery in rockery models with and without backfill ( $n-b$ - model without backfill, w-b - model with backfill) for the bed width $24 \mathrm{ft}$.

Figure 6-7: Vertical distribution of hydrodynamic forces per unit length. Models with batter 4:1 and 12:1

Figure 6-8: Vertical distribution of hydrodynamic forces per unit length of rockery with face batter 4:1 and base width $7 \mathrm{ft}$ at water height $12 \mathrm{ft}$

Figure 6-9: Vertical distribution of hydrodynamic forces per unit length of rockery with face batter $4: 1$ and base width $7 \mathrm{ft}$ at water height $9 \mathrm{ft}$ 
Figure 6-10: Vertical distribution of hydrodynamic forces per unit length of rockery with face batter $4: 1$ and base width $7 \mathrm{ft}$ at water height $7 \mathrm{ft}$.....

Figure 6-11: Vertical distribution of hydrodynamic forces per unit length of rockery with face batter $4: 1$ and base width $8 \mathrm{ft}$ at water height $12 \mathrm{ft}$

Figure 6-12: Vertical distribution of hydrodynamic forces per unit length of rockery with face batter 12:1 and base width $7 \mathrm{ft}$ at water height $12 \mathrm{ft}$

Figure 6-13: Vertical distribution of hydrodynamic forces per unit length of rockery with face batter 12:1 and base width $7 \mathrm{ft}$ at water height $9 \mathrm{ft}$

Figure 6-14: Vertical distribution of hydrodynamic forces per unit length of rockery with face batter 12:1 and base width $7 \mathrm{ft}$ at water height $7 \mathrm{ft}$.....

Figure 6-15: Vertical distribution of hydrodynamic forces per unit length of rockery with face batter 12:1 and base width $8 \mathrm{ft}$ at water height $12 \mathrm{ft}$.....

Figure 6-16: Hydrodynamic forces per unit length vs. channel width, $\mathrm{W}_{\mathrm{B}}$. L1 $-1^{\text {st }}$ layer, L2 $-2^{\text {nd }}$ layer, L3 $-3^{\text {rd }}$ layer, L4 $-4^{\text {th }}$ layer, L5 $-5^{\text {th }}$ layer.

Figure 6-17: Velocity magnitude profile on a cross section perpendicular to the flow. Channel width, $W=12 \mathrm{ft}$, ratio of channel width to water level height $\mathrm{W} / \mathrm{H}=1$, rockery face batter (a) $\mathrm{b}=4: 1$, (b) $\mathrm{b}=12: 1$.

Figure 6-18: Velocity magnitude profile on a cross section perpendicular to the flow. Channel width, $\mathrm{W}=24 \mathrm{ft}$, ratio of channel width to water level height $\mathrm{W} / \mathrm{H}=2$, rockery face batter (a) $\mathrm{b}=4: 1,(\mathrm{~b}) \mathrm{b}=12: 1$

Figure 6-19: Velocity magnitude profile on a cross section perpendicular to the flow. Channel width, $\mathrm{W}=48 \mathrm{ft}$, ratio of channel width to water level height $\mathrm{W} / \mathrm{H}=4$, rockery face batter (a)

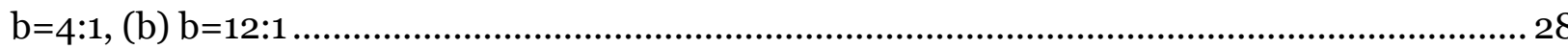

Figure 6-20: Line of points between the point of maximum flow velocity and layers 3 (L3). Red color shows the location of the highest flow velocity magnitude.....

Figure 6-21: Flow velocity magnitude along a line between the rock surface and the point of maximum velocity, shown in Figure 6-20, for a set of channels with water height $12 \mathrm{ft}$, rockery face batter 4:1 and varying width equal to $6 \mathrm{ft}, 12 \mathrm{ft}, 24 \mathrm{ft}, 48 \mathrm{ft}$.

Figure 6-22: An example rock belonging to the third layer of rocks, (a) pressure distribution, (b) partition of the rock surface: part interacting with fluid (blue) and part interacting with backfill (red)

Figure 6-23: Resultant force acting on a rock shown in Figure 6-22 vs. the ratio of the maximum flow velocity and the distance between the rock and the location of the maximum velocity. Water height $12 \mathrm{ft}$, rockery face batter 4:1 and varying width equal to $6 \mathrm{ft}, 12 \mathrm{ft}, 24 \mathrm{ft}, 48,96 \mathrm{ft}$. 32 
Figure 6-24: Ratio of hydrodynamic forces to weight of the rocks vs. channel width. Case number $1(\mathrm{C} 1)-\mathrm{H}=12 \mathrm{ft}, \mathrm{B}=7 \mathrm{ft}$, case number $2(\mathrm{C} 2)-\mathrm{H}=7 \mathrm{ft}, \mathrm{B}=7 \mathrm{ft}$, case number $3\left(\mathrm{C}_{3}\right)-$ $\mathrm{H}=12 \mathrm{ft}, \mathrm{B}=8 \mathrm{ft}$.

Figure 6-25: Ratio of hydrodynamic forces to weight of the rocks vs. channel width and the linear trend lines for (a) case number $1(\mathrm{C} 1)-\mathrm{H}=12 \mathrm{ft}, \mathrm{B}=7 \mathrm{ft}$, (b) case number $2(\mathrm{C} 2)-\mathrm{H}=7 \mathrm{ft}$, $\mathrm{B}=7 \mathrm{ft}$, (c) case number $3\left(\mathrm{C}_{3}\right)-\mathrm{H}=12 \mathrm{ft}, \mathrm{B}=8 \mathrm{ft}$

Figure 6-26: Vertical distribution of hydrodynamic forces per unit length of rockery with face batter 4:1 and 12:1, base width $7 \mathrm{ft}$ at water height $16 \mathrm{ft}$.

Figure 6-27: Vertical distribution of hydrodynamic forces per unit length of rockery with face batter 4:1 and 12:1, base width $7 \mathrm{ft}$ at water height $18 \mathrm{ft}$

Figure 6-28: Hydrodynamic forces per unit length vs. channel width for cases of water height overtopping the rockery, W. L1 - 1st layer, L2 - 2nd layer, L3 - 3rd layer, L4 - 4th layer, L5 $5^{\text {th }}$ layer

Figure 6-29: Variables in the numerical example

Figure 6-30: An example cross section through a model, $\mathrm{W}=12 \mathrm{ft}, \mathrm{W} / \mathrm{H}=1$. The dynamic force acting on the $i_{\text {th }}$ layer was shown. Points $C$ and $C_{\mathrm{r}}$, as well as distance $d i$, and rock layer height $h i$ were marked for reference.

Figure 6-31: Lateral force coefficient vs. $d / h$ for cases with water level lower than the rockery height (no overtopping)

Figure 6-32: Lateral force coefficient vs. $\mathrm{d} / \mathrm{h}$ for cases with water level higher than the rockery height (overtopping).

Figure 6-33: Example chart to be used in design of rockeries in river environment

Figure 6-34: Lateral force coefficient $\mathrm{C}_{\text {lat }}$ vs. $\mathrm{d} / \mathrm{h}$ in log-log scale for cases without overtopping. Forces acting on the bottom layers of rocks were omitted from the chart, as they are the lowest. A linear function fitted into the data points was marked with a red dashed line $(y=-$ $0.012 \mathrm{X}+0.2128)$.

Figure 6-35: Lateral force coefficient vs. Reynolds number scaled with the ratio of channel width to water height (forces acting on the bottom layers of rocks were omitted from the chart, as they are the lowest). The best fit is a linear function $y=-0.0641 x+0.1424$ (blue dotted line), and the linear upper limit is defined as $\mathrm{y}=-0.0641 \mathrm{x}+0.1784$ (red dashed line). 46

Figure 6-36: Cluster of stones selected for analysis 48

Figure 6-37: Hydrodynamic forces per rock vs. channel width.

Figure 6-38: Lateral force coefficient per rock vs. a non-dimensional parameter.

Computational Assessment of Hydrodynamic Loads on Rockeries for River Bank Protection 
Figure 6-39: Geometry of an example channel with a sharp bend ( $\alpha$ is the bend angle). The clusters of representative stones were marked in pink. The direction of the hydrodynamic forces was shown. 50

Figure 6-40: Velocity magnitude at the level of the 2nd layer of rocks (a) at various angles of the bend, (b) 15 degrees, (c) 30 degrees, (d) 45 degrees, (e) 60 degrees. 52

Figure 6-41: Velocity magnitude at the level of the 3rd layer of rocks (a) at various angles of the bend, (b) 15 degrees, (c) 30 degrees, (d) 45 degrees, (e) 60 degrees.

Figure 6-42: Velocity magnitude at the level of the 4th layer of rocks (a) at various angles of the bend, (b) 15 degrees, (c) 30 degrees, (d) 45 degrees, (e) 60 degrees......

Figure 6-43: Hydrodynamic forces on clusters of rocks in the $2^{\text {nd }}$ layer at varying angle of the channel bend. Rocks located in the rockery (a) on the left side, and (b) on the right side of the channel.

Figure 6-44: Hydrodynamic forces on clusters of rocks in the 3rd layer at varying angle of the channel bend. Rocks located in the rockery (a) on the left side, and (b) on the right side of the channel.

Figure 6-45: Hydrodynamic forces on clusters of rocks in the 4th layer at varying angle of the channel bend. Rocks located in the rockery (a) on the left side, and (b) on the right side of the channel.

Figure 6-46: Cumulative plot of the force ratio for the rocks in the 2nd layer at varying angle of the bend 58

Figure 6-47: Cumulative plot of the force ratio for the rocks in the 3rd layer at varying angle of the bend

Figure 6-48: Cumulative plot of the force ratio for the rocks in the 4th layer at varying angle of the bend

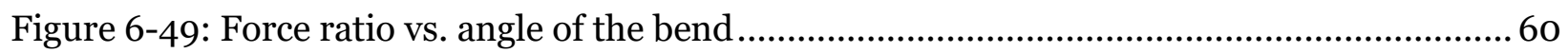

Figure 6-50: Numerical example - channel with a bend .................................................61 


\section{List of Tables}

Table 6-1: Average pressure and lateral forces acting on the front and back surface of a selected rock, and the resultant lateral force for a set of channels with water height $12 \mathrm{ft}$, rockery face batter 4:1 and varying width equal to $6 \mathrm{ft}, 12 \mathrm{ft}, 24 \mathrm{ft}, 48,96 \mathrm{ft}$

Table 6-2: The parameters in the numerical example

Table 6-3: Stability analysis for sliding and overturning failure of a selected set of rockeries. The weight of the retained soil is $\gamma_{\mathrm{s}}=115 \mathrm{pcf}\left(17.2 \mathrm{kN} / \mathrm{m}^{3}\right)$.

Table 6-4: Stability analysis for sliding and overturning failure of a selected set of rockeries. The

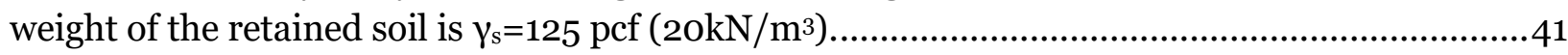

Table 6-5: Maximum force ratio vs. the angle of the channel bend ......................................... 59 


\section{Nomenclature}

\begin{tabular}{|c|c|}
\hline Symbol & Physical quantity \\
\hline$A$ & area of the channel cross-section \\
\hline$A_{r}$ & area of vertical cross-section of a rock \\
\hline$b$ & rockery face batter \\
\hline$B$ & rockery base width \\
\hline C & point in the center of a channel on the water surface \\
\hline$C_{\text {lat }}$ & lateral force coefficient \\
\hline$C_{r}$ & point in the center of a rock front surface \\
\hline$d$ & distance between points $C$ and $C_{r}$ \\
\hline$D$ & rockery embedment depth \\
\hline$D_{50}$ & particle diameter \\
\hline$F_{H}$ & horizontal force acting on the back of a rockery \\
\hline$F_{A, H}$ & lateral earth pressure \\
\hline$F_{A, V}$ & vertical component of the Coulomb active earth pressure \\
\hline$F_{H D}$ & hydrodynamic force \\
\hline$F_{S}$ & surcharge load \\
\hline$F S_{O T}$ & factor of safety against overturning \\
\hline$F S_{S L}$ & factor of safety against sliding \\
\hline$F_{\mu}$ & frictional resistance \\
\hline$h$ & rockery layer height \\
\hline$H$ & rockery height from bottom of base rock to top of backfill \\
\hline$H_{\text {exp }}$ & exposed rockery height \\
\hline$H_{w}$ & river water height \\
\hline$i$ & index, rockery layer number \\
\hline K & coefficient, transformation of units \\
\hline$K_{A}$ & lateral earth pressure coefficient \\
\hline$L$ & distance \\
\hline$M_{O}$ & overturning moment \\
\hline$M_{R}$ & resisting moment \\
\hline$n$ & Manning number \\
\hline$p$ & pressure \\
\hline$P$ & wetted perimeter \\
\hline$q_{s}$ & surcharge pressure \\
\hline$Q$ & flow rate \\
\hline$r_{F}$ & ratio of force in a channel with a bend to force in a straight channel \\
\hline$R$ & hydraulic radius \\
\hline$R e$ & Reynolds number \\
\hline$S$ & channel bed slope \\
\hline$v$ & mean flow velocity \\
\hline$W$ & weight of the rocks \\
\hline$W_{B}$ & channel bed width \\
\hline
\end{tabular}

Computational Assessment of Hydrodynamic Loads on Rockeries for River Bank Protection 


$\begin{array}{ll}\alpha & \text { back slope inclination angle } \\ \alpha_{B} & \text { angle of channel bend } \\ \beta & \text { ground surface inclination angle } \\ \gamma_{R} & \text { rock unit weight } \\ \gamma_{S} & \text { soil unit weight } \\ \delta & \text { interface friction angle } \\ \mu & \text { friction coefficient between the rockery and foundation soil } \\ \mu_{w} & \text { dynamic viscosity of water } \\ \rho & \text { density of water } \\ \phi & \text { friction angle } \\ \chi & \text { porosity of the backfill } \\ \psi & \text { back cut angle }\end{array}$




\section{Introduction}

A rockery is a structure built of dry-stacked angular rocks in an interlocking pattern without mortar or any reinforcement. They have been used around the world for centuries, but only recently have design and construction recommendations been issued in the U.S. The literature on the subject is not extensive. Several municipal codes [1], [2] as well as state regulations [3], [4] were published. They do not consider rockeries as retaining structures and significantly limit the rockery height (to as low as $4 \mathrm{ft}$ ). The federal design guidelines can be found in [5] where it is recommended to use rockeries mainly for erosion control in cases where only minor support is needed at the slope face. The document describes the recommendations regarding the design, materials and construction. The most recent and comprehensive document available is [6], where the authors presented a unified analysis and design framework of rockeries as protecting or retaining structures.

To minimize river encroachments in locations such as narrow mountain canyons, roadway fill embankment must often be over steepened beyond the maximum slope ratio of $1.5 \mathrm{~h}: 1 \mathrm{v}$ typically designed for loose riprap. Rather than constructing traditional, costly vertical cast-in-place concrete retaining structures, an emerging trend is to construct aesthetically pleasing, less expensive, gravity dry-stack rockeries. However, no engineering analysis procedures are available for evaluating the hydraulic stability of such structures when exposed to the various forces acting upon them in the river environment. There is a knowledge gap between evaluating the hydraulic stability of loose rock on a sloping surface versus stacked rock in a near-vertical orientation. As the application of rockeries in such an environment should be expected to increase in time, there is a need to establish the technical basis for design guidelines of rockeries in river and coastal environments.

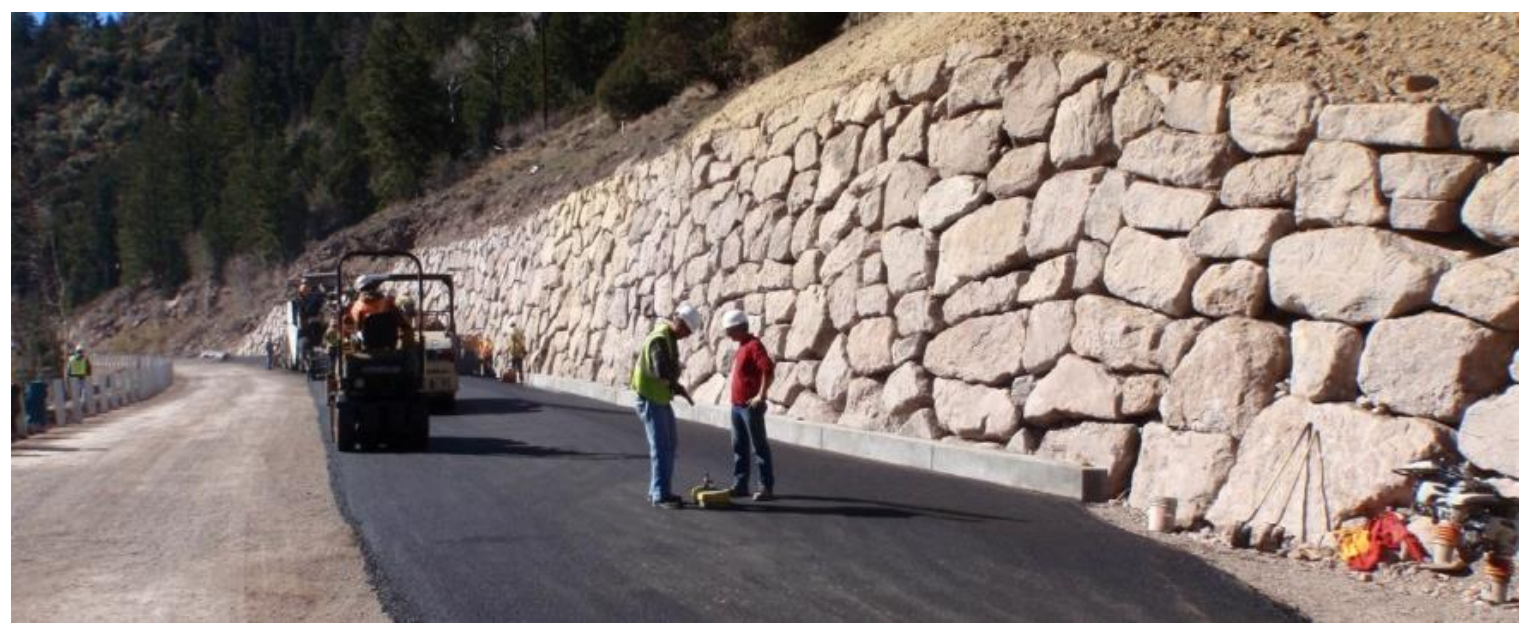

Computational Assessment of Hydrodynamic Loads on Rockeries for River Bank Protection 


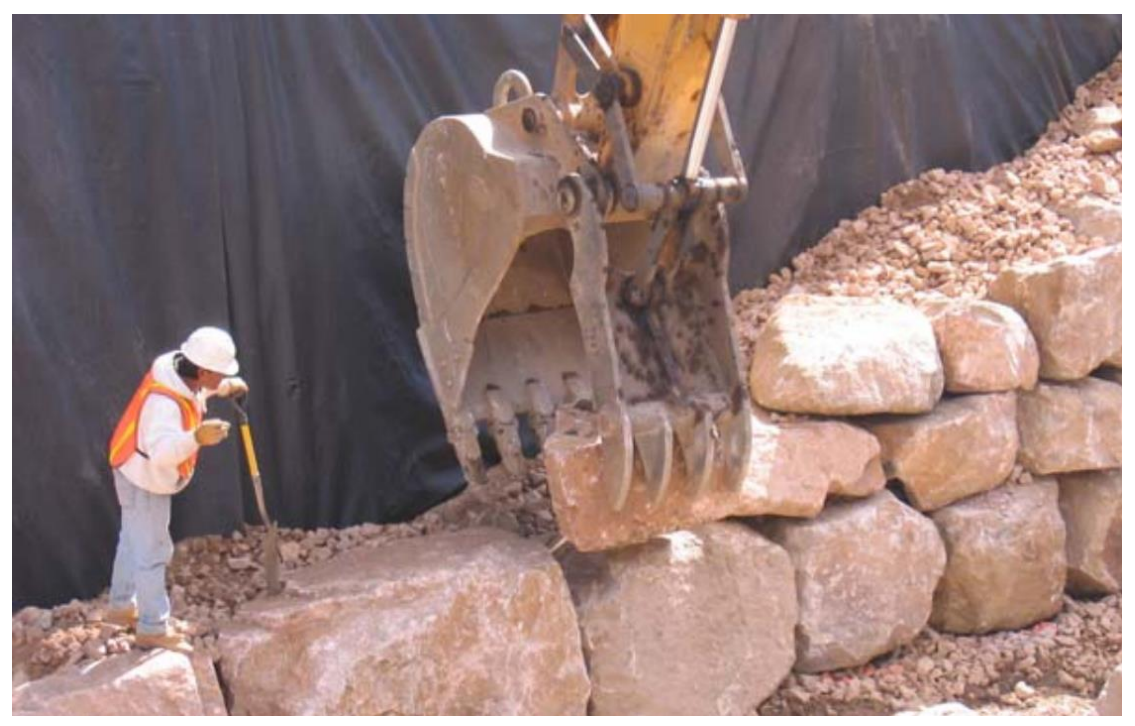

Figure 1-1: Example dry-stack rockeries built as retaining structures. Photo source: CFL staff from the "Beaver to Junction Project" in south-western Utah; project designed by CH2MHill

Gravity force, lateral earth pressure, surcharge pressure, buoyancy, hydrodynamic forces, and contact/friction forces are the main forces acting on the rocks in a dry-stack rockery in a riverine environment. While most of these forces can be determined with well-known geotechnical engineering methods, the estimation of hydrodynamic and contact forces can only be performed in scaled laboratory tests or by using advanced, three-dimensional numerical methods.

In an effort to determine the feasibility of using rockeries in such applications, an investigation was conducted on a section of a model rockery comprised of large boulders exposed to a variety hydraulic flow conditions [7]. A repeatable geometric section of the typical rockery structure was modeled in a computer aided design (CAD) program and used to create boundaries for the computational fluid dynamics (CFD) model. CFD analysis was carried out for a limited number of rockery orientations, the hydrodynamic forces on a set of representative rocks at different locations along the wall, and different water surface heights.

The unknown flowing water dynamic pressure distribution at the rockery surface is a driving force and the CFD analysis is used to calculate a conservative value for it. The rock surface shear stress distribution from the flow is also computed and included forces acting on the rocks, however, it is a second order effect and does not significantly impact the stability of a rockery.

An additional CFD parametric case study [8] was performed to identify the geotechnical and hydraulic factors that govern the stability of rockeries in straight channels and channel bends. The test case matrix covered a set of geometries of the rockery and various water levels.

Two failure mechanisms of rockery structures, sliding and overturning, were considered. The governing equations for both modes were identified in [6]. A product of the current study is the addition of hydrodynamic force terms, estimated in numerical analysis, to the existing design equations. Moreover, formulas for dimensionless hydraulic force coefficients are proposed that 
can be used in the design of new rockeries or in evaluation of existing dry-stack rockeries in river environments.

\section{Research objectives}

The primary objective of the first study [7] was to use a CFD model of channel flow along a rockery for a variety of conditions to compute the detailed dynamic pressure, static pressure, and shear stress distributions on a set of rocks in a rockery. These pressure and stress distributions were then summed up to compute the resultant force on selected representative rocks, and the resultant force was compared to the submerged weight of the rocks to see if the hydraulic forces are potentially large enough to dislodge individual rocks in a rockery.

The current study expands this work and examines hydraulic effects on the entire rockeries. The main goal of the current study was to gain a fundamental understanding of the failure modes of rockeries and identify the hydraulic and geotechnical parameters required to evaluate rockery stability and to design rockeries for application in a river environment.

Accordingly, the following objectives are identified for this study:

1) Resolve, in three dimensions, all forces acting upon a dry-stack rockery when constructed to function as river bank protection.

a. The driving forces:

i. lateral earth pressure,

ii. surcharge pressure,

iii. hydrodynamic pressure,

iv. buoyancy.

b. The resisting forces:

i. weight of the rockery,

ii. inter - rock friction,

iii. base rock - foundation friction.

2) Conduct a parametric study to identify the geotechnical and hydraulic factors that govern the stability of rockeries. Test the governing parameters over a large range of values to demonstrate robustness of the numerical analysis.

a. Geotechnical parameters:

i. rockery height,

ii. outside face batter angle of the rockery,

iii. rockery base width,

iv. river bed width.

b. Hydraulic parameters:

i. flow depth,

ii. flow velocity,

iii. hydraulic angle of attack. 
3) Analyze the potential failure modes of rockeries in the river environment, i.e. sliding and overturning. The overall balance, well as the stability of individual rocks, are taken into consideration.

4) Develop practical, dimensionless equations that will allow rockeries to be designed and/or evaluated for the range of geotechnical and hydraulic site conditions in the study.

\section{Analysis of rockery failure modes}

Two types of failure modes are taken into consideration in the analysis of rockeries: sliding and overturning. The governing equations for both modes in 'dry' conditions are presented in [6]. As the result of the present research, the hydrodynamic forces, estimated in numerical analysis, are added to these equations.

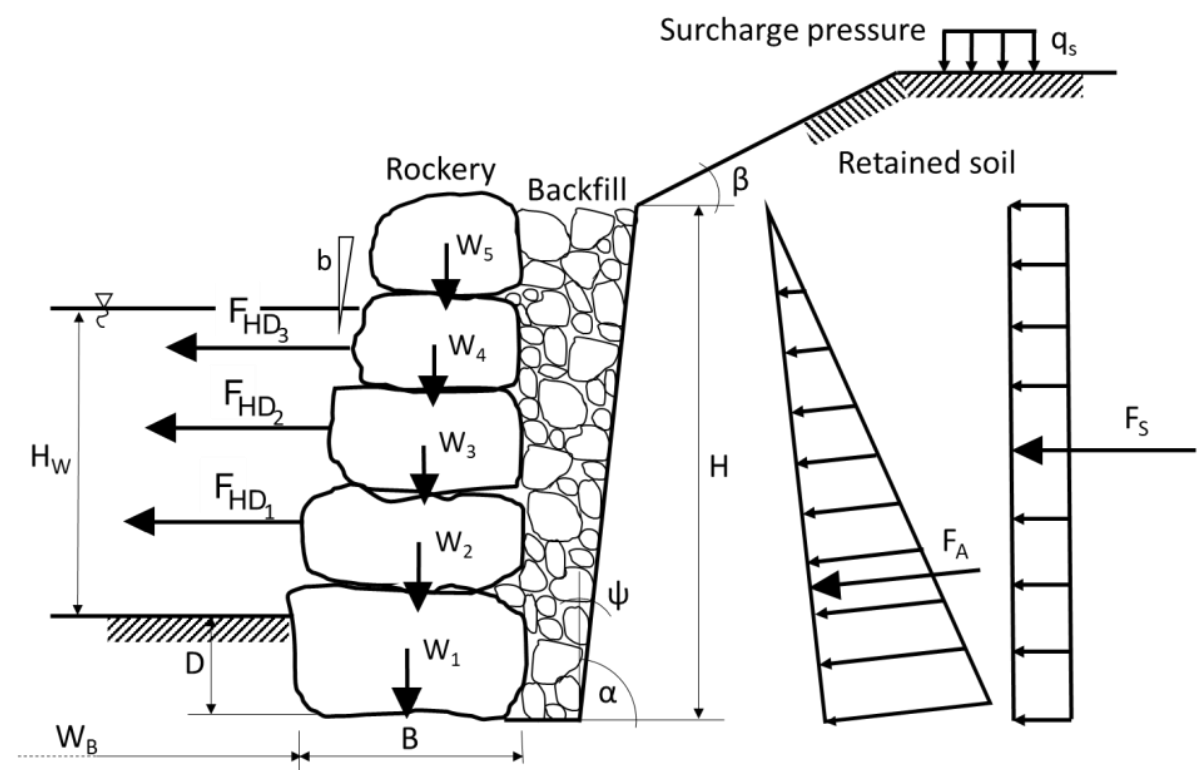

Figure 3-1: Forces acting on a rockery in water environment

\subsection{Sliding failure}

Horizontal force acting on the back of a rockery

where:

$$
F_{H}=F_{A, H}+F_{S}+F_{H D},
$$

- lateral earth pressure

- surcharge load

$$
F_{A, H}=\frac{1}{2} \gamma_{S} K_{A} H^{2} \cos (\delta-\psi),
$$

$$
F_{S}=q_{S} K_{A} H,
$$


- hydrodynamic force from CFD analysis (as a sum of forces acting on separate rocks, where $i$ is the rock number) is

$$
F_{H D}=\sum_{i} F_{H D_{i}} .
$$

Frictional resistance along the base of a rockery

where:

$$
F_{\mu}=\mu\left(W+F_{A, V}\right)
$$

- $\mu$ - friction factor between the rockery and foundation soil (in most cases in a range between 0.4 and 0.8 )

- weight of the rocks

$$
W=\sum_{i} W_{i},
$$

- vertical component of the Coulomb active earth pressure (valid only for $\psi \leq \delta$ )

$$
F_{A, V}=\frac{1}{2} \gamma_{S} K_{A} H^{2} \sin (\delta-\psi) \text {. }
$$

The ratio of resisting to driving forces should be greater than or equal to the factor of safety against sliding. For 'dry' conditions its value was established as

$$
F S_{S L}=\frac{F_{\mu}}{F_{H}} \geq 1.5 .
$$

This study adds a hydrodynamic term to $F_{H}$, thus requiring a larger resisting force to meet the same safety factor condition recommended for dry conditions. For riverbank environment applications, however, the costs and other consequences of failure may or may not indicate that an adjustment to the safety factor for river application should be made. This determination will be made by FHWA.

\subsection{Overturning failure}

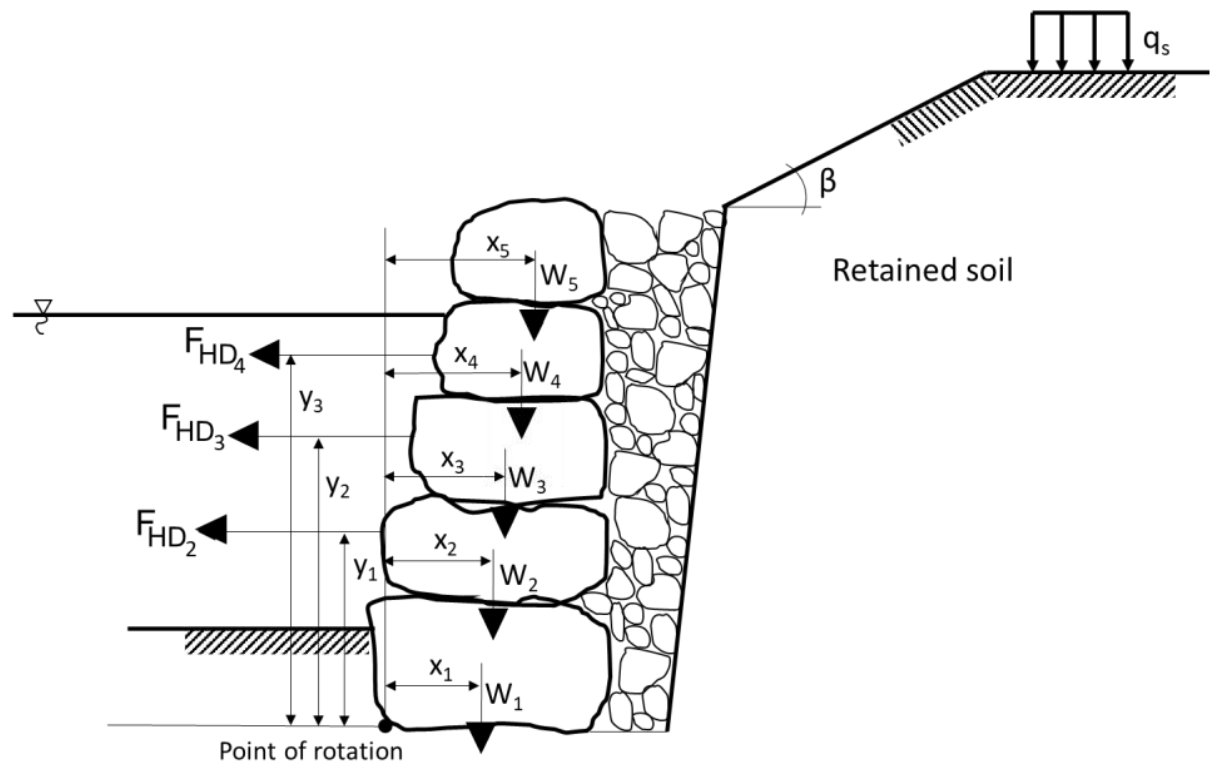

Figure 3-2: The distances between the point of rotation and forces 
The overall overturning moment consists of three terms deriving from: (1) lateral earth pressure, $F_{A, H},(2)$ surcharge load, $F_{S}$, and (3) hydrodynamic force, $F_{H D}$, and is equal to

$$
M_{O}=\frac{1}{2} \gamma_{S} K_{A} H^{2} \cos (\delta-\psi) \frac{H}{3}+q_{S} K_{A} H \frac{H}{2}+\sum_{i}\left(F_{H D_{i}} y_{i}\right) \text {. }
$$

Figure 3 shows the hydrodynamic forces acting on the submerged rocks and their weight as well as their distances from the point of rotation.

The resisting moment originates from the weight of the rockery, $W$, and vertical component of the Coulomb active earth pressure, $F_{A, V}$,

$$
M_{R}=\sum_{i}\left(W_{i} x_{i}\right)+\frac{1}{2} \gamma_{S} K_{A} H^{2} \sin (\delta-\psi)\left(\frac{H}{3} \tan (\psi)+B\right)
$$

The factor of safety against overturning for a rockery in 'dry' conditions was established as

$$
F S_{O T}=\frac{M_{R}}{M_{O}} \geq 2 \text {. }
$$

The inter-rock sliding and overturning on different levels will be checked as well. Conservative values for the friction coefficients are assumed based on the literature. Accurate inter - rock friction forces could be obtained from a computational structural mechanics' analysis, but this approach would require a detailed description of the geometry of each rock and a precisely constructed rockery structure in the software. It is too expensive to do with current software and available data.

In river environments, the $M_{O}$ term contains the additional driving forces arising from hydrodynamic conditions, and consequently the resisting terms will need to be larger to meet the safety factor condition above. As noted for sliding failure, the cost of failure and other failure consequences in this type of application may be low enough to allow changing the safety factor. FHWA will make that determination.

\section{Parametric case study}

The parametric analysis covers geotechnical and flow characteristics. The base case considers a $13 \mathrm{ft}$-high rockery with base width $7 \mathrm{ft}$ (the recommended base widths for a rockery in dry conditions are from $0.3 \mathrm{H}$ to $0.5 \mathrm{H}$, where $\mathrm{H}$ is the rockery height) and the face batter is $4: 1$. The water level is $12 \mathrm{ft}$ with angle of attack o deg (the flow is parallel to the rockery). The channel bed is $24 \mathrm{ft}$ wide, the bed slope is 0.023, and Manning's coefficient is taken to be 0.05. Using this data in Manning's equation allows determination of the average velocity of the flow as $14 \mathrm{ft} / \mathrm{s}$. The Froude number equals 0.76 .

The base case is defined for initial testing and to use as a basis for parameter variation. Several parametric case sets for the CFD model analysis were created by varying the parameter values of the base case over a broad range. The set of test cases considers all parameters used in rockery design over ranges that can reasonably be expected in field conditions during extreme flood events. The chosen set of variables and their ranges is as follows:

- $\quad$ water height, $H_{w}: 7,9,12,16$, and $18 \mathrm{ft}(2.1,2.74,3.7,4.88,5.5 \mathrm{~m})$,

- $\quad$ stream bed width, $W_{B}: 12,24,48 \mathrm{ft}$, up to $96 \mathrm{ft}$ ( $3.7 \mathrm{~m}$ to $29 \mathrm{~m}$ ),

Computational Assessment of Hydrodynamic Loads on Rockeries for River Bank Protection 
- face batter, $b: 4: 1,12: 1$,

- $\quad$ base width, $B: 4,7$ and $8 \mathrm{ft}(1.2,2.1,2.4 \mathrm{~m})$,

- flow angle of attack, $\alpha_{B}$ : o, 30, 45 and 60 degrees.

$$
\mathrm{H}_{\mathrm{W}}=16,18 \mathrm{ft}
$$

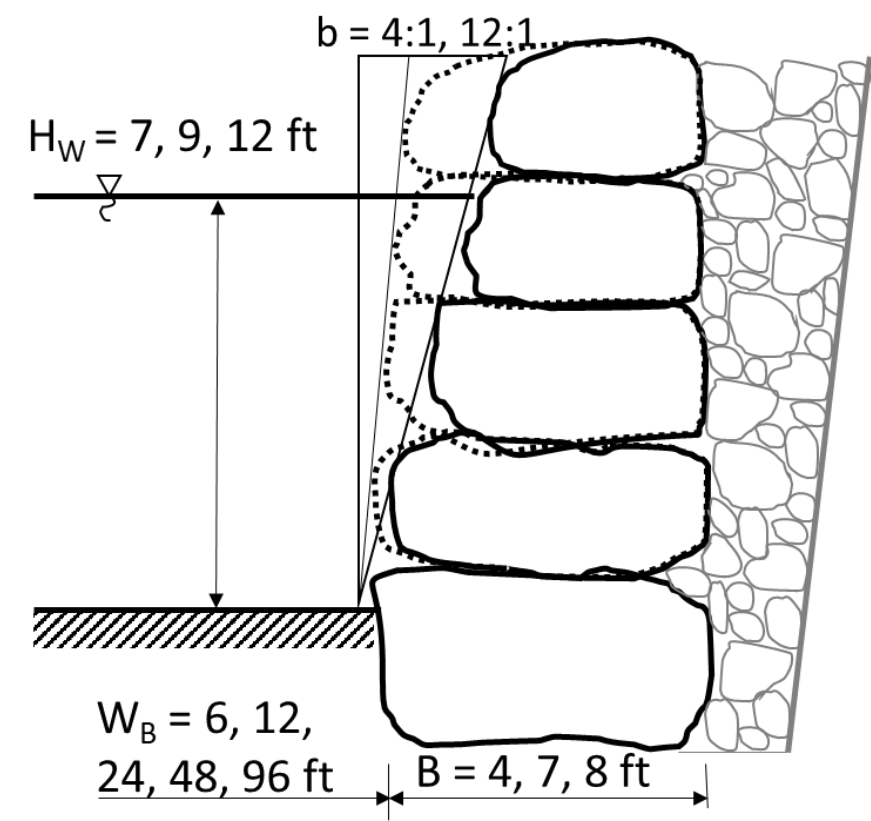

Figure 4-1: The studied parameters and adopted values

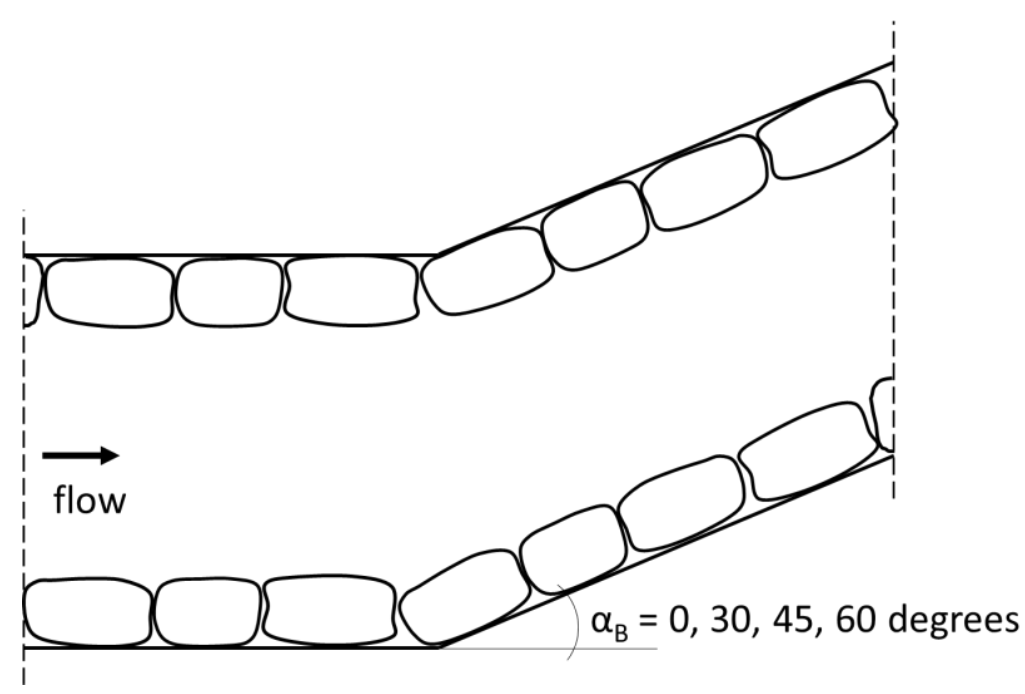

Figure 4-2: Channels with sharp bends with marked angle of the bend 


\section{Modeling approach}

The CFD models were developed in a way to represent in detail the geometry of a rockery used as bank protection for a channel. The models consist of rocks forming a rockery, with the geometry of the separate rocks meshed out, backfill, modeled as a porous region, and the channel filled with water. The individual rocks are separated with small gaps that allow the water to flow in between, and behind them. The geometry and size of the rocks differ to account for the irregularities of real rocks. Figure 6-1 presents a model of a straight channel and Figure 6-2 shows a model of a channel with a bend.

In order to complete the set of cases on a faster schedule with fewer computational resources and develop a hydrodynamic force relation for rockeries as a function of the parameters tested, several simplifying assumptions were made.

Flood flows that pose failure risk for rockeries are sufficiently deep that variations in the free surface can be neglected. Under these conditions, two phase (water and air) flow analysis with a free surface can be replaced with a single phase, water only, analysis with the top boundary being an atmospheric pressure boundary or free slip surface boundary at the specified water depth. Using this approach can save a lot of time, because two phase air-water free surface CFD computations often require adjustments to inlet and exit boundary conditions on a case by case basis to achieve a stable flow at the required depth. Being able to enforce water depth as a boundary condition makes it much easier to achieve stable convergence of a test case on the first attempt.

In the case of the straight channel it was assumed that its geometry and flow conditions were symmetrical and therefore only a half of the model was considered, with appropriate symmetry boundary condition on the mid surface, as shown in Figure 6-3. Decreasing the number of computational cells by an order of two, allowed more simulations to be run and study to include more cases. In the analysis of channels with bends this assumption could not be used, because of lack of symmetry, and therefore a full model was studied.

In this study only fully developed flow conditions were analyzed. The impact of a sudden inflow of water into a channel was not considered. Fully developed flow conditions can be achieved in CFD analysis by using cyclic boundary conditions at the domain entry and exit, see Figure 5-3. This is done by taking the velocity profile that develops at the exit boundary and feeding it back in as the inlet velocity distribution. The analysis is considered converged when the velocity profile in the interior is no longer changing and is approximately equal to the exit velocity profile. This approach makes it possible to analyze only a short stretch of a channel, instead of a very long one, which would be necessary for the flow to develop. 


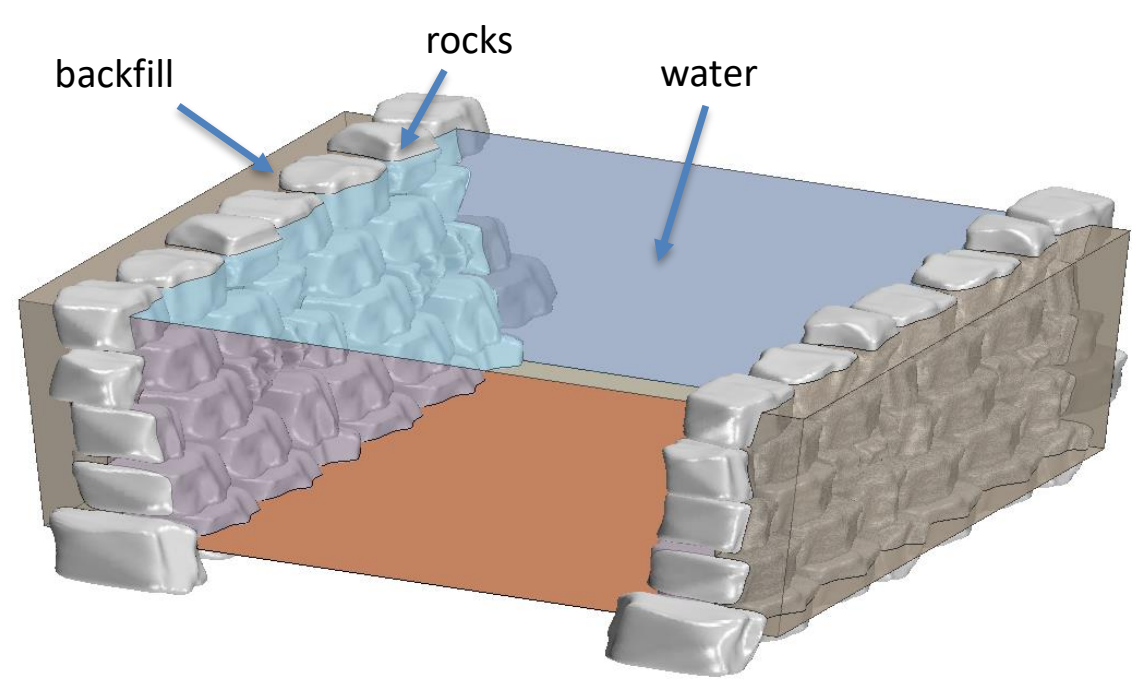

Figure 5-1: An example computational model of a straight channel

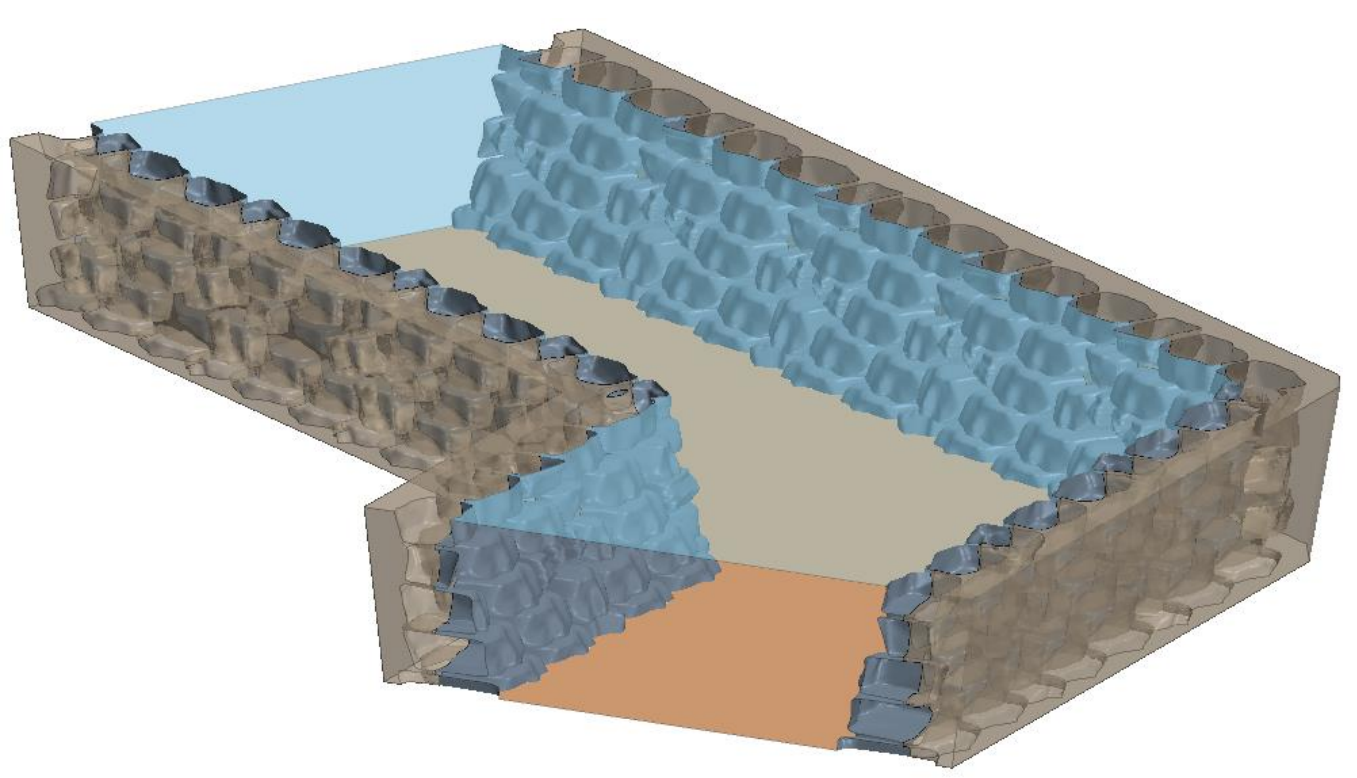

Figure 5-2: An example computational model of a channel with a sharp bend 

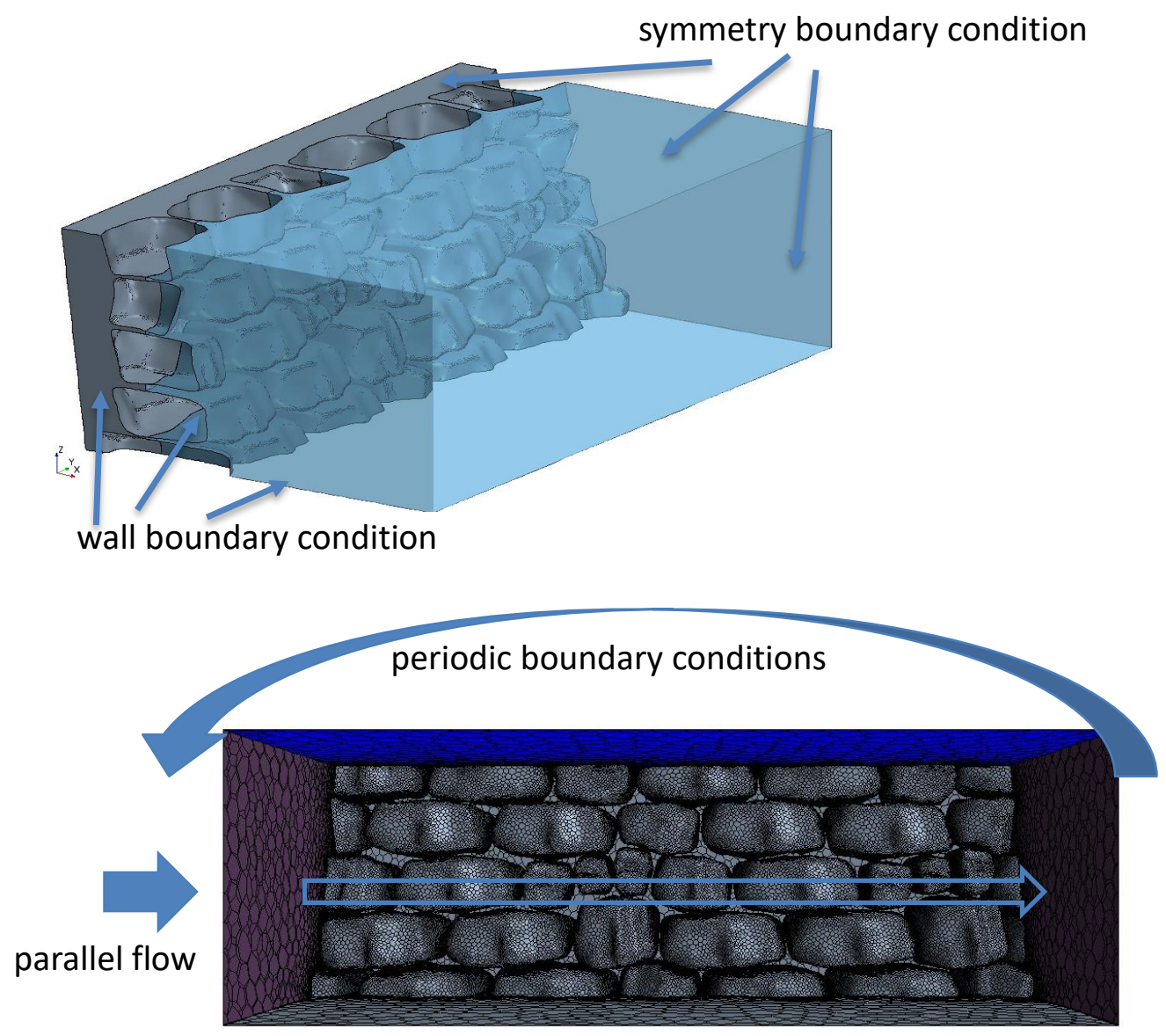

Figure 5-3: The adopted boundary conditions in CFD models of straight channels

The mean flow velocity values were calculated from Manning's formula

$$
v=\frac{1}{n} R^{2 / 3} S^{1 / 2}
$$

where $n$ is the Manning number ( $n=0.05$, constant), $S$ is the slope ( $S=0.023$, constant), $R$ is the hydraulic radius, $R=A / P, A$ is the area of the channel cross-section, $P$ is the wetted perimeter,

$$
\begin{gathered}
A=0.5 H\left(2 W_{B}+2 \frac{H}{b}\right), \\
P=W_{B}+2 \sqrt{H^{2}+\left(\frac{H}{b}\right)^{2}},
\end{gathered}
$$

where $H$ is the water height, $W_{B}$ is the channel bed width, and $b$ is the rockery face batter. The flow rate can be obtained from

$$
Q=v A \text {. }
$$


The dependence of the mean flow velocity and volume flow rate on channel width for two water heights, $H$, equal $7 \mathrm{ft}$ and $12 \mathrm{ft}$, and face batters 4:1, and 12:1, as well as a vertical wall were illustrated in Figure 6-4 and Figure 6-5 respectively. In these figures, two sets of curves can be distinguished, for the two water height values. The lower set of curves consists of the data points calculated for $H=7 \mathrm{ft}$, and the upper set of curves is for $H=12 \mathrm{ft}$. The mean flow velocity increases with the increase of the channel width, with a more rapid change for narrow channels than for very wide channels. The change of the volume flow rate due to channel width in the considered range could be approximated with a linear function.

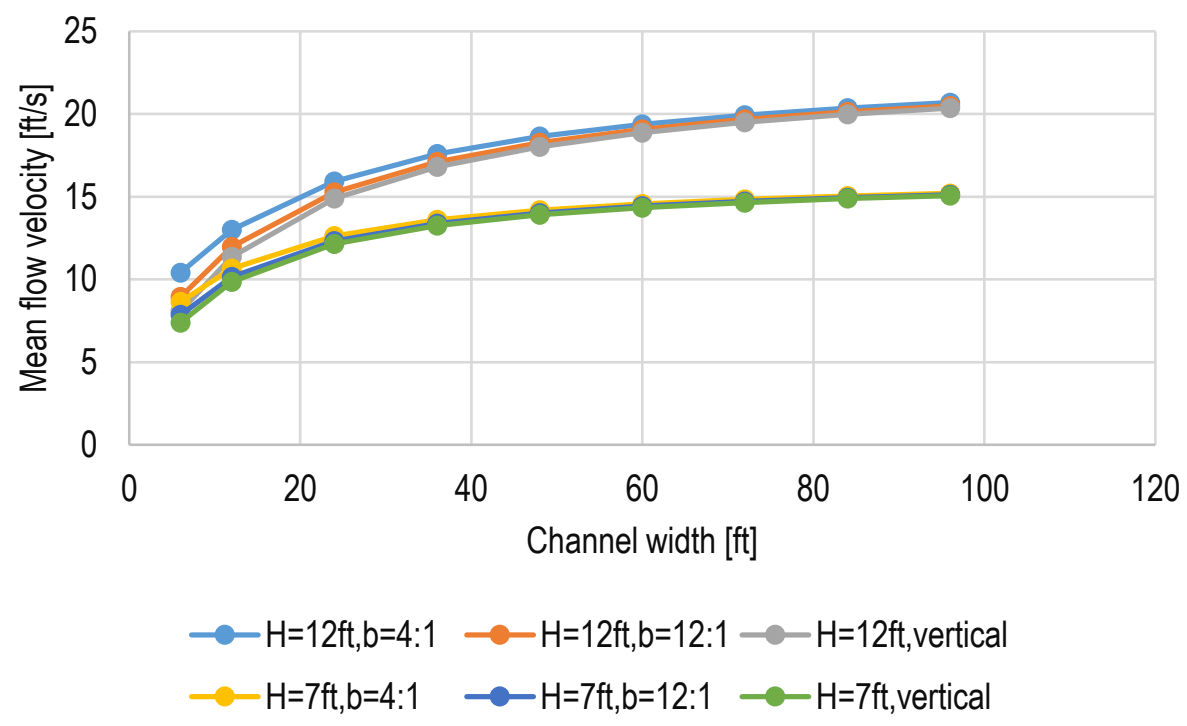

Figure 5-4: Mean flow velocity vs. channel width

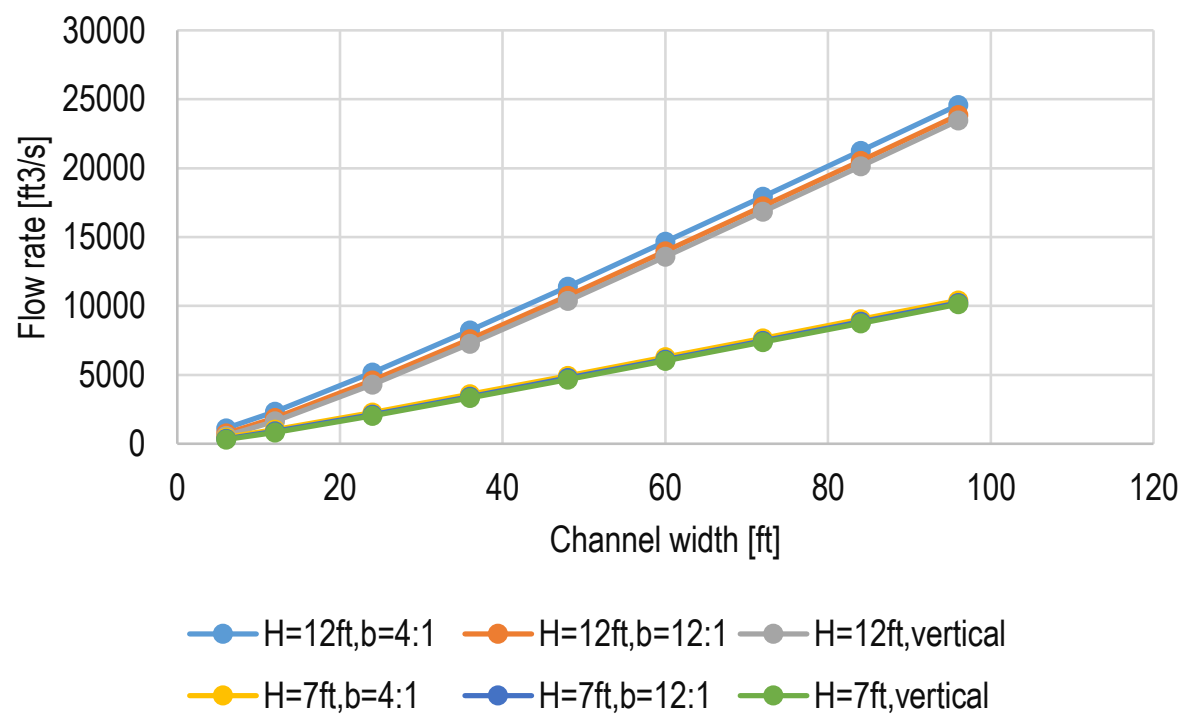

Figure 5-5: Volume flow rate vs. channel width

Computational Assessment of Hydrodynamic Loads on Rockeries for River Bank Protection 
(a)

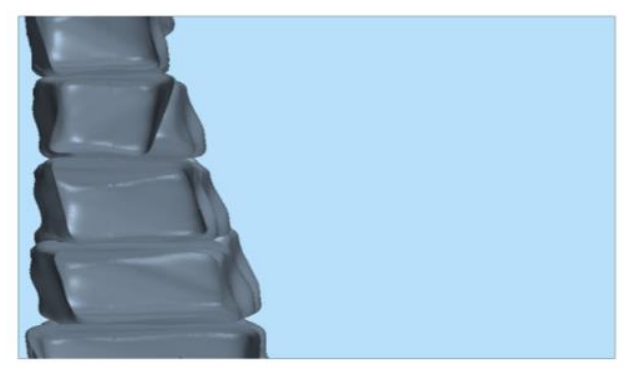

(b)

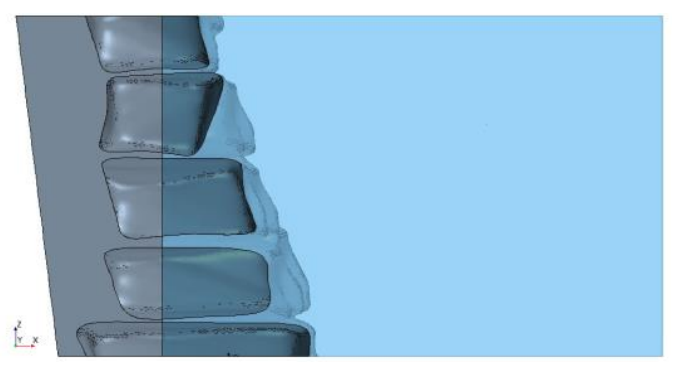

Figure 5-6: Cross-sections through CFD domains (a) without backfill, (b) with backfill

The space behind a dry-stack rockery, between the rocks and the retained soil, covered with a geotextile, is filled with smaller granular material. Two approaches were tested for use in modeling this part, (1) the backfill was not included in the model and flow was possible in a narrow slot behind the rockery, (2) the backfill was included in the CFD domain as a porous medium. Figure 6-6 shows cross-sections through computational domains with and without backfill.

In the model with backfill it was assumed that it was made of gravel with $D_{50}=2$ in $(5 \mathrm{~cm})$. The geometry of the small grains forming the backfill was not included in the model explicitly. The fine grid that would be necessary to capture the flow in the small gaps between the grains, would result in models being much too computer resource consuming to run multiple simulations. Instead, a simplification was proposed to model the backfill as a porous region with a specified porosity, $\chi=0.4$.

The linear pressure drop across a porous region along a distance $L$ is characterized by the following formula in Star-CCM+ [9]:

$$
-\frac{d p}{L}=\frac{150 \mu_{w}(1-\chi)^{2} v}{\chi^{3} D_{50}^{2}}+\frac{1.75 \rho(1-\chi) v^{2}}{\chi^{3} D_{50}},
$$

where $p$ is the pressure, $\mu_{w}$ is the dynamic viscosity of water, $\rho$ is the density of water, $\chi$ is the porosity, $D_{50}$ is the particle diameter, and $v$ is the superficial velocity.

The multipliers of velocity were calculated for the considered case and the formula programmed into the software (in SI units) was as following

$$
-\frac{d p}{L}=438.75 v+3.28 \cdot 10^{5} v^{2}
$$




\section{Analysis of forces on rockeries}

\subsection{Static and dynamic forces acting on a rockery}

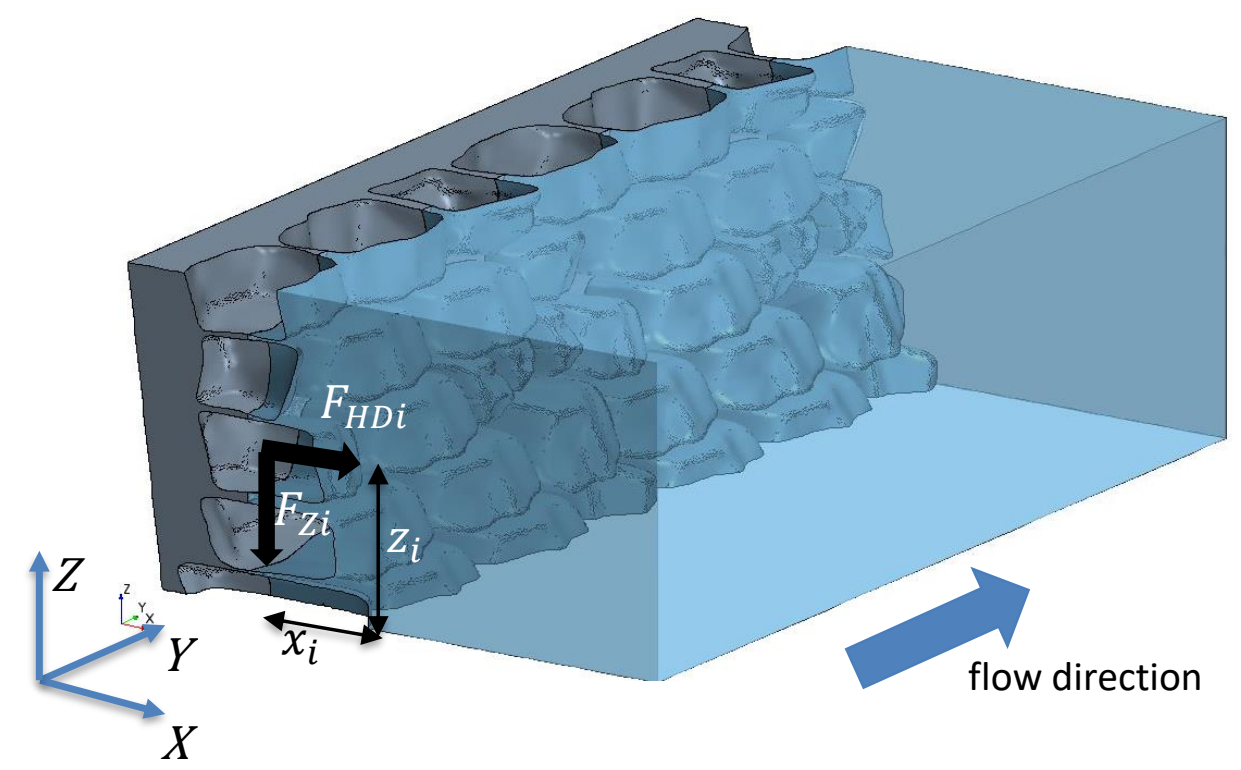

Figure 6-1: Forces computed for each of the rocks

The CFD simulations were used primarily to establish the horizontal hydrodynamic force (along $\mathrm{X}$ axis, $F_{H D i}$ ) and the buoyancy force (along $Z$ axis, $F_{Z i}$ ) for each of the rocks. The forces were added to the other loads acting on a rockery, such as: active earth pressure, surcharge pressure, weight of the rockery, inter-rock friction, and base rock-foundation friction, in the analysis of the rockery stability.

The hydrodynamic forces were computed internally in the software by integration of pressure and shear over the surface of rocks. The influence of shear is not significant, as in all cases it was several orders of magnitude lower than pressure. Figure 7-2 shows an example pressure distribution on rocks on the water side (front) and the backfill side (back). On the back side the pressure values were more uniform and close to $32 \mathrm{psf}(1.5 \mathrm{kPa})$. On the front side the pressure ranges between negative $-286 \mathrm{psf}(-13.7 \mathrm{kPa})$ to positive $112 \mathrm{psf}(5.34 \mathrm{kPa})$ values. The distribution on the front side is very non-uniform. The non-uniformity is a consequence of the irregularities of the rocks shape and size, as well as their position relative to other rocks and the flow. There are spots on the front surface of very high pressure values on the parts of the rocks that are exposed to the flow and areas of very low pressure on the parts that are shielded from the flow. 
(a)

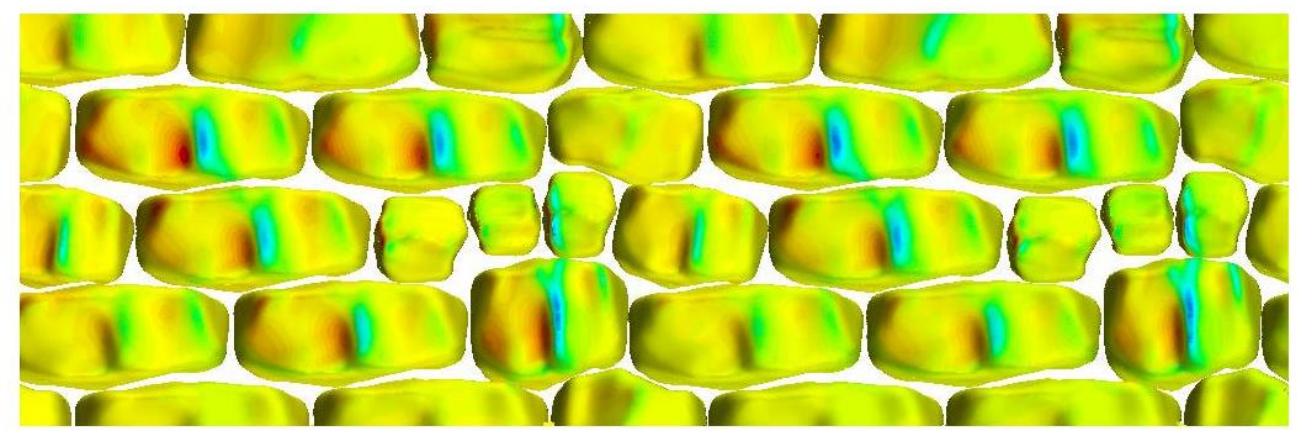

(b)

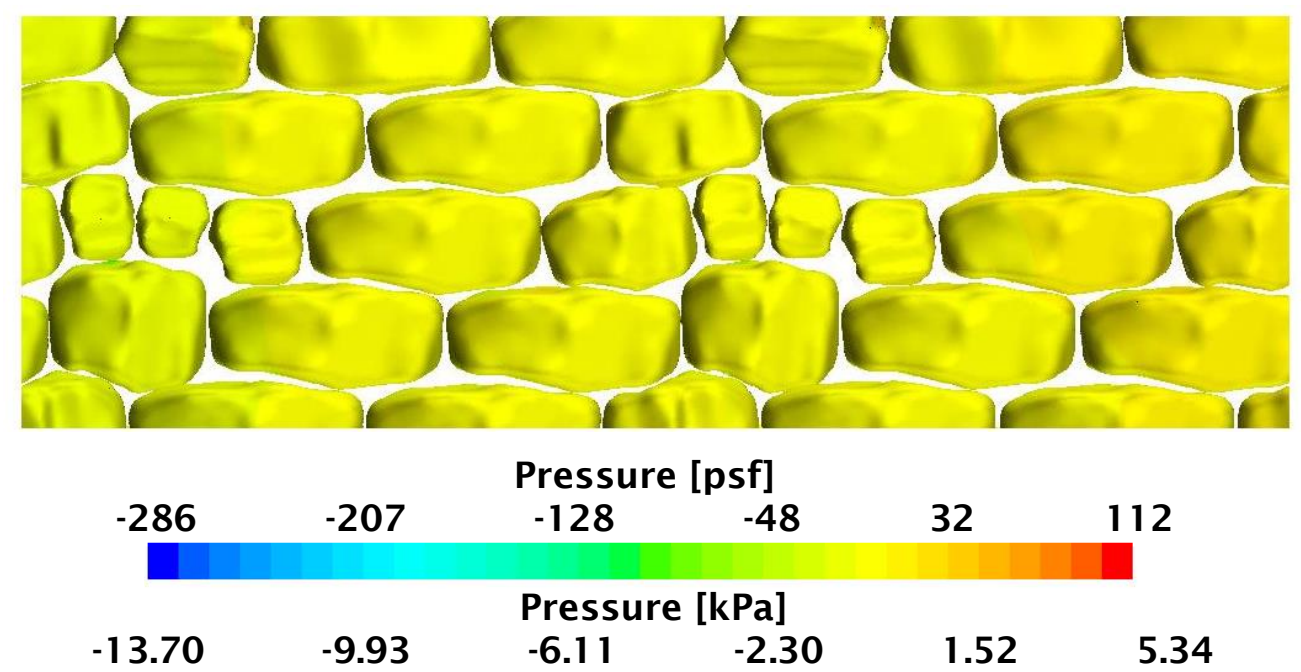

Figure 6-2: Pressure distribution on rocks, (a) front side of the rockery (water side), (b) back side of the rockery (backfill side) in the base test case.

Because of the complexity of the pressure field, the values of the hydrodynamic driving forces acting on separate rocks vary in value. Figure 6-3 shows hydrodynamic forces for separate rocks in the base test case. Layer 3 is formed with 10 rocks, layers 2 and 4 are formed with 6 rocks. The biggest rocks form the bottom layer of the rockery. They are $\sim 7 \mathrm{ft}$ in width and length, and $\sim 3 \mathrm{ft}$ in height. The width of the rockery decreases in vertical direction and reaches $\sim 4 \mathrm{ft}$ on the top. The forces acting on the second layer of rocks (counting from the bottom) are uniform and equal about $225 \mathrm{lbf}(1 \mathrm{kN})$ per rock. For the third and fourth layers they range from $60 \mathrm{lbf}(0.3$ $\mathrm{kN})$ to about $300 \mathrm{lbf}(1.4 \mathrm{kN})$. Figure 6-4 shows a point plot of the hydrodynamic forces vs. buoyancy of the rocks, which makes it possible to learn how the dynamic forces depend on the weight of the rocks. In most cases they assume higher values for bigger rocks and lower values for smaller sized rocks, but they can differ slightly for rocks of the same size and shape, but located at various places in the rockery. For example, rocks 2, 3, 5, and 6 from the $4^{\text {th }}$ layer occupy the same volume, with buoyancy of about $4685 \mathrm{lbf}(21 \mathrm{kN})$, but the forces $F_{H D}$ vary between $235 \mathrm{lbf}(1.05 \mathrm{kN})$ and $306 \mathrm{lbf}(1.36 \mathrm{kN})$. The lateral dynamic forces exerted by the flow make up to only a few percent (less than 4.5\%) of the weight of the rocks, as presented in Figure 6-5. 


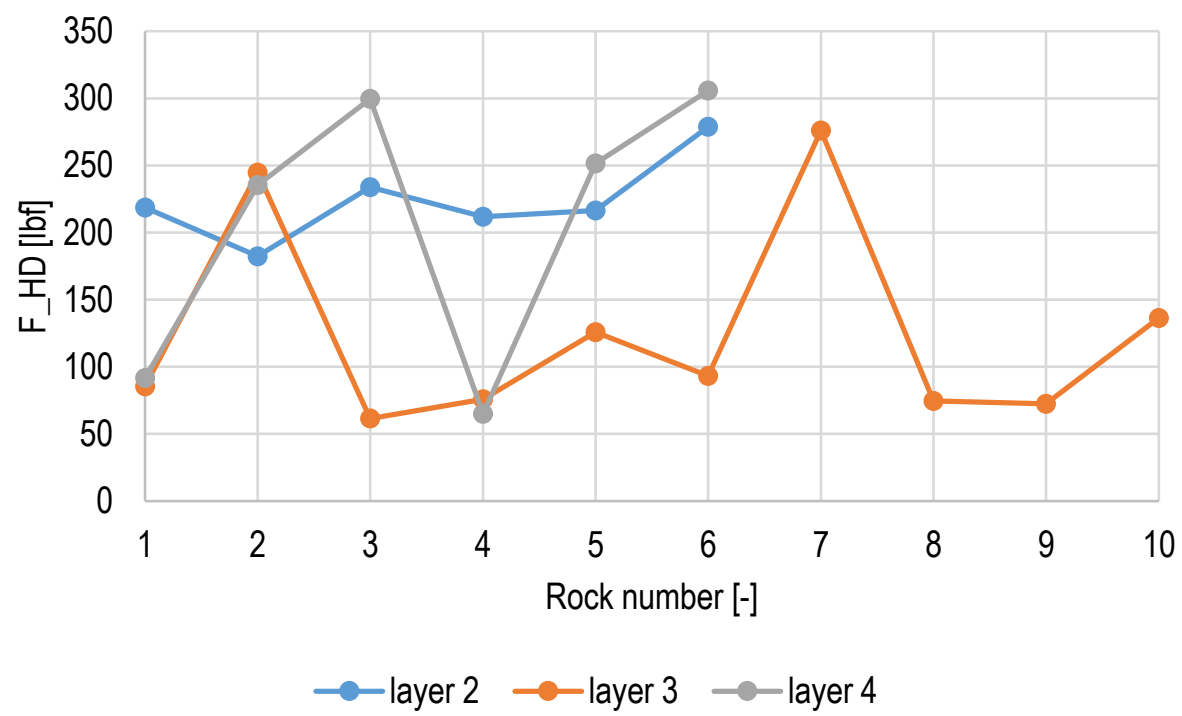

Figure 6-3: Hydrodynamic forces for separate rocks in the base test case

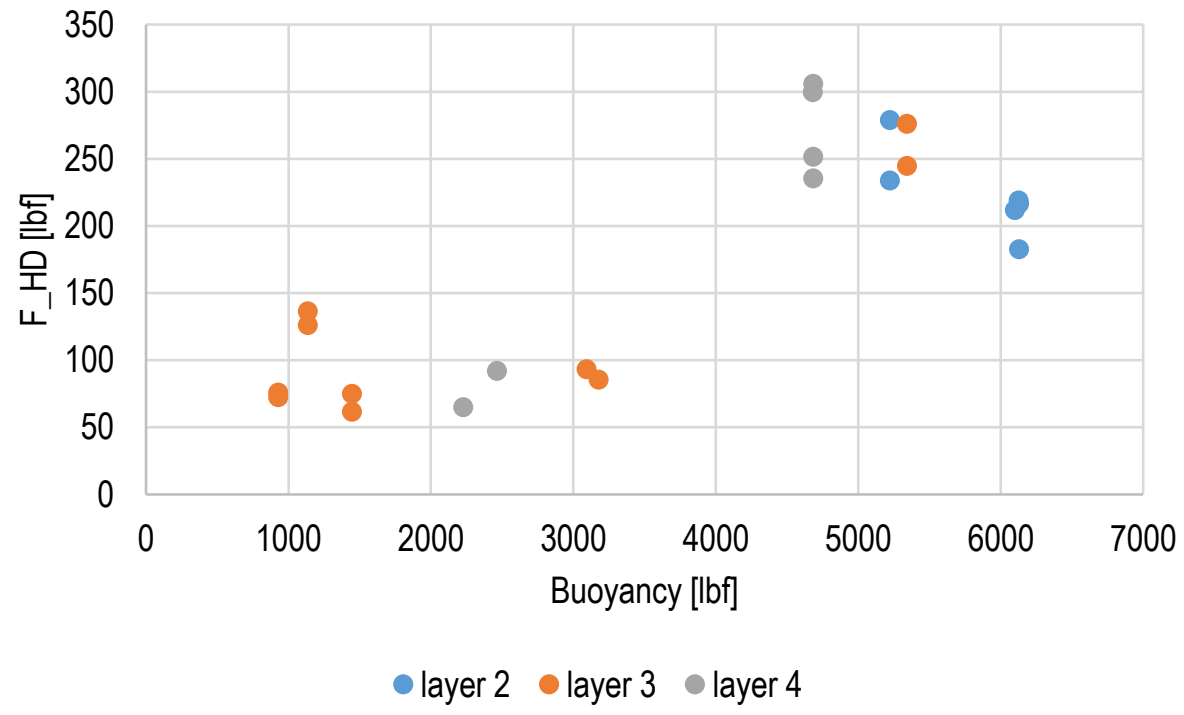

Figure 6-4: Hydrodynamic forces vs. buoyancy of the rocks in the base test case 


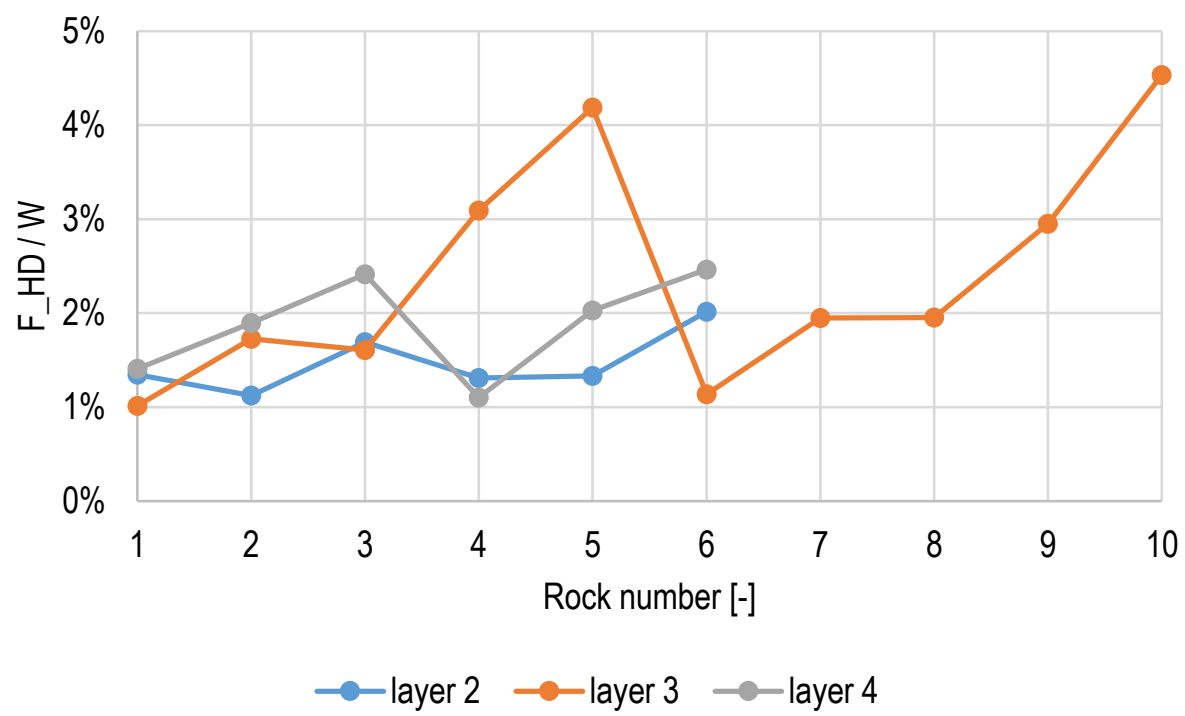

Figure 6-5: Ratio of the hydrodynamic force to weight for separate rocks in the base test case

\subsubsection{Influence of the backfill}

Figure 6-6 shows a plot of hydrodynamic forces averaged for each layer over the rockery length in the models with and without backfill at: two water heights, $7 \mathrm{ft}$ and $12 \mathrm{ft}$, and two rockery base widths, $7 \mathrm{ft}$ and $8 \mathrm{ft}$, when the face batter is 4:1. The forces are higher for the hydraulic conditions corresponding to the higher water height. Also, an increased rockery base width, leads to higher loads. The forces on the first layer of rocks were the lowest in every tested case because these rocks were only partially subjected to the flow (in a real rockery these rocks would be partially buried in the river bed to increase stability of the structure, therefore they were not included in the CFD model), and the flow was the slowest close to the bed. The highest forces in each case were obtained for the rocks that belong to the second layer, and the forces decrease for upper layers. Overall, in every case, the model with backfill gave higher forces as compared to the model without backfill. The distribution of the forces changed as well. When the backfill was included in the model, the third and fourth layers of rocks experienced proportionally much higher forces than other layers, as compared to model without backfill. As the more complex model gave more conservative results, it was adopted for further analysis. 


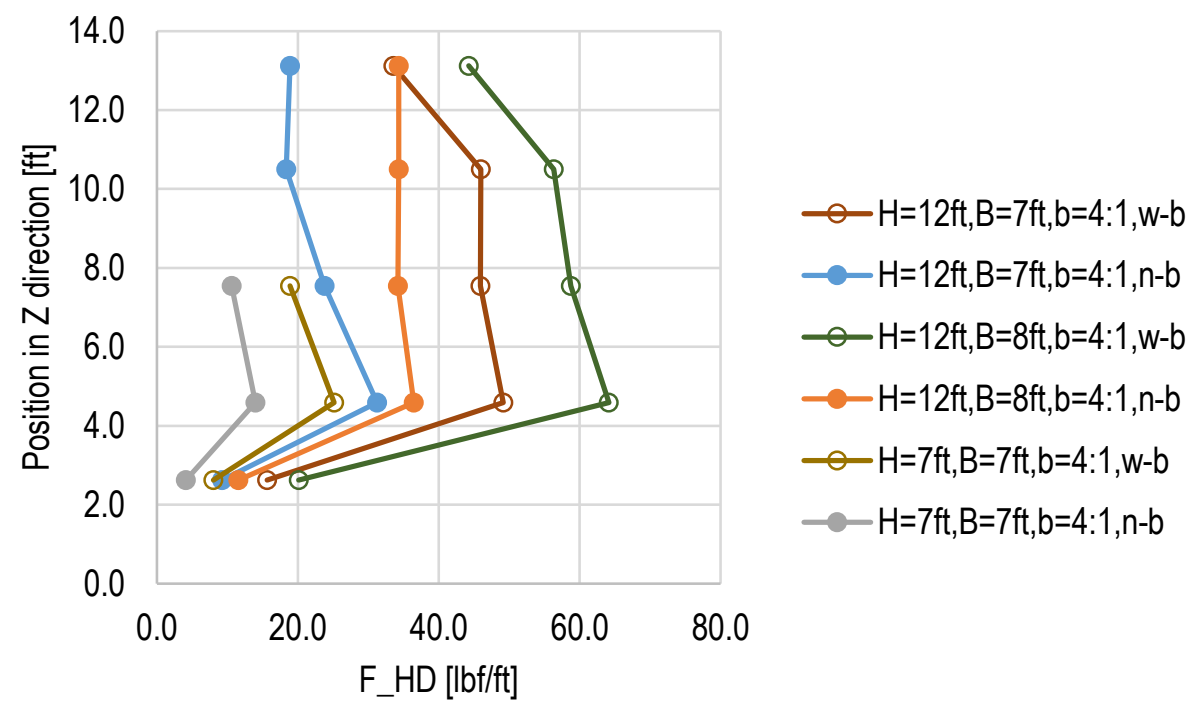

Figure 6-6: Vertical distribution of hydrodynamic forces per unit length of rockery in rockery models with and without backfill (n-b - model without backfill, w-b - model with backfill) for the bed width $24 \mathrm{ft}$

\subsubsection{Influence of the rockery face batter and base width}

Figure 6-7 presents a plot of hydrodynamic forces per unit rockery length at two water levels, for face batter values of $4: 1$ and 12:1. Two base widths were considered: $7 \mathrm{ft}$ and $8 \mathrm{ft}$. The dimensions of the biggest base rocks are: $7 \mathrm{ft}$ by $7 \mathrm{ft}$ by $3 \mathrm{ft}$, and $8 \mathrm{ft}$ by $7 \mathrm{ft}$ by $3 \mathrm{ft}$, respectively. The vertical distribution of forces changes due to the batter change. The loads are lower for the steeper rockery face (4:1). Also, when batter is 4:1, the rocks from the second layer (counting from the bottom) experienced the highest forces; when the batter was equal to 12:1, the fourth layer was the most influenced by the flow. The forces on the bottom and top layers of rocks did not change significantly.

Increasing the rockery base width increases the hydrodynamic loads on the rocks, but does not change the distribution pattern. E.g. for a rockery subjected to a $12 \mathrm{ft} \mathrm{flow} \mathrm{level,} \mathrm{with} \mathrm{a} \mathrm{face} \mathrm{batter}$ of $4: 1$, the average force acting on the second layer of rocks equals $50 \mathrm{lbf} / \mathrm{ft}(0.72 \mathrm{kN} / \mathrm{m})$ when the base is $7 \mathrm{ft}$ wide, and $175 \mathrm{lbf} / \mathrm{ft}(0.94 \mathrm{kN} / \mathrm{m})$ when the base is 8 -foot wide. 


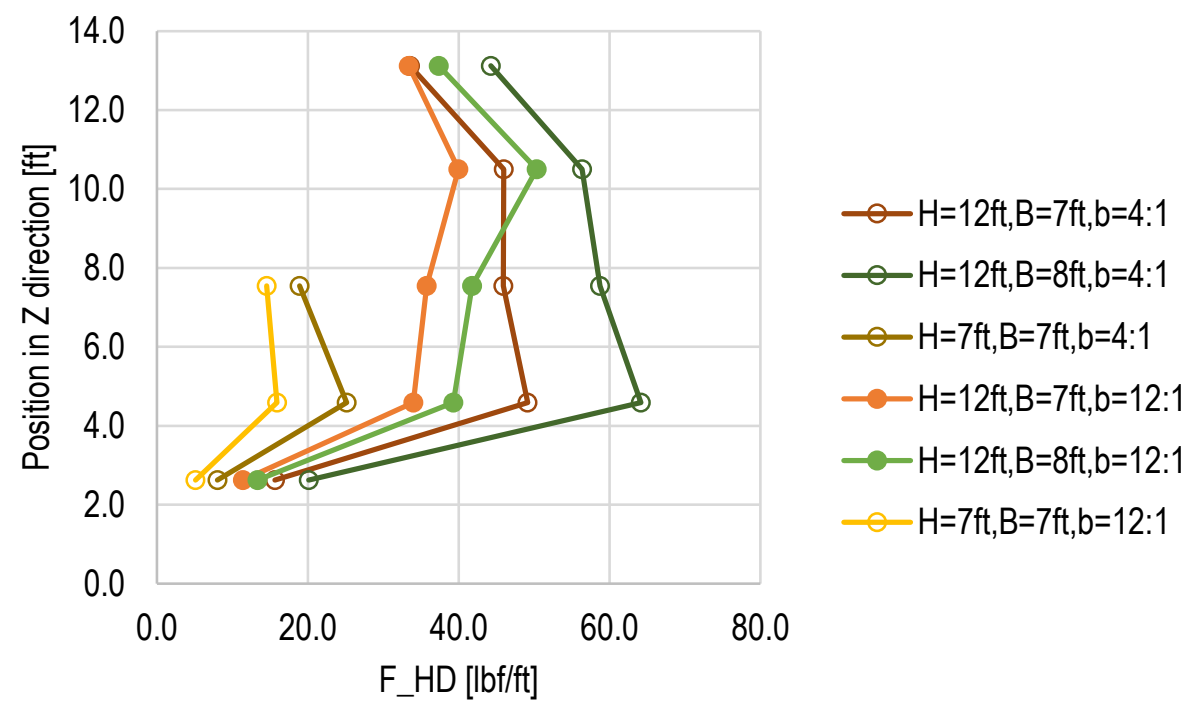

Figure 6-7: Vertical distribution of hydrodynamic forces per unit length. Models with batter 4:1 and 12:1

\subsubsection{Influence of the channel width}

A set of channel widths, from $6 \mathrm{ft}$ to $96 \mathrm{ft}$, which gives a ratio of $\mathrm{H} / \mathrm{W}$ (water height to channel width) from 0.5 to 8 , was considered. Figure 6-8 shows the vertical distribution of hydrodynamic forces per unit length of rockery with water level at $12 \mathrm{ft}$. The forces decrease for an increasing channel width for the ratio $\mathrm{W} / \mathrm{H}$ higher than two, they have very similar values for $\mathrm{W} / \mathrm{H}=1$ and $\mathrm{W} / \mathrm{H}=2$, and they drop when $\mathrm{W} / \mathrm{H}=0.5$. In addition, for the wider channels, the force distribution becomes more uniform within the layers 2 to 5 . A similar trend is noticeable in Figure 6-9 and Figure 6-10 for lower water height conditions, $\mathrm{H}=9 \mathrm{ft}$ and $7 \mathrm{ft}$. A smaller set of channel widths was considered, from $6 \mathrm{ft}$ to $48 \mathrm{ft}$ due to the assumption that for wider channels the decreasing of loads will continue. At the channel width $6 \mathrm{ft}$ and $12 \mathrm{ft}$ (W/H ratio is 0.86 and 1.71, respectively) the loads are very close in value and they decrease for the increasing width.

Figure 6-11 illustrates loads for a rockery with base width $8 \mathrm{ft}$ at $12 \mathrm{ft}$ high water for the selected channel widths: $12 \mathrm{ft}, 24 \mathrm{ft}$, and $48 \mathrm{ft}$. The plot shows that the vertical distribution of forces follows the same trend as for the smaller base. The forces are very similar with respect to value for channel width $12 \mathrm{ft}$ and $24 \mathrm{ft}$, and they drop for the 48 -foot wide channel.

Figures from Figure 6-12 to Figure 6-15 show vertical distributions of hydrodynamic forces per unit length of rockery for a selected set of three channel widths: $12 \mathrm{ft}, 24 \mathrm{ft}$, and $48 \mathrm{ft}$, for the three cases of water height and rockery base width. The face batter for these cases is 12:1. The trends are consistent with the previous findings.

The results mentioned above are combined in Figure 6-16 in a form of a plot of average force vs. channel width. The curves represent the change in force values per rockery layer. 


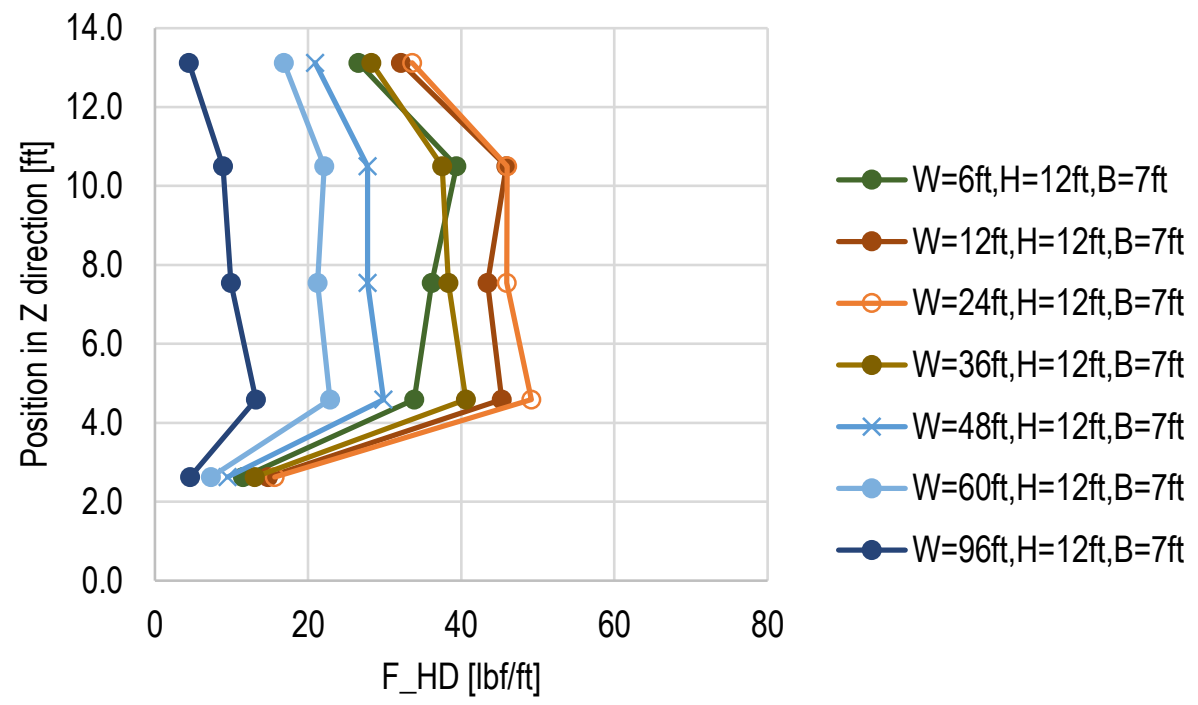

Figure 6-8: Vertical distribution of hydrodynamic forces per unit length of rockery with face batter 4:1 and base width $7 \mathrm{ft}$ at water height $12 \mathrm{ft}$

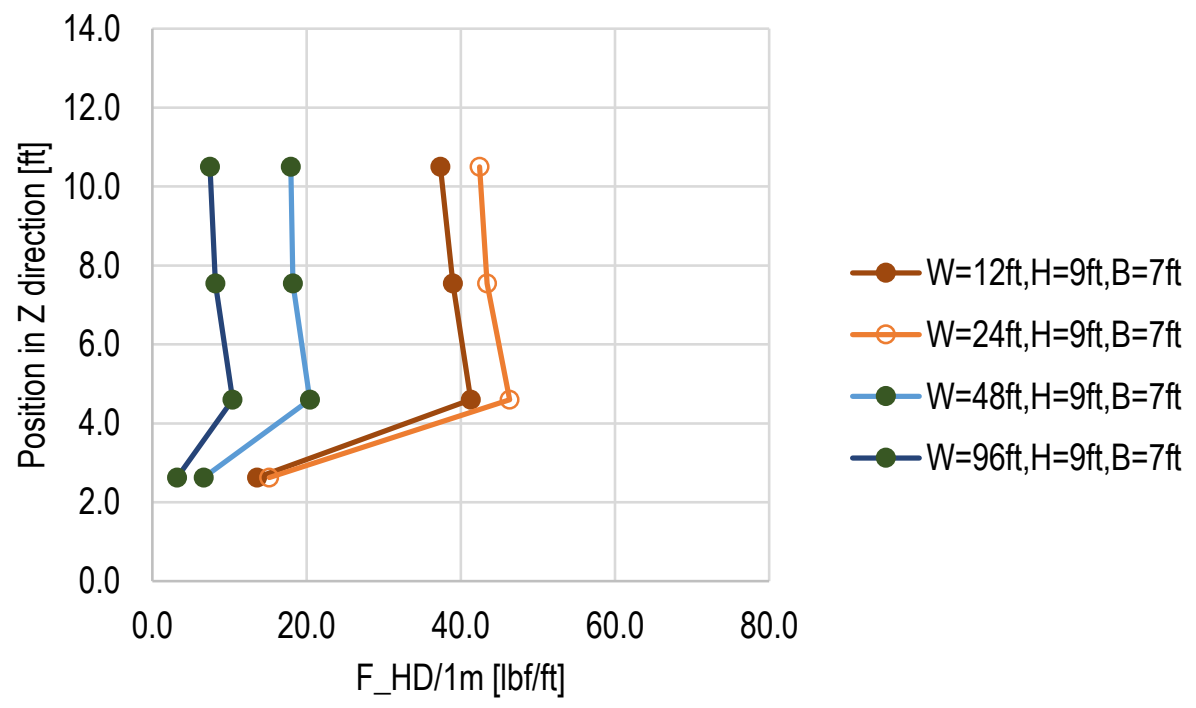

Figure 6-9: Vertical distribution of hydrodynamic forces per unit length of rockery with face batter 4:1 and base width $7 \mathrm{ft}$ at water height $9 \mathrm{ft}$ 


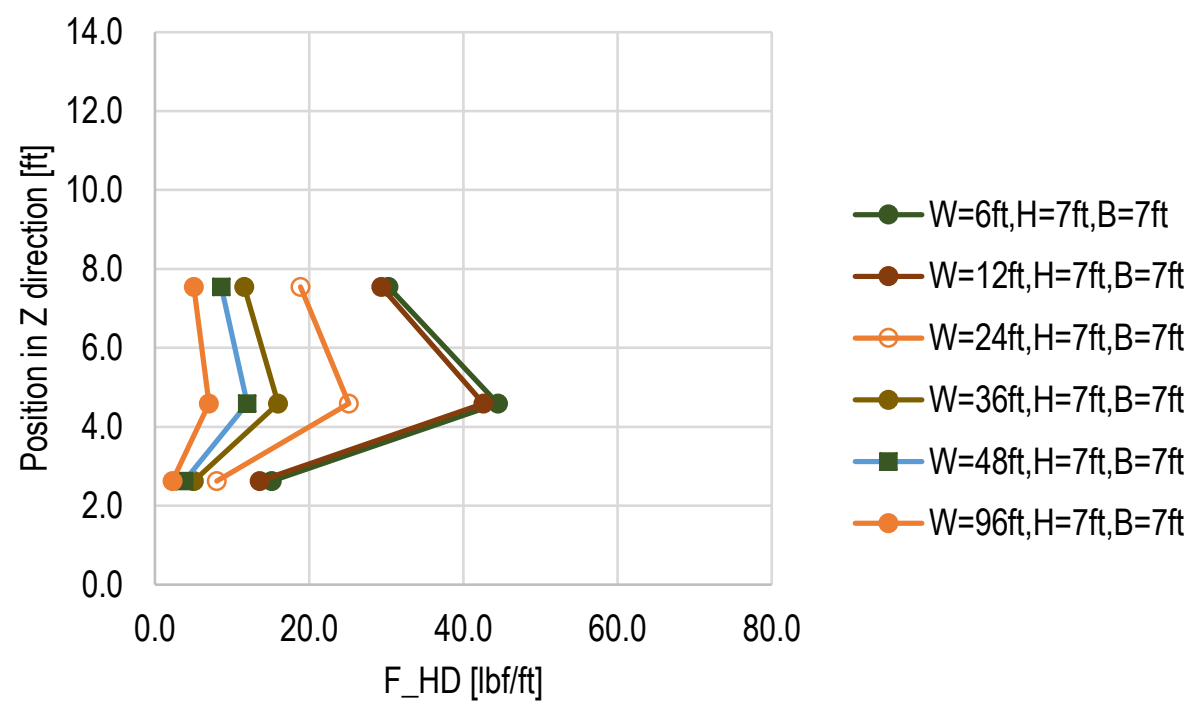

Figure 6-10: Vertical distribution of hydrodynamic forces per unit length of rockery with face batter 4:1 and base width $7 \mathrm{ft}$ at water height $7 \mathrm{ft}$

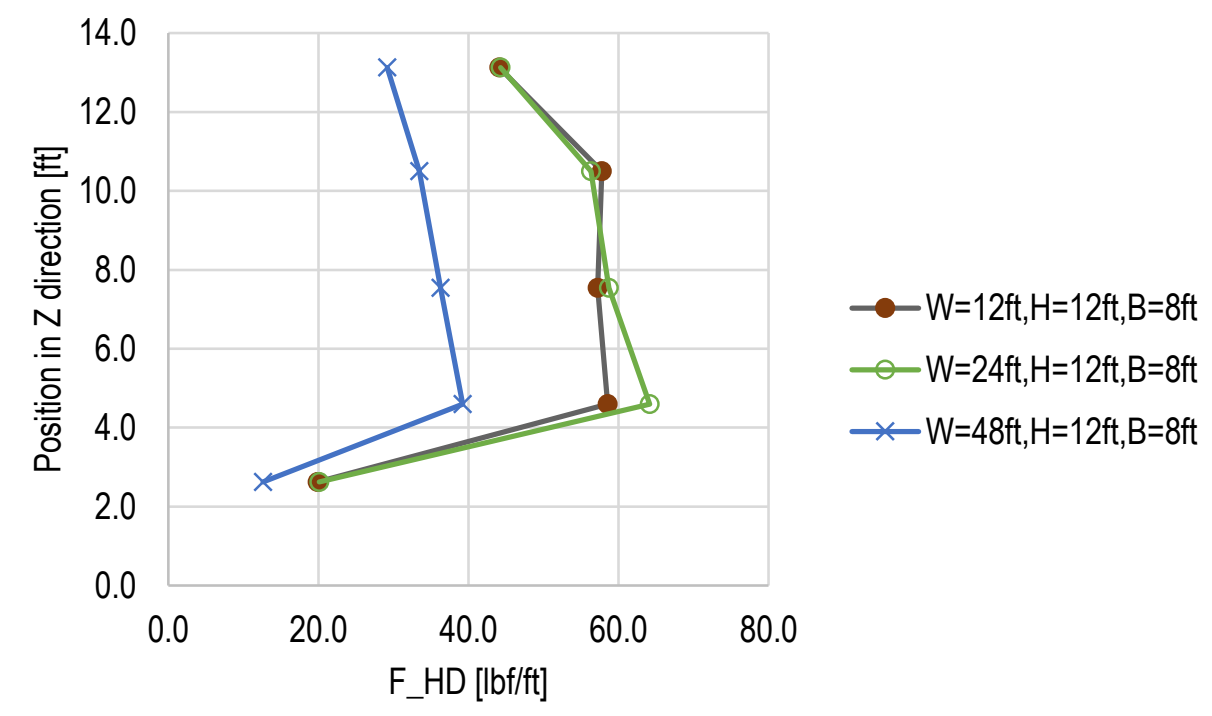

Figure 6-11: Vertical distribution of hydrodynamic forces per unit length of rockery with face batter 4:1 and base width $8 \mathrm{ft}$ at water height $12 \mathrm{ft}$ 


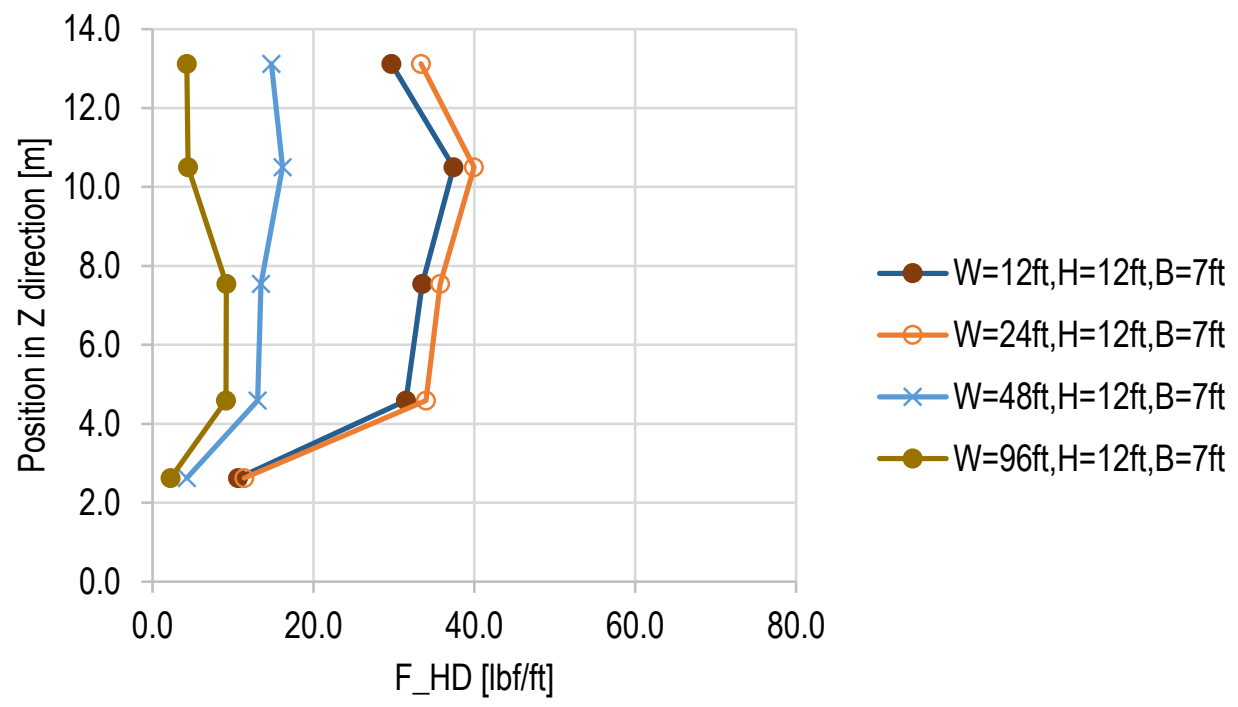

Figure 6-12: Vertical distribution of hydrodynamic forces per unit length of rockery with face batter 12:1 and base width $7 \mathrm{ft}$ at water height $12 \mathrm{ft}$

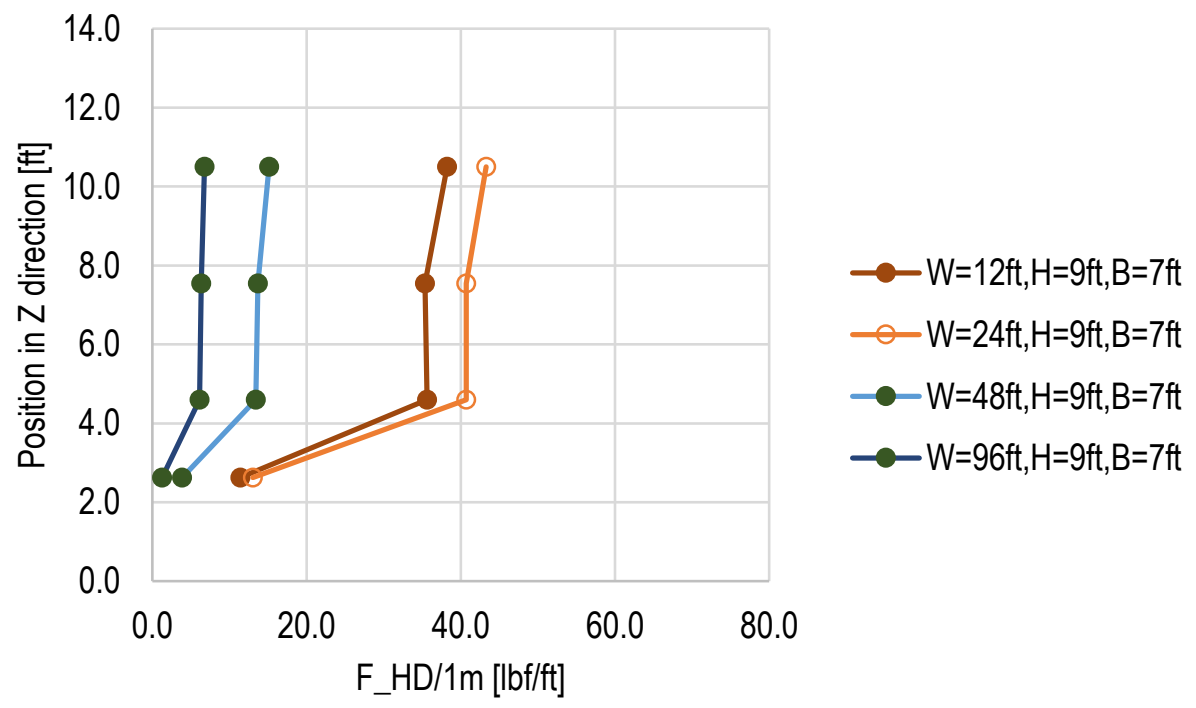

Figure 6-13: Vertical distribution of hydrodynamic forces per unit length of rockery with face batter 12:1 and base width $7 \mathrm{ft}$ at water height $9 \mathrm{ft}$ 


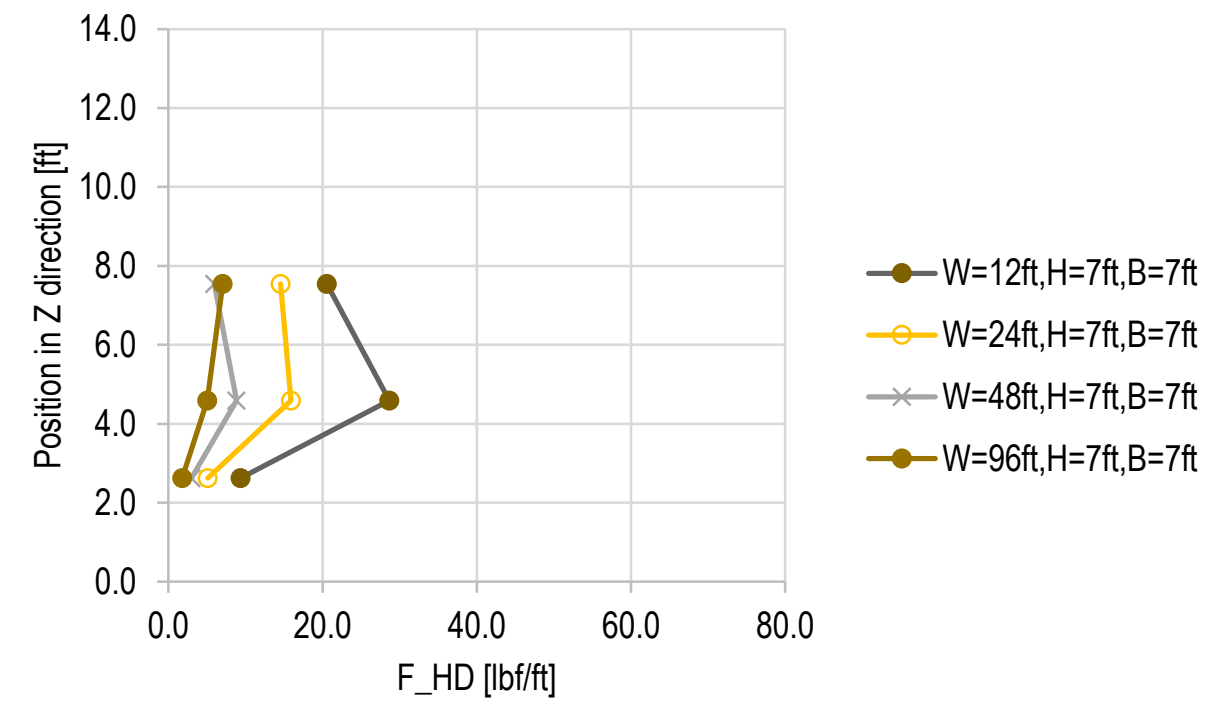

Figure 6-14: Vertical distribution of hydrodynamic forces per unit length of rockery with face batter 12:1 and base width $7 \mathrm{ft}$ at water height $7 \mathrm{ft}$

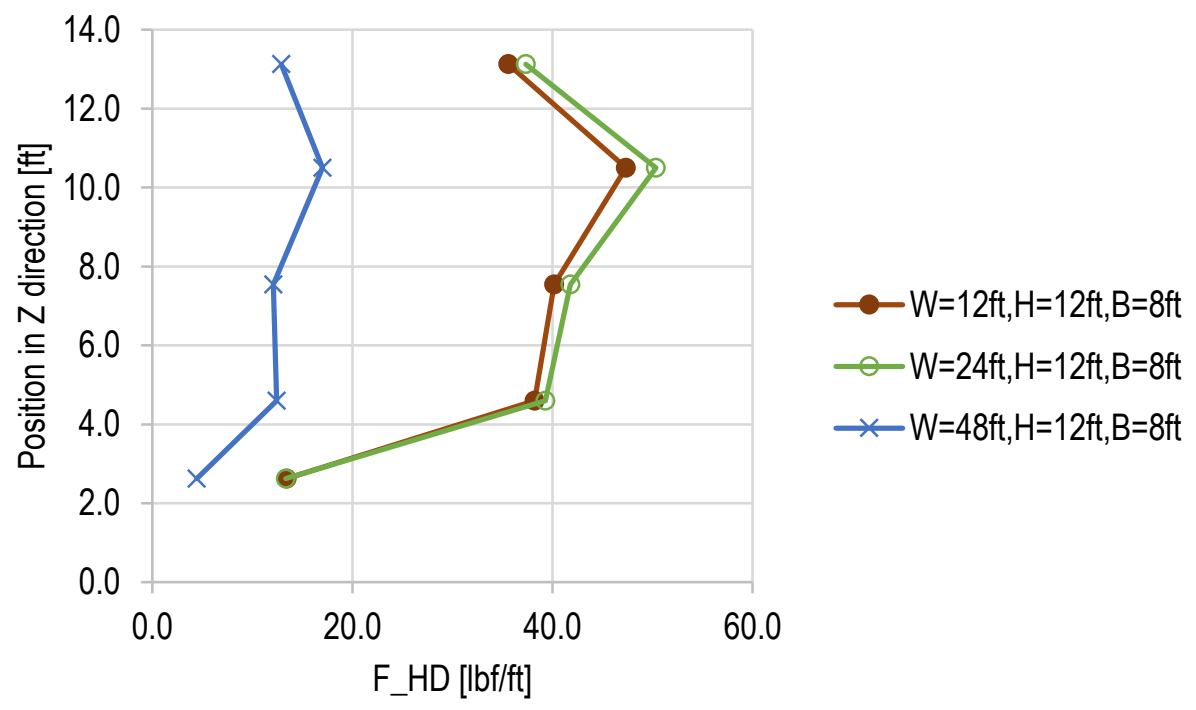

Figure 6-15: Vertical distribution of hydrodynamic forces per unit length of rockery with face batter 12:1 and base width $8 \mathrm{ft}$ at water height $12 \mathrm{ft}$ 


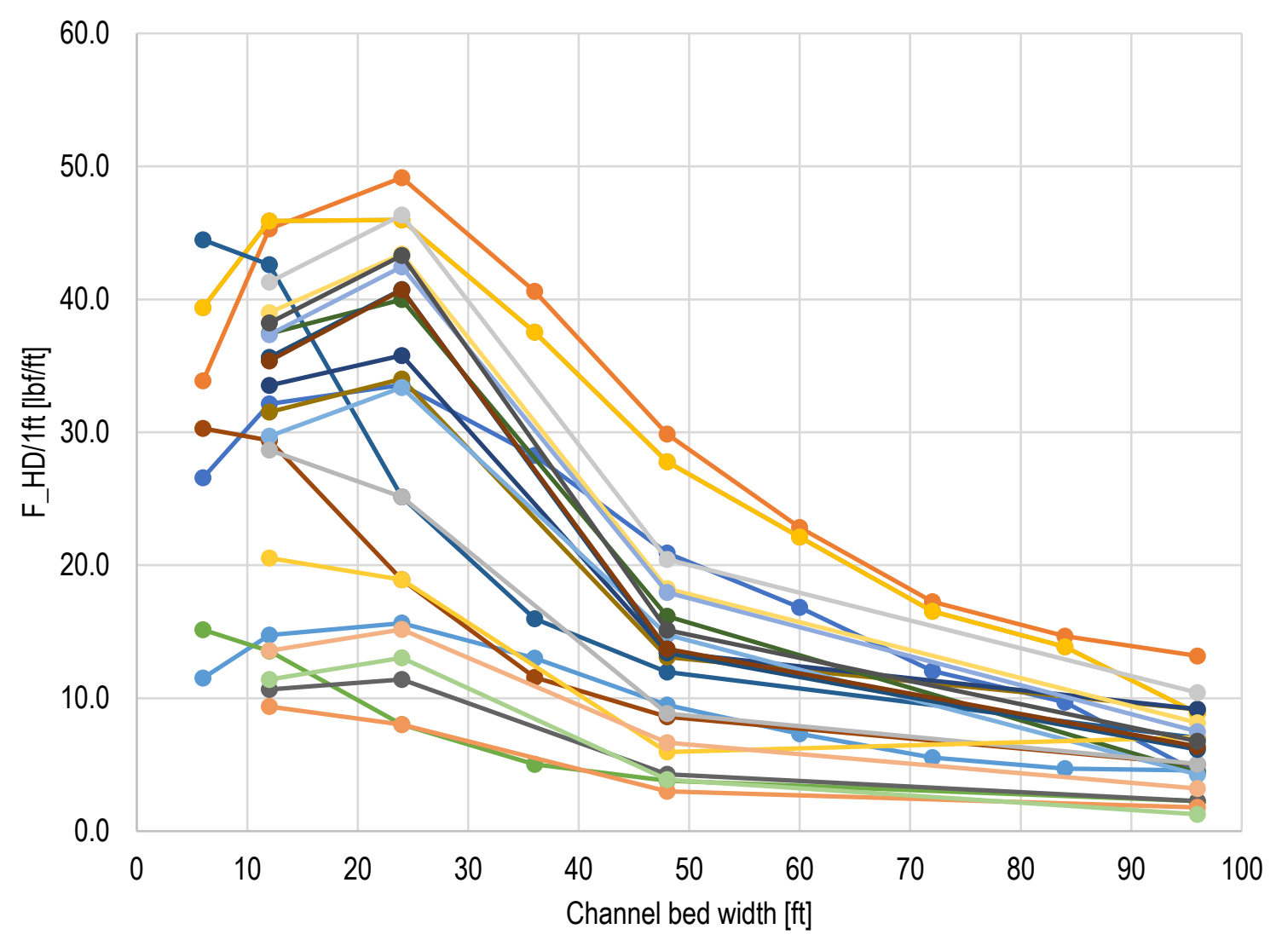

$$
\begin{aligned}
& \longrightarrow \mathrm{L} 1, \mathrm{H} 12 \mathrm{ft}, \mathrm{b} 4: 1-\mathrm{L} 2, \mathrm{H} 12 \mathrm{ft}, \mathrm{b} 4: 1-\mathrm{L} 3, \mathrm{H} 12 \mathrm{ft}, \mathrm{b} 4: 1-\mathrm{L} 4, \mathrm{H} 12 \mathrm{ft}, \mathrm{b} 4: 1 \\
& \longrightarrow \mathrm{L} 5, \mathrm{H} 12 \mathrm{ft}, \mathrm{b4}: 1-\mathrm{L} 1, \mathrm{H} 7 \mathrm{ft}, \mathrm{b4}: 1 \rightarrow \mathrm{L} 2, \mathrm{H} 7 \mathrm{ft}, \mathrm{b} 4: 1 \rightarrow \mathrm{L} 3, \mathrm{H} 7 \mathrm{ft}, \mathrm{b4}: 1 \\
& \longrightarrow \mathrm{L} 1, \mathrm{H} 12 \mathrm{ft}, \mathrm{b} 12: 1 \multimap \mathrm{L} 2, \mathrm{H} 12 \mathrm{ft}, \mathrm{b} 12: 1-\mathrm{L} 3, \mathrm{H} 12 \mathrm{ft}, \mathrm{b} 12: 1 \multimap \mathrm{L} 4, \mathrm{H} 12 \mathrm{ft}, \mathrm{b} 12: 1 \\
& \longrightarrow \mathrm{L} 5, \mathrm{H} 12 \mathrm{ft}, \mathrm{b} 12: 1 \longrightarrow \mathrm{L} 1, \mathrm{H} 7 \mathrm{ft}, \mathrm{b} 12: 1-\mathrm{L} 2, \mathrm{H} 7 \mathrm{ft}, \mathrm{b} 12: 1-\mathrm{L} 3, \mathrm{H} 7 \mathrm{ft}, \mathrm{b} 12: 1 \\
& -\mathrm{L} 1, \mathrm{H} 9 \mathrm{ft}, \mathrm{b4}: 1-\mathrm{L} 2, \mathrm{H} 9 \mathrm{ft}, \mathrm{b4}: 1-\mathrm{L} 3, \mathrm{H} 9 \mathrm{ft}, \mathrm{b4}: 1-\mathrm{L} 4, \mathrm{H} 9 \mathrm{ft}, \mathrm{b4}: 1 \\
& \longrightarrow \mathrm{L} 1, \mathrm{H} 9 \mathrm{ft}, \mathrm{b} 12: 1 \rightarrow \mathrm{L} 2, \mathrm{H} 9 \mathrm{ft}, \mathrm{b} 12: 1 \rightarrow \mathrm{L} 3, \mathrm{H} 9 \mathrm{ft}, \mathrm{b} 12: 1 \rightarrow \mathrm{L} 4, \mathrm{H} 9 \mathrm{ft}, \mathrm{b} 12: 1
\end{aligned}
$$

Figure 6-16: Hydrodynamic forces per unit length vs. channel width, $\mathrm{W}_{\mathrm{B}}$. L1 $-1^{\text {st }}$ layer, L2 - $2^{\text {nd }}$ layer, L3 $-3^{\text {rd }}$ layer, L4 $-4^{\text {th }}$ layer, L5 $-5^{\text {th }}$ layer. 
(a)

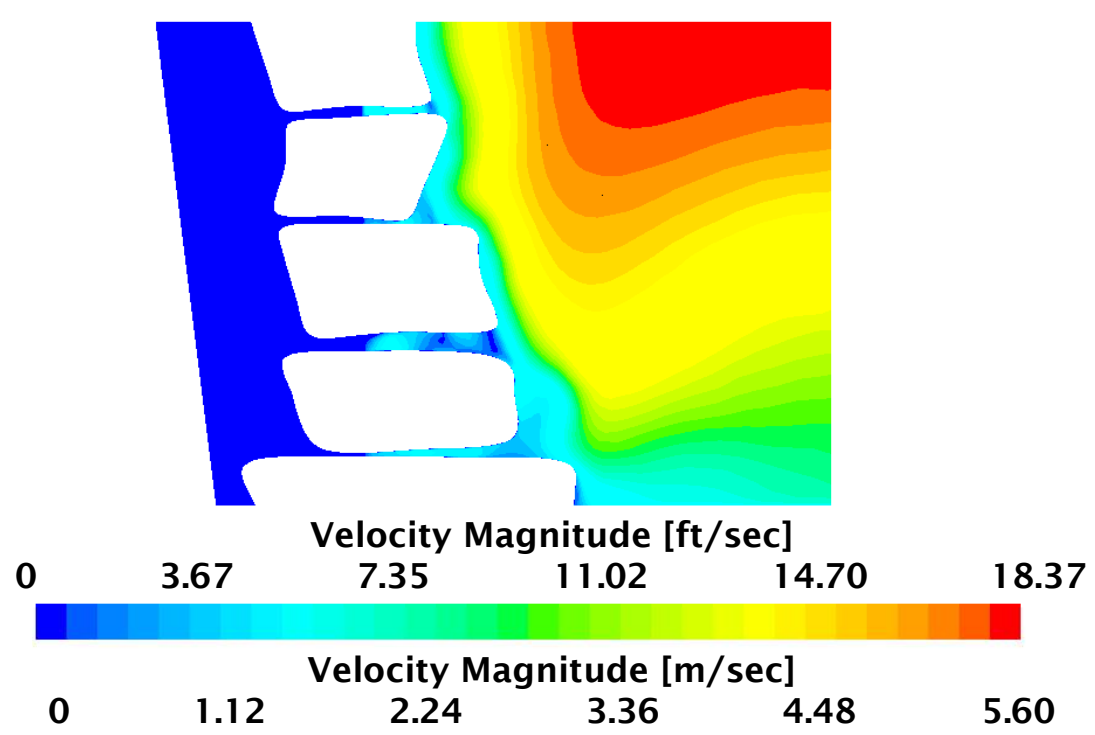

(b)

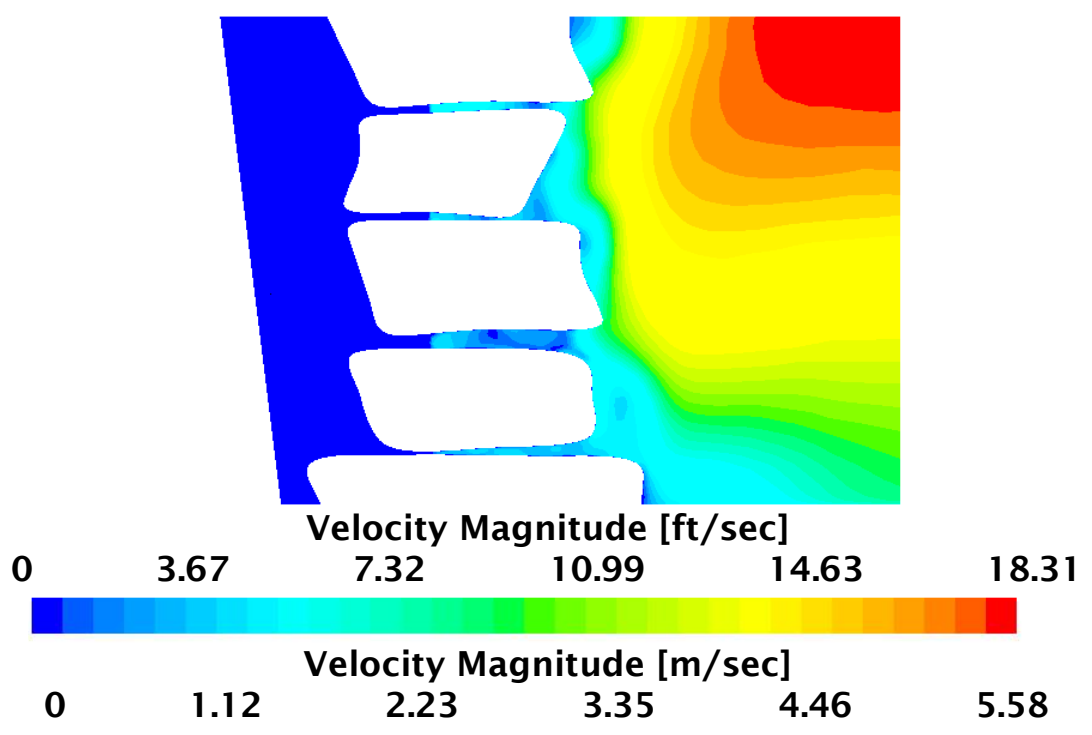

Figure 6-17: Velocity magnitude profile on a cross section perpendicular to the flow. Channel width, $W=12 f t$, ratio of channel width to water level height $W / H=1$, rockery face batter (a) $b=4: 1,(b) b=12: 1$. 
(a)

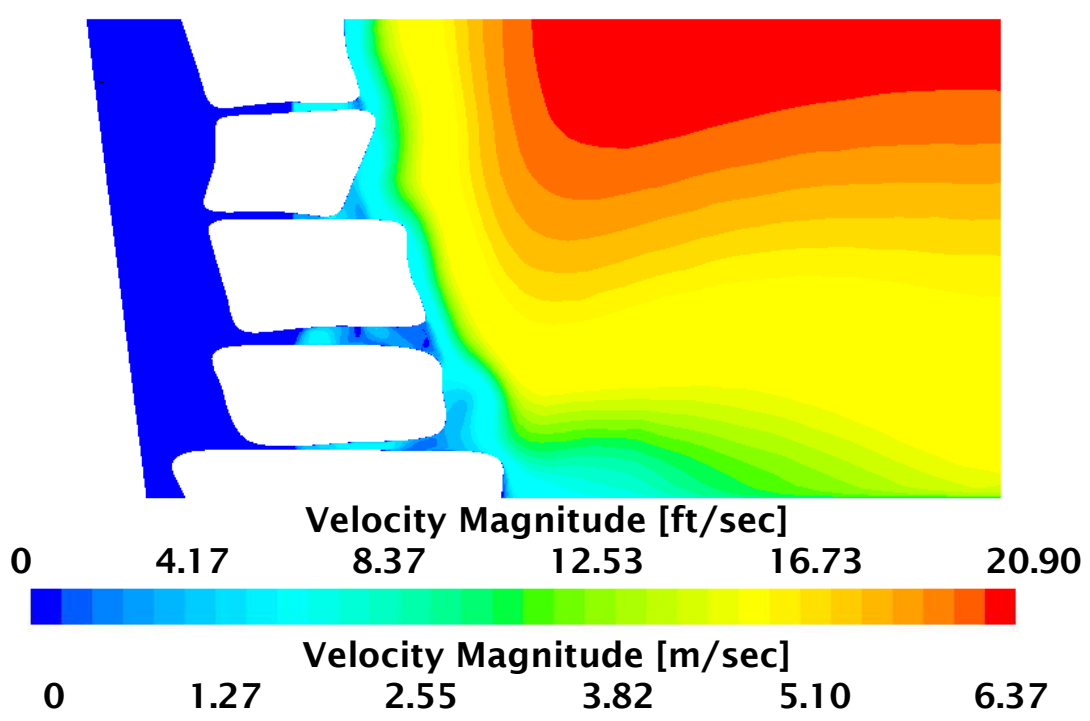

(b)

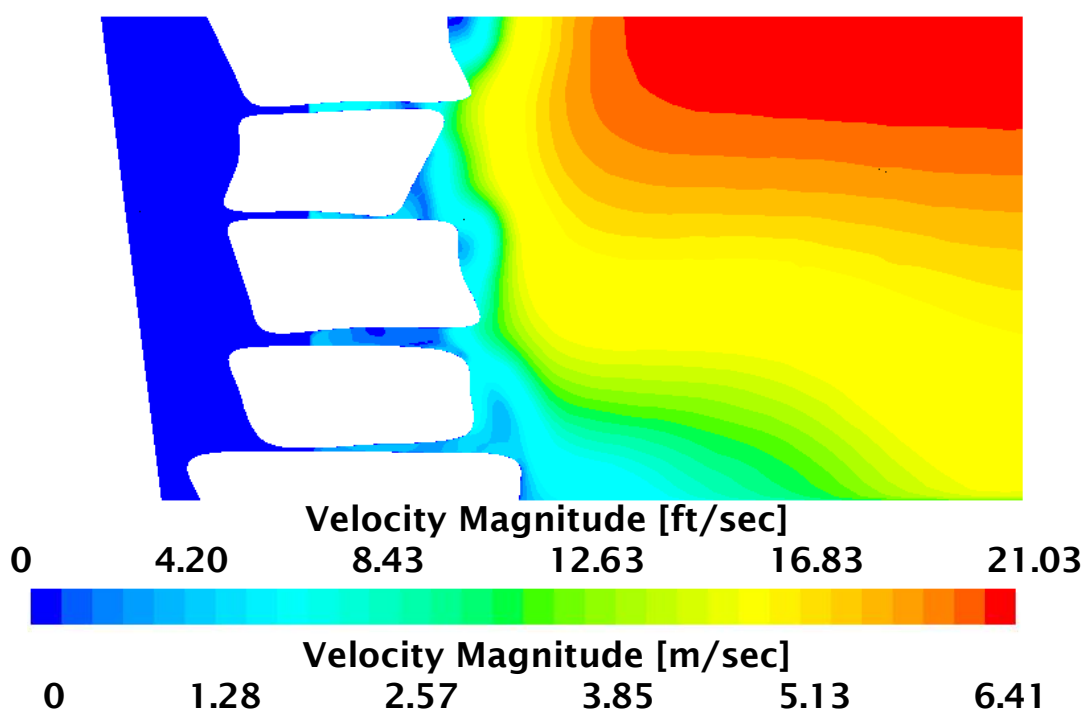

Figure 6-18: Velocity magnitude profile on a cross section perpendicular to the flow. Channel width, $\mathrm{W}=24 \mathrm{ft}$, ratio of channel width to water level height $\mathrm{W} / \mathrm{H}=2$, rockery face batter (a) $b=4: 1,(b) b=12: 1$ 
(a)

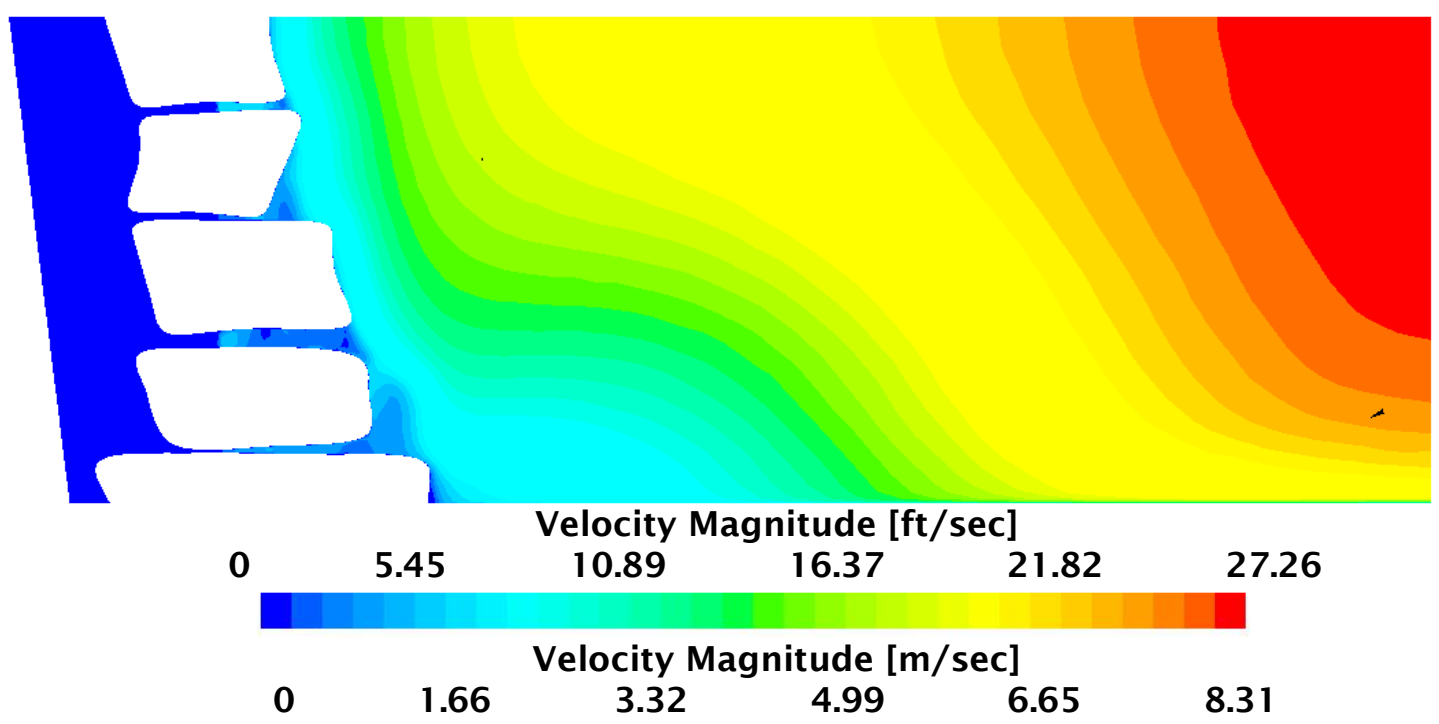

(b)

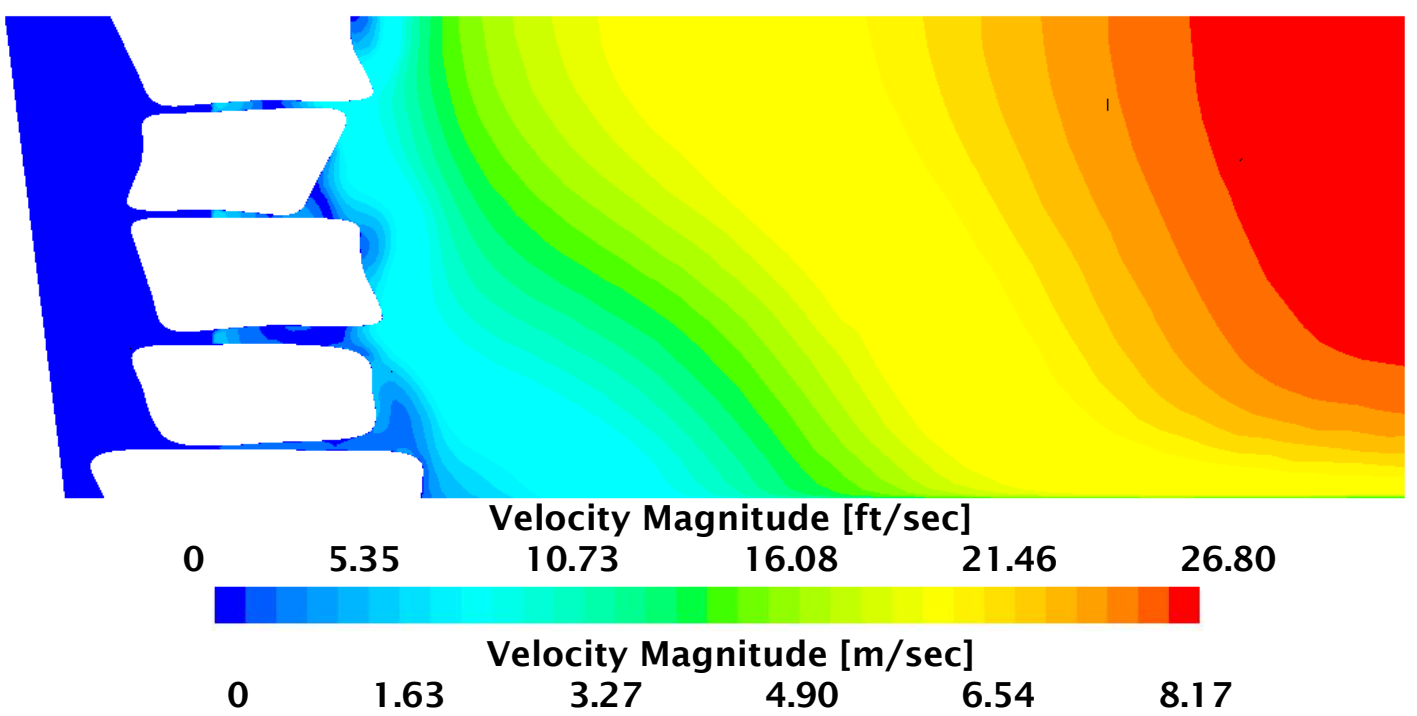

Figure 6-19: Velocity magnitude profile on a cross section perpendicular to the flow. Channel width, $W=48 f t$, ratio of channel width to water level height $W / H=4$, rockery face batter (a) $b=4: 1,(b) b=12: 1$

Figures Figure 6-17, Figure 6-18, and Figure 6-19 show the velocity magnitude profiles on a cross section perpendicular to the flow for channel width, $12 \mathrm{ft}, 24 \mathrm{ft}$, and $48 \mathrm{ft}$, respectively, and rockery face batter $b=4: 1$, and 12:1. The location of the maximum flow velocity differs, and does not always fall in the center of the channel, as it would in an open channel with smooth walls. At channel width $12 \mathrm{ft}$ and $24 \mathrm{ft}$ it is located closer to the rockery: at $\mathrm{W}=12 \mathrm{ft}$, it is $3.6 \mathrm{ft}(1.1 \mathrm{~m})$ away from the channel center, and at $\mathrm{W}=24 \mathrm{ft}$, it is $(8.5 \mathrm{ft}) 2.6 \mathrm{~m}$ away from the center. This change of the velocity profile is attributed to the influence of rocks on the water flow in narrower channels. With an uneven surface as well as gaps between the rocks, many small scale local points of separation form on the front surface of the rocks, causing eddies to be shed, introducing more turbulence to the flow, breaking up the near rock boundary layer, and resulting in the highest velocity shifting to a point that is off channel center. In wider channels the influence of the near rock flow pattern 
on the velocity distribution over a larger channel cross section area is not as significant, and the highest velocity flow is located in the center of the channel.

The point of the highest flow velocity parallel to the rockery corresponds to the location of the highest dynamic pressure, or highest flow kinetic energy. At this location, less of the flow energy is in the combined fluid pressure and gravitational potential energy (static pressure). The closer the points of high dynamic pressure are to the rock surfaces, the lower the fluid pressure tends to be at the rock surface. The geometric variations of the rock surfaces can yield points at which the fluid pressure on the stream side exceeds the pressure on the fill side. However, in general, the mean pressure obtained by integrating the fluid pressure over the rock surface on the stream side will be lower than that on the fill side in a section of a straight channel. The closer a point of high flow velocity is to the rockery surface, the greater the difference between the fill side and the stream side pressure tends to be, leading to higher lateral hydrodynamic forces.

Figure 6-20 presents an example probe line between a rock from the third layer and the point of maximum flow velocity magnitude (marked with red color). Analogous lines were created for each channel width to monitor and plot the velocity component in the flow direction along them. The combined curves, for varying channel width, were presented in Figure 6-21. The plot shows that the location of the maximum velocity is very similar for the channel widths of $6 \mathrm{ft}, 12 \mathrm{ft}$, and $24 \mathrm{ft}$. The distance is much larger for the width $48 \mathrm{ft}$ and corresponds to the distance between the rock and the center of the channel.

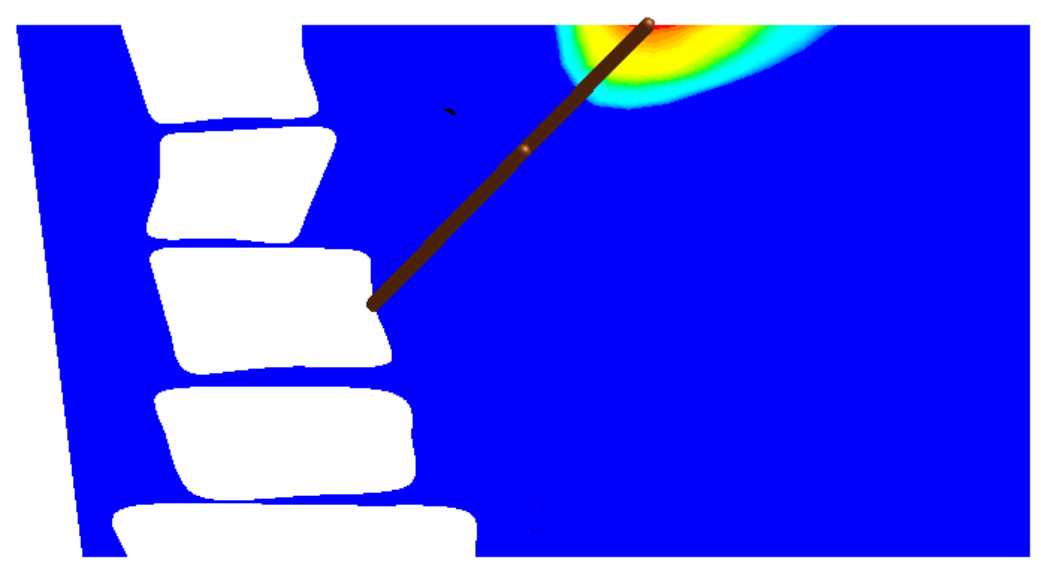

Figure 6-20: Line of points between the point of maximum flow velocity and layers 3 (L3). Red color shows the location of the highest flow velocity magnitude 


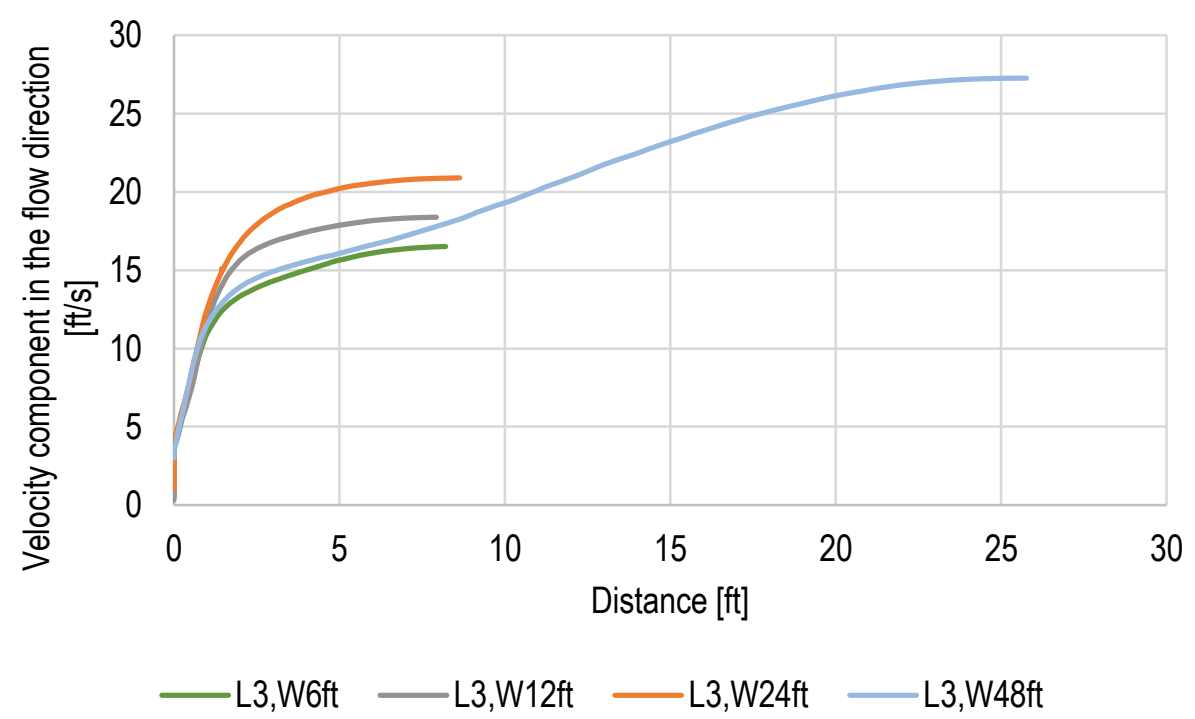

Figure 6-21: Flow velocity magnitude along a line between the rock surface and the point of maximum velocity, shown in Figure 6-20, for a set of channels with water height $12 \mathrm{ft}$, rockery face batter 4:1 and varying width equal to $6 \mathrm{ft}, 12 \mathrm{ft}, 24 \mathrm{ft}, 48 \mathrm{ft}$.

The fluid pressure acting on the third layer of rocks on various cross-section planes differs, which again is a result of the eddy shedding close to the rockery front surface, and therefore the values will change depending on which cross-section is chosen for the analysis. Figure 6-22 (a) illustrates a pressure distribution on one of the rocks forming the rockery with pressure distribution plotted on its surface. To show the difference in pressure values on the front (water) and back (fill) sides, the rock surface was divided, as illustrated in Figure 6-22 (b). The average pressure on these two surfaces was calculated for a set of channel width values and shown in Table 6-1. The hydrodynamic force components acting on the rock are calculated as integrals over its surface. The lateral forces acting on the two surfaces, as well as the resultant forces were included in the table. The highest pressure difference occurs when the channel is 24 feet wide, decreases for $\mathrm{W}=12$ $\mathrm{ft}$ and $\mathrm{W}=6 \mathrm{ft}$, and assumes the lowest value when $\mathrm{W}=96 \mathrm{ft}$. This trend corresponds to the dependence of hydrodynamic forces per unit rockery length on the channel width, presented in Figure 6-8. Figure 6-23 shows a plot of the resultant force acting on a rock, shown in Figure 6-22, vs. the ratio of the maximum flow velocity and the distance between the rock and the location of the maximum velocity. The values of the lateral hydrodynamic forces grow with the increasing ratio. A higher velocity corresponds to a higher dynamic pressure, which results in a lower working pressure at the rock face. Also, when the distance between the high dynamic pressure zone and the rock surface is smaller, the working pressure is expected to be on average lower there. 
(a)

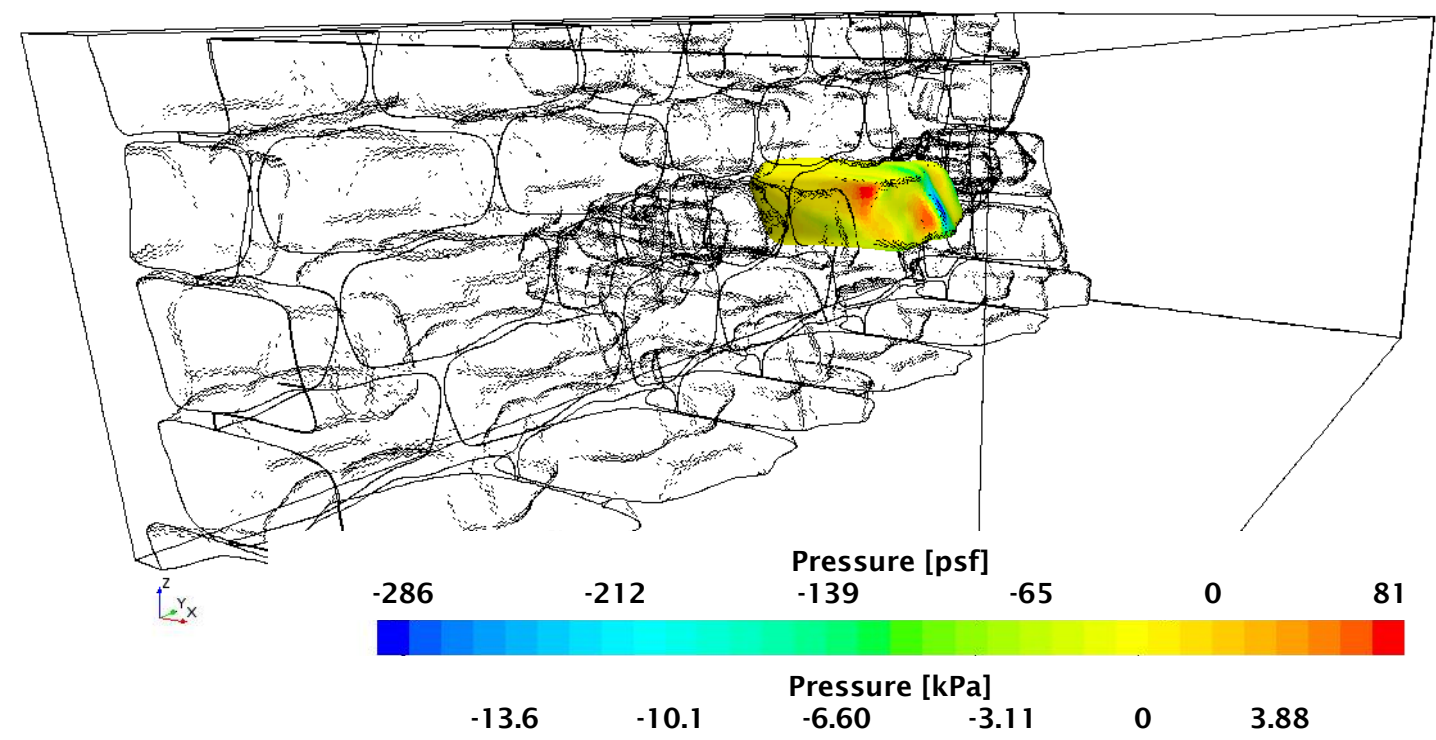

(b)

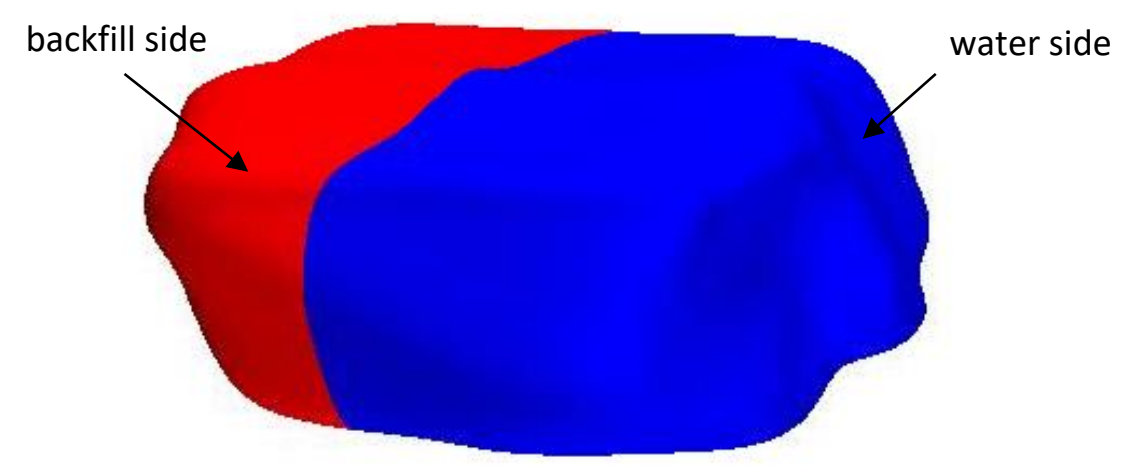

Figure 6-22: An example rock belonging to the third layer of rocks, (a) pressure distribution, (b) partition of the rock surface: part interacting with fluid (blue) and part interacting with backfill (red)

Table 6-1: Average pressure and lateral forces acting on the front and back surface of a selected rock, and the resultant lateral force for a set of channels with water height $12 \mathrm{ft}$, rockery face batter 4:1 and varying width equal to $6 \mathrm{ft}, 12 \mathrm{ft}, 24 \mathrm{ft}, 48,96 \mathrm{ft}$

\begin{tabular}{|c|c|c|c|}
\hline $\begin{array}{c}\text { channel } \\
\text { width [ft] }\end{array}$ & $\begin{array}{c}\text { average pressure } \\
\text { front / back } \\
\text { [psf] ([Pa]) }\end{array}$ & $\begin{array}{c}\text { lateral force } \\
\text { front / back } \\
{[\mathrm{lbf}]([\mathrm{kN}])}\end{array}$ & $\begin{array}{c}\text { resultant lateral } \\
\text { force } \\
[\mathrm{lbf}](\mathrm{kN}])\end{array}$ \\
\hline \multirow{2}{*}{6} & $-0.13 / 9.82$ & $-6295 / 6587$ & 292 \\
& $(-6 / 470)$ & $(-28 / 29.3)$ & $(1.3)$ \\
\hline \multirow{2}{*}{12} & $-8.36 / 3.26$ & $-6115 / 6474$ & 360 \\
& $(-400 / 156)$ & $(-27.2 / 28.8)$ & $(1.6)$ \\
\hline
\end{tabular}




\begin{tabular}{|c|c|c|c|}
\hline \multirow{2}{*}{24} & $-28.93 /-17.17$ & $-7193 / 7643$ & 450 \\
& $(-1385 /-822)$ & $(-32 / 34)$ & $(2.0)$ \\
\hline \multirow{2}{*}{48} & $-79.80 /-73.22$ & $-5036 / 5238$ & 202 \\
& $(-3820 /-3505)$ & $(-22.4 / 23.3)$ & $(0.9)$ \\
\hline \multirow{2}{*}{96} & $-122.10 /-119.64$ & $-4406 / 4496$ & 90 \\
& $(-5844 /-5727)$ & $(-19.6 / 20)$ & $(0.4)$ \\
\hline
\end{tabular}

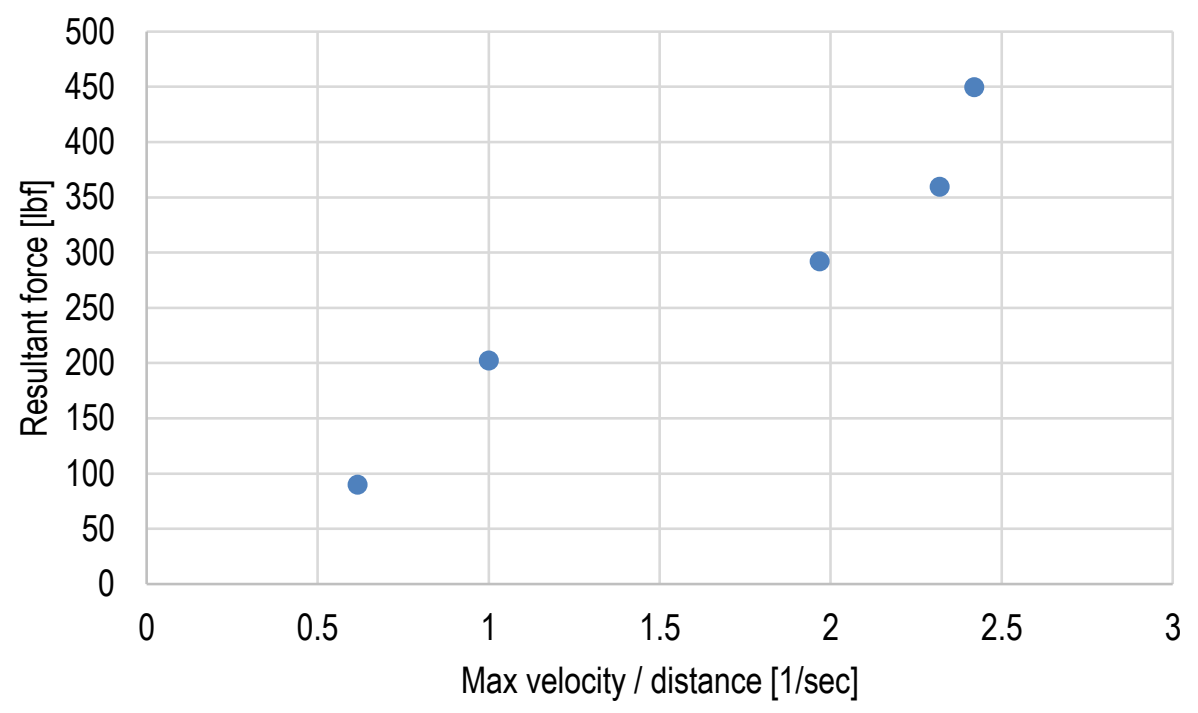

Figure 6-23: Resultant force acting on a rock shown in Figure 6-22 vs. the ratio of the maximum flow velocity and the distance between the rock and the location of the maximum velocity. Water height $12 \mathrm{ft}$, rockery face batter 4:1 and varying width equal to $6 \mathrm{ft}, 12 \mathrm{ft}, 24 \mathrm{ft}, 48,96 \mathrm{ft}$

The ratio of hydrodynamic forces to dry weight vs. channel width was calculated for three combinations of different rockery geometry and water level: case $1(\mathrm{C} 1)-\mathrm{H}=12 \mathrm{ft}, \mathrm{B}=7 \mathrm{ft}$, case 2 $(\mathrm{C} 2)-\mathrm{H}=7 \mathrm{ft}, \mathrm{B}=7 \mathrm{ft}$, case $3\left(\mathrm{C}_{3}\right)-\mathrm{H}=12 \mathrm{ft}, \mathrm{B}=8 \mathrm{ft}$. The results of these analyses were plotted in Figure 6-24. The highest values of the ratio were obtained for the channel width $12 \mathrm{ft}(\mathrm{W} / \mathrm{H}=1)$ when the rockery face batter is 4:1 and its base is 8-foot wide; the hydrodynamic forces reach up to $2.4 \%$ of the weight of the rocks. The lowest value of the ratio is equal to $0.11 \%$ for the widest considered channel ( $48 \mathrm{ft}$ ), water height $7 \mathrm{ft}$ and rockery face batter 12:1 and 7-foot wide base. The ratio decreases with a trend close to linear when the channel width increases. These trends, as well as the fitted linear functions are illustrated in Figure 6-25. 


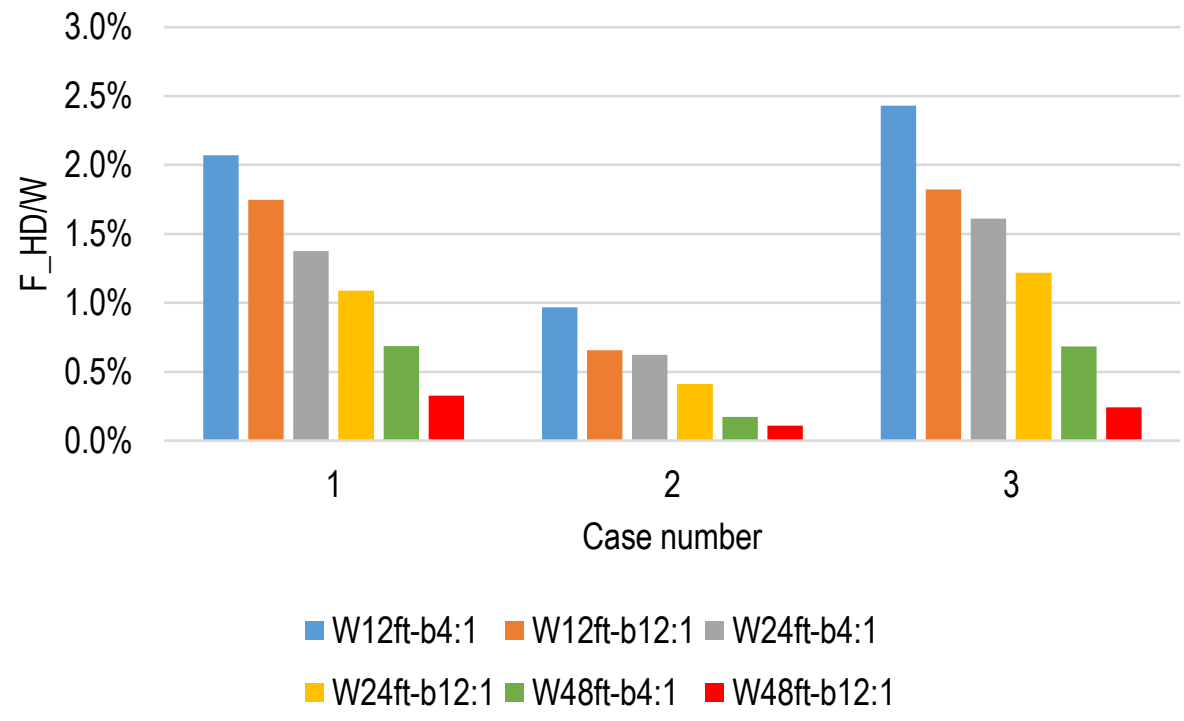

Figure 6-24: Ratio of hydrodynamic forces to weight of the rocks vs. channel width. Case number 1 (C1) $\mathrm{H}=12 \mathrm{ft}, \mathrm{B}=7 \mathrm{ft}$, case number $2(\mathrm{C} 2)-\mathrm{H}=7 \mathrm{ft}, \mathrm{B}=7 \mathrm{ft}$, case number $3\left(\mathrm{C}_{3}\right)-\mathrm{H}=12 \mathrm{ft}, \mathrm{B}=8 \mathrm{ft}$.

(a)

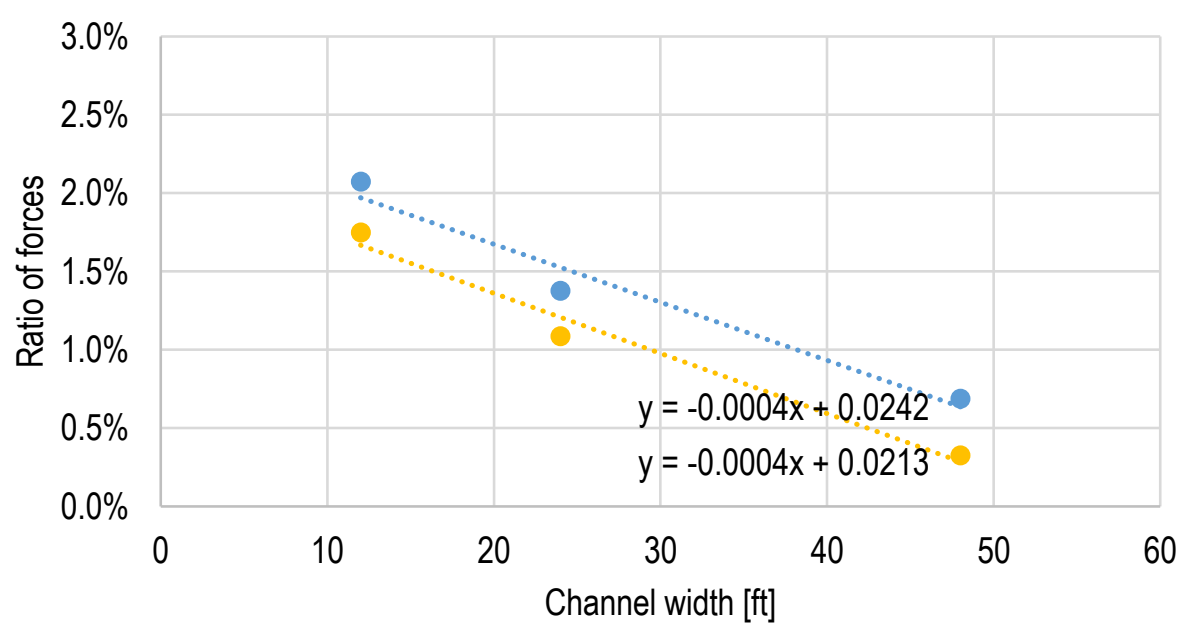

- C1b4:1 C C1b12:1 …...... Linear (C1b4:1) …...... Linear (C1b12:1) 
(b)

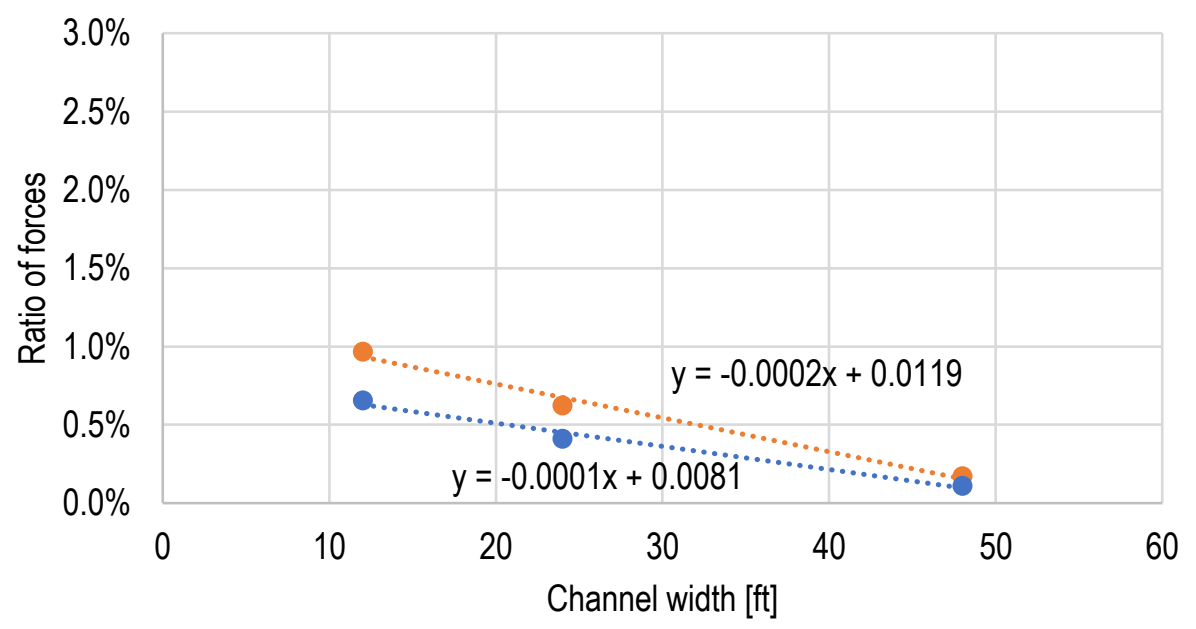

- $\mathrm{C} 2 \mathrm{~b} 4: 1 \quad \bullet \quad \mathrm{C} 2 \mathrm{~b} 12: 1 \ldots \ldots \ldots$ Linear $(\mathrm{C} 2 \mathrm{~b} 4: 1) \ldots \ldots \ldots$ Linear $(\mathrm{C} 2 \mathrm{~b} 12: 1)$

(c)

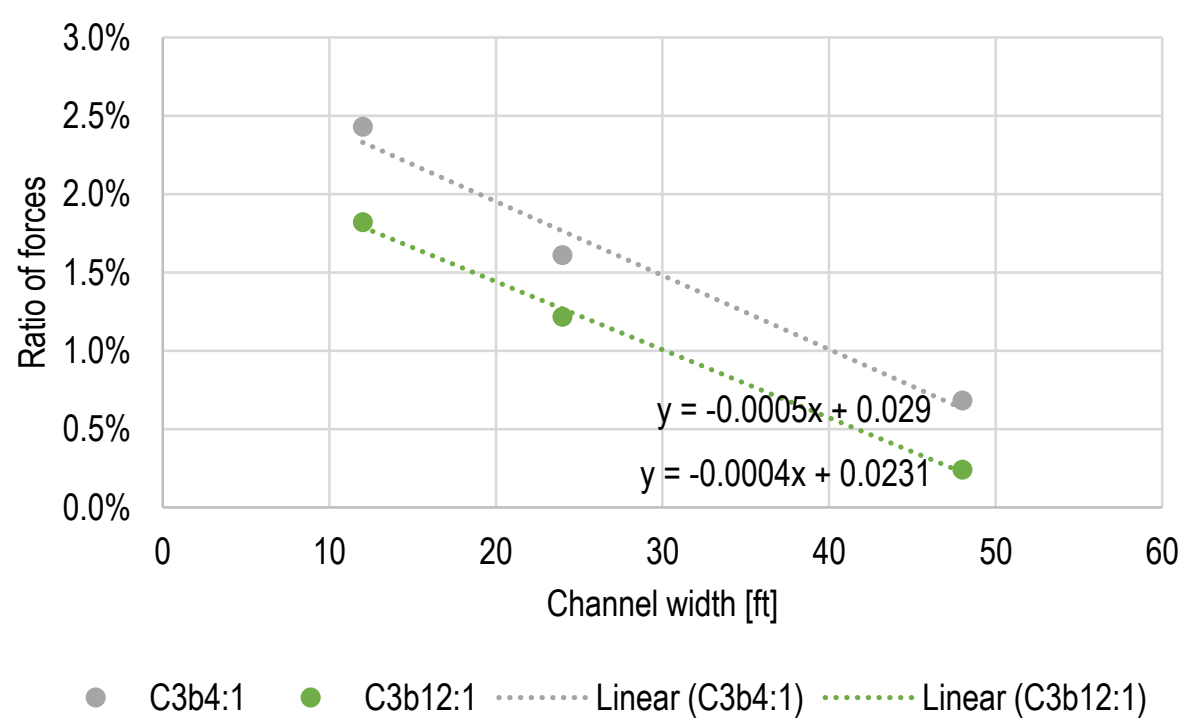

Figure 6-25: Ratio of hydrodynamic forces to weight of the rocks vs. channel width and the linear trend lines for (a) case number $1(\mathrm{C} 1)-\mathrm{H}=12 \mathrm{ft}, \mathrm{B}=7 \mathrm{ft}$, (b) case number $2(\mathrm{C} 2)-\mathrm{H}=7 \mathrm{ft}, \mathrm{B}=7 \mathrm{ft}$, (c) case number $3\left(\mathrm{C}_{3}\right)-\mathrm{H}=12 \mathrm{ft}, \mathrm{B}=8 \mathrm{ft}$ 


\subsubsection{Overtopping of a rockery structure}

The hydraulic conditions described in previous chapters resulted in flows with water levels lower than the rockery height. In this chapter two cases of water level, $16 \mathrm{ft}$ and $18 \mathrm{ft}$, which are higher than the rockery, were considered. The flow overtopping the rockery exerts overall higher forces on the layers of rocks, with a significant increase of force values acting on the top layer. Figure 6-26 and Figure 6-27 show plots of vertical distribution of hydrodynamic forces per unit length of rockery with face batter 4:1 and 12:1, base width $7 \mathrm{ft}$ at water height $16 \mathrm{ft}$ and $18 \mathrm{ft}$, respectively. The results were combined in Figure 6-28 in the form of a plot of average force vs. channel bed width. The curves represent the change in force values for each rockery layer. The forces plotted against this non-dimensional parameter follow the same trend. They increase for $\mathrm{W}_{\mathrm{B}}<48 \mathrm{ft}$ and then decrease.

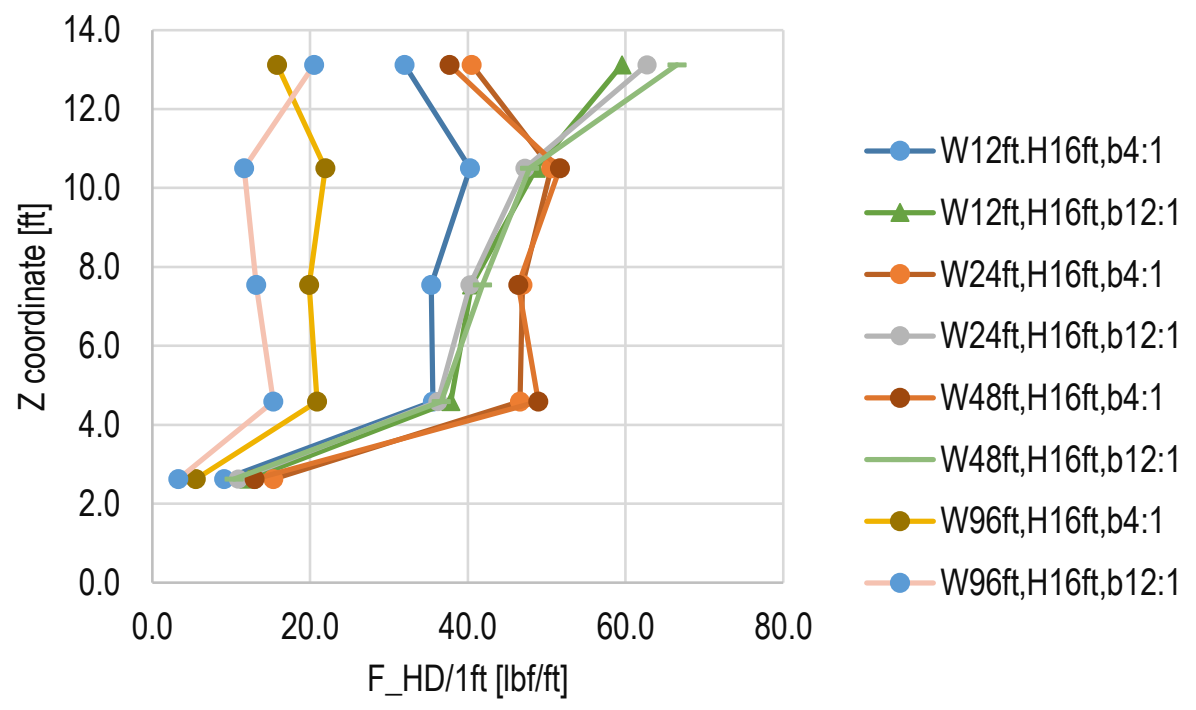

Figure 6-26: Vertical distribution of hydrodynamic forces per unit length of rockery with face batter 4:1 and 12:1, base width $7 \mathrm{ft}$ at water height $16 \mathrm{ft}$

Computational Assessment of Hydrodynamic Loads on Rockeries for River Bank Protection 


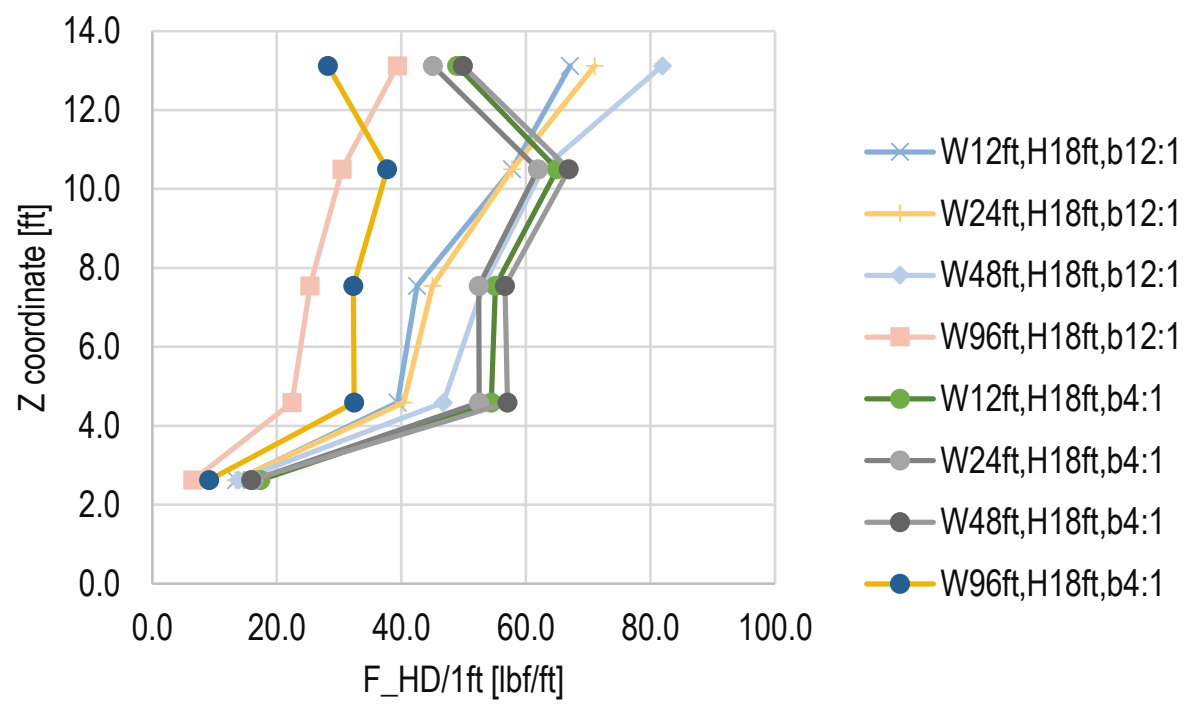

Figure 6-27: Vertical distribution of hydrodynamic forces per unit length of rockery with face batter 4:1 and 12:1, base width $7 \mathrm{ft}$ at water height $18 \mathrm{ft}$

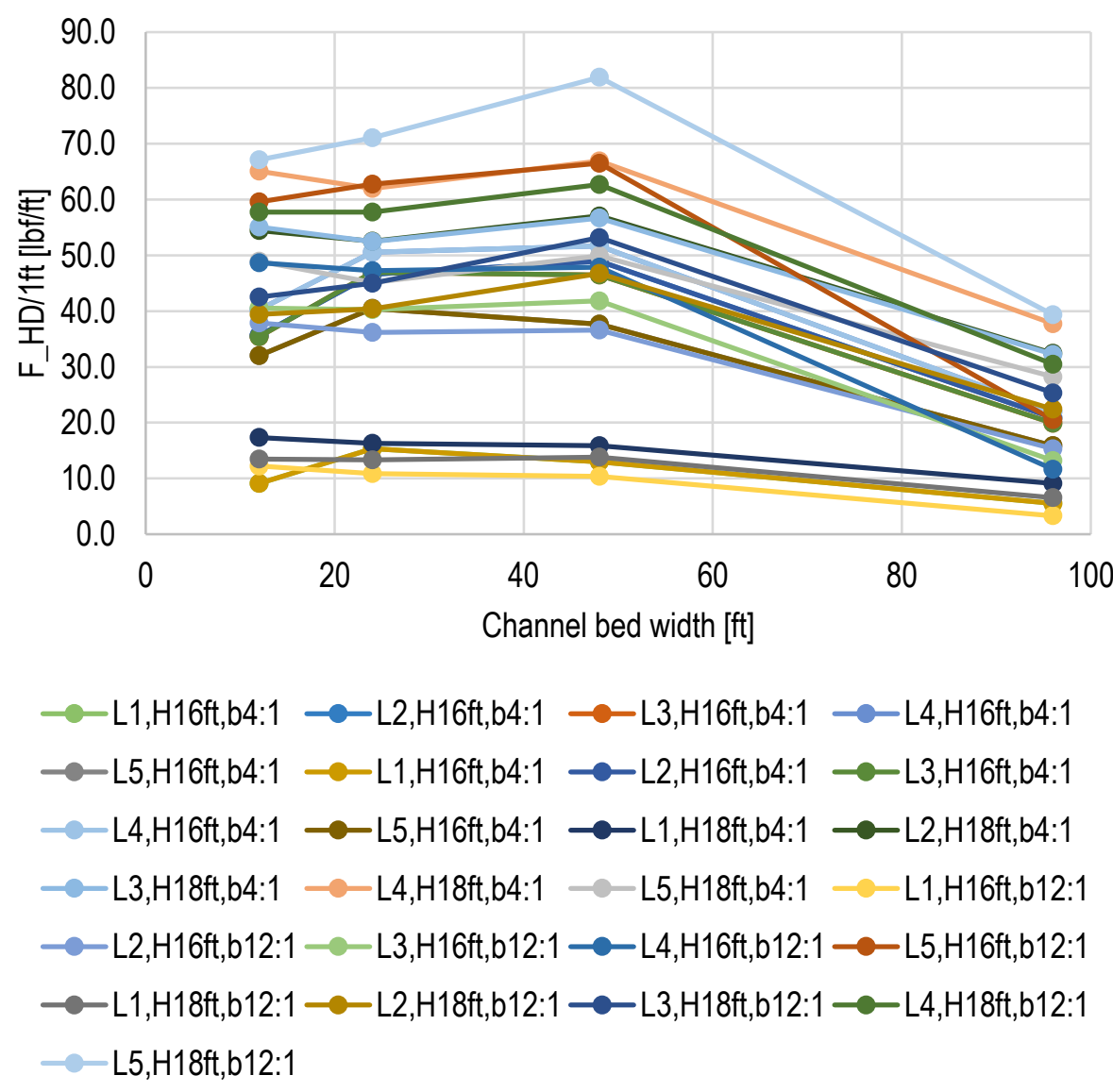

Figure 6-28: Hydrodynamic forces per unit length vs. channel width for cases of water height overtopping the rockery, W. L1 - 1st layer, L2 - 2nd layer, L3 - 3rd layer, L4 - 4th layer, L5 - 5th layer

Computational Assessment of Hydrodynamic Loads on Rockeries for River Bank Protection 


\subsection{Numerical example of rockery failure criteria. Straight channel}

The criteria for the two types of failure modes: sliding and overturning, as well as the governing equations were presented in chapter 4 . The equations for both modes in 'dry' conditions were modified to take into account the loads exerted on the structure by the water flow. The average hydrodynamic forces (in units of force per unit length) estimated in the computational simulations were added to these equations.

Two examples were presented which differ in only one geometric parameter, the rockery face batter. Two values were assumed, 4:1 and 12:1. All other geotechnical and hydraulic parameters used in the examples, as well as their values, were combined in Table 6-2. It was assumed that the rocks forming the rockery are granite, with unit weight $150 \mathrm{pcf}\left(23.5 \mathrm{kN} / \mathrm{m}^{3}\right)$, according to the recommendations [6]. The unit weight of the soil retained by the rockery can vary due to the onsite conditions. Typically, it is assumed to be between $110 \mathrm{pcf}\left(17.2 \mathrm{kN} / \mathrm{m}^{3}\right)$ and $130 \mathrm{pcf}\left(20.4 \mathrm{kN} / \mathrm{m}^{3}\right)$ [6]. In this example, the upper limit of the unit soil weight was adopted. The surcharge load from traffic was determined according to the American Association of State Highway Transportation Officials (AASHTO) [10] as a uniform vertical load equivalent to additional $2 \mathrm{ft}$ of soil behind the rockery. The additional load acting on the rockery is the hydrodynamic force exerted by the moving water. A plot of the vertical distribution of the hydrodynamic forces per unit length of a rockery, used in this example, is presented in Figure 6-7. The water level in this example reaches approximately half of the top layer height. It was assumed conservatively in the calculations that all layers of rocks are submerged, therefore the weight of the layers was decreased to take into account the influence of buoyancy.

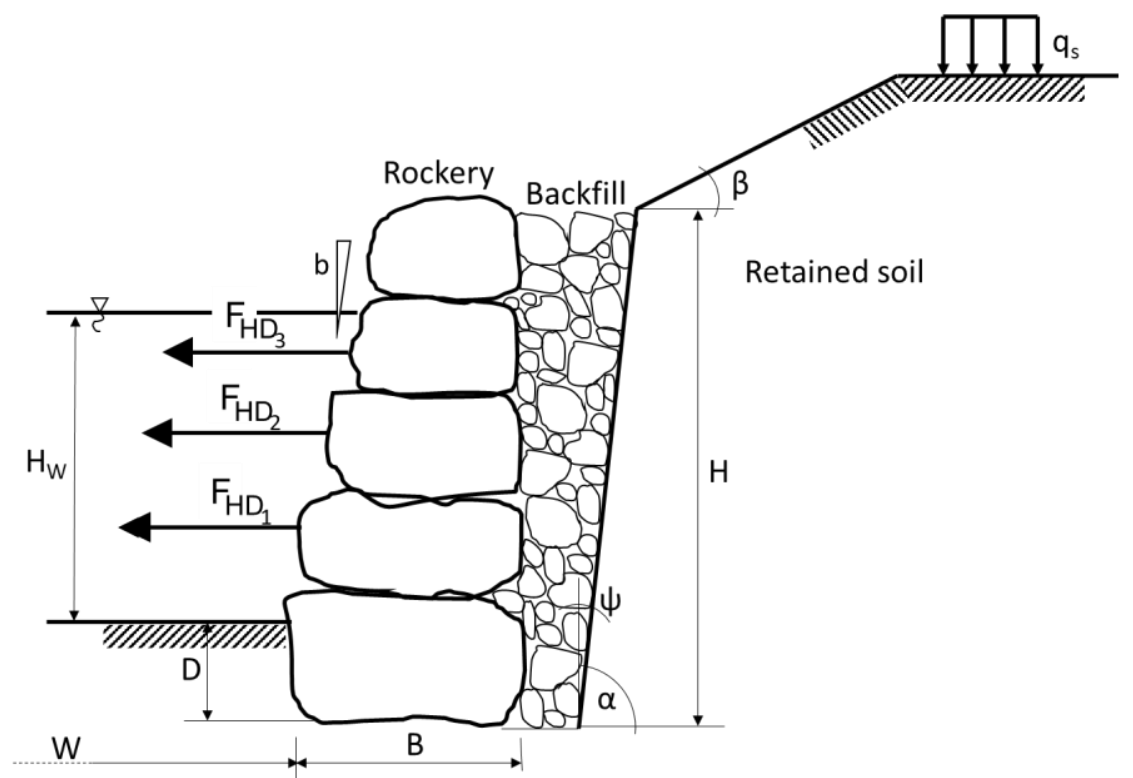

Figure 6-29: Variables in the numerical example 
Table 6-2: The parameters in the numerical example

\begin{tabular}{|c|c|c|c|}
\hline \multicolumn{2}{|c|}{ Geotechnical parameters: } & \multicolumn{2}{|c|}{ Hydraulic parameters: } \\
\hline - total rockery height & $\mathrm{H}=14.4 \mathrm{ft}(4.4 \mathrm{~m})$ & - water depth & $\mathrm{H}_{\mathrm{w}}=12 \mathrm{ft}(3.7 \mathrm{~m})$ \\
\hline $\begin{array}{l}\text { - exposed rockery } \\
\text { height }\end{array}$ & $\mathrm{H}_{\mathrm{exp}}=12.5 \mathrm{ft}(3.8 \mathrm{~m})$ & - channel width & $\mathrm{W}_{\mathrm{B}}=24 \mathrm{ft}(7.3 \mathrm{~m})$ \\
\hline - embedment depth & $\mathrm{D}=2 \mathrm{ft}(0.6 \mathrm{~m})$ & - mean flow velocity & $\begin{array}{l}\mathrm{v}=14 \mathrm{ft} / \mathrm{s} \\
(4.27 \mathrm{~m} / \mathrm{s})\end{array}$ \\
\hline - face batter & $\mathrm{b}=4: 1$ and $12: 1$ & - angle of attack & $\alpha_{B}=0$ deg \\
\hline - friction angle & $\phi=33$ deg & & \\
\hline - retained soil weight & $\begin{array}{l}\gamma_{S}=127 \mathrm{pcf} \\
\left(20 \mathrm{kN} / \mathrm{m}^{3}\right)\end{array}$ & & \\
\hline - rock weight & $\begin{array}{l}\gamma_{R}=150 \mathrm{pcf} \\
\left(23.5 \mathrm{kN} / \mathrm{m}^{3}\right)\end{array}$ & & \\
\hline - friction coefficient & $\mu=\tan \phi=0.65$ & & \\
\hline $\begin{array}{l}\text { - interface friction } \\
\text { angle }\end{array}$ & $\delta=\frac{2}{3} \phi=22 \operatorname{deg}$ & & \\
\hline - back cut angle & $\begin{array}{l}\alpha=\tan ^{-1}(8 / 1)=82.9 \mathrm{deg} ; \\
\psi=90 \mathrm{deg}-\alpha= \\
=7.13 \mathrm{deg}\end{array}$ & & \\
\hline $\begin{array}{l}\text { - active lateral earth } \\
\text { pressure coefficient }\end{array}$ & $\mathrm{K}_{\mathrm{A}}=0.217$ & & \\
\hline
\end{tabular}

Sliding failure of the rockery occurs if the ratio of resisting to driving forces is less than one, see chapter 1 . The driving forces for a rockery with face batter 4:1 are calculated as

$$
\begin{gathered}
F_{H}=F_{A, H}+F_{S}+F_{H D}=\frac{1}{2} \gamma_{S} K_{A} H^{2} \cos (\delta-\psi)+q_{S} K_{A} H+\sum_{i} F_{H D_{i}} \\
F_{H}=(2784+786+190) \frac{l b f}{f t}\left((40.63+11.47+2.78) \frac{\mathrm{kN}}{\mathrm{m}}\right)=3760 \frac{\mathrm{lbf}}{\mathrm{ft}}\left(54.9 \frac{\mathrm{kN}}{\mathrm{m}}\right)
\end{gathered}
$$

The resisting force is equal to

$$
\begin{gathered}
F_{\mu}=\mu\left(W+F_{A, V}\right)=\mu\left(\sum_{i} W_{i}+\frac{1}{2} \gamma_{S} K_{A} H^{2} \sin (\delta-\psi)\right)= \\
=0.65(5234+739) \frac{l b f}{f t}\left(0.65(76.39+10.79) \frac{\mathrm{kN}}{\mathrm{m}}\right)=3879 \frac{\mathrm{lbf}}{\mathrm{ft}}\left(56.62 \frac{\mathrm{kN}}{\mathrm{m}}\right)
\end{gathered}
$$

The ratio of the resisting to driving forces is higher than, but very close to, one,

$$
\frac{F_{\mu}}{F_{H}}=1.03<1.5
$$

which means that the structure is stable, but any increase in e.g. surcharge load or soil unit weight will result in a structure prone to failure. For example, if the retained soil weight increases to 21

Computational Assessment of Hydrodynamic Loads on Rockeries for River Bank Protection 
$\mathrm{kN} / \mathrm{m}^{3}$, then the ratio $\frac{F_{\mu}}{F_{H}}=0.99$. In this example the geotechnical parameters were chosen such that the stability of the rockery in 'dry' conditions is assured and that the ratio of resisting to driving forces is higher than the safety factors $\left(\frac{F_{\mu}}{F_{H}}=1.8>1.5\right)$. The additional term in the formula that takes into account the sum of the dynamic loads, $\sum_{i} F_{H D_{i}}=190 \frac{\mathrm{lbf}}{\mathrm{ft}}\left(2.78 \frac{\mathrm{kN}}{\mathrm{m}}\right)$, does not have much effect on the overall driving force, $F_{H}$; it adds $5 \%$ to the total force. A much more significant difference is found in the resisting force and it is a result of the decreased weight of the rocks when submerged in water. If the rockery was constructed in an environment where no channel flow is expected, its weight per unit length would be equal to $\sum_{i} W_{i}=9112 \frac{\mathrm{lb} f}{\mathrm{ft}}\left(133 \frac{\mathrm{kN}}{\mathrm{m}}\right)$. The rockery is almost fully submerged in water in this example (the exposed rockery height is $12.5 \mathrm{ft}$, and the water depth is $12 \mathrm{ft}$ ), therefore it was assumed that the total weight of the structure should be decreased due to the buoyancy, which gives $5234 \frac{\mathrm{lbf}}{\mathrm{ft}}\left(76.39 \frac{\mathrm{kN}}{\mathrm{m}}\right)$. The drop in the weight of the structure and the addition of the hydrodynamic forces causes the ratio to decrease below the safety factor. It should be noted that when lower water levels are considered, only the weight of the submerged rocks should be decreased accordingly, and the weight of the top layers should remain unchanged.

The governing equation for the overturning failure was presented in chapter 3.2. The moment of the driving forces is calculated as

$$
\begin{gathered}
M_{O}=\frac{1}{2} \gamma_{S} K_{A} H^{2} \cos (\delta-\psi) \frac{H}{3}+q_{S} K_{A} H \frac{H}{2}+\sum_{i}\left(F_{H D_{i}} z_{i}\right)= \\
=(13397+5671+1047) \frac{l b f f t}{f t}\left((59.59+25.22+4.66) \frac{\mathrm{kN} \mathrm{m}}{\mathrm{m}}\right)=20115 \frac{\mathrm{lbf} f t}{\mathrm{ft}}\left(89.48 \frac{\mathrm{kN} \mathrm{m}}{\mathrm{m}}\right)
\end{gathered}
$$

The resisting moment is equal

$$
\begin{gathered}
M_{R}=\sum_{i}\left(W_{i} x_{i}\right)+\frac{1}{2} \gamma_{S} K_{A} H^{2} \sin (\delta-\psi)\left(\frac{H}{3} \tan (\psi)+B\right)= \\
=(24133+5630) \frac{l b f f t}{f t}\left((107.35+25.04) \frac{\mathrm{kN} \mathrm{m}}{\mathrm{m}}\right)=29763 \frac{\mathrm{lbfft}}{\mathrm{ft}}\left(132.39 \frac{\mathrm{kN} \mathrm{m}}{\mathrm{m}}\right)
\end{gathered}
$$

The ratio of moments is higher than one, which indicates that an overturning failure will not occur. It is also lower than the safety factor for overturning applicable in the 'dry' conditions

$$
\frac{M_{R}}{M_{O}}=1.48<2.0
$$

If the analyzed conditions did not include the influence of water, the ratio would be higher than the safety factor and equal to $\frac{M_{R}}{M_{O}}=2.50$. The term resulting from the hydrodynamic forces constitutes $5 \%$ of the total driving force. The resisting moment is primarily decreased as a result of the drop in the weight of the rocks when submerged.

Computational Assessment of Hydrodynamic Loads on Rockeries for River Bank Protection 
In the case of a rockery with a lower slope (face batter equals 4:1), the sliding failure will occur before the overturning failure. In the second example, the rockery face is almost vertical (face batter 12:1), which means that the rocks of the upper layers are bigger than in the previous example and the center of gravity is located higher. This leads to an increase in probability of the overturning failure to occur earlier than the sliding failure.

The driving forces for a rockery with face batter 12:1 are calculated as

$$
\begin{gathered}
F_{H}=F_{A, H}+F_{S}+F_{H D}=\frac{1}{2} \gamma_{S} K_{A} H^{2} \cos (\delta-\psi)+q_{S} K_{A} H+\sum_{i} F_{H D_{i}} \\
F_{H}=(2784+786+154) \frac{l b f}{f t}\left((40.63+11.47+2.26) \frac{\mathrm{kN}}{\mathrm{m}}\right)=3724 \frac{\mathrm{lbf}}{\mathrm{ft}}\left(54.35 \frac{\mathrm{kN}}{\mathrm{m}}\right)
\end{gathered}
$$

The resisting force is equal to

$$
\begin{gathered}
F_{\mu}=\mu\left(W+F_{A, V}\right)=\mu\left(\sum_{i} W_{i}+\frac{1}{2} \gamma_{S} K_{A} H^{2} \sin (\delta-\psi)\right)= \\
=0.65(5922+739) \frac{l b f}{f t}\left(0.65(86.43+10.79) \frac{\mathrm{kN}}{\mathrm{m}}\right)=4326 \frac{\mathrm{lbf}}{\mathrm{ft}}\left(63.14 \frac{\mathrm{kN}}{\mathrm{m}}\right)
\end{gathered}
$$

The ratio of the resisting to driving forces is higher than, but very close to, one,

$$
\frac{F_{\mu}}{F_{H}}=1.16<1.5
$$

The moment of the driving forces is calculated as

$$
\begin{gathered}
M_{O}=\frac{1}{2} \gamma_{S} K_{A} H^{2} \cos (\delta-\psi) \frac{H}{3}+q_{S} K_{A} H \frac{H}{2}+\sum_{i}\left(F_{H D_{i}} z_{i}\right)= \\
=(13397+5671+911) \frac{l b f f t}{f t}\left((59.59+25.22+4.05) \frac{\mathrm{kN} \mathrm{m}}{\mathrm{m}}\right)=19979 \frac{\mathrm{lbfft}}{\mathrm{ft}}\left(88.87 \frac{\mathrm{kN} \mathrm{m}}{\mathrm{m}}\right)
\end{gathered}
$$

The resisting moment is equal

$$
\begin{gathered}
M_{R}=\sum_{i}\left(W_{i} x_{i}\right)+\frac{1}{2} \gamma_{S} K_{A} H^{2} \sin (\delta-\psi)\left(\frac{H}{3} \tan (\psi)+B\right)= \\
=(15837+5630) \frac{l b f f t}{f t}\left((70.45+25.04) \frac{\mathrm{kN} \mathrm{m}}{\mathrm{m}}\right)=21467 \frac{\mathrm{lbfft}}{\mathrm{ft}}\left(95.49 \frac{\mathrm{kN} \mathrm{m}}{\mathrm{m}}\right)
\end{gathered}
$$

The ratio of moments is higher than one, which indicates that an overturning failure will not occur, but the stability can be undermined if any of the loads increase. It is also lower than the safety factor for overturning applicable in the 'dry' conditions

$$
\frac{M_{R}}{M_{O}}=1.07<2.0
$$

The stability of a set of rockery structures under various geotechnical and hydraulic conditions was analyzed. The ratio of resisting to driving forces was compared against the safety factors and 
the example results were combined in Table 7-1 and Table 7-2. The tables showed that for narrower channels and smaller rockery bases, the ratio tends to be less than the factor for safety. Nevertheless, the structures were stable under the considered loads in the presented examples.

Table 6-3: Stability analysis for sliding and overturning failure of a selected set of rockeries. The weight of the retained soil is $\gamma_{\mathrm{s}}=115 \mathrm{pcf}\left(17.2 \mathrm{kN} / \mathrm{m}^{3}\right)$.

\begin{tabular}{|c|c|c|c|c|c|c|c|c|}
\hline & \multicolumn{4}{|c|}{ SLIDING } & \multicolumn{4}{|c|}{ OVERTURNING } \\
\hline \multicolumn{9}{|c|}{ Face batter 4:1 } \\
\hline Case & $\mathbf{W}[\mathbf{f t}]$ & 12 & 24 & 48 & $\mathbf{W}[\mathbf{f t}]$ & 12 & 24 & 48 \\
\hline $\mathbf{1}$ & $\mathrm{B}=7 \mathrm{ft}, \mathrm{H}=12 \mathrm{ft}$ & $\mathrm{N}$ & $\mathrm{N}$ & $\mathrm{N}$ & $\mathrm{B}=7 \mathrm{ft}, \mathrm{H}=12 \mathrm{ft}$ & $\mathrm{N}$ & $\mathrm{N}$ & $\mathrm{N}$ \\
\hline 2 & $\mathrm{~B}=7 \mathrm{ft}, \mathrm{H}=7 \mathrm{ft}$ & $\mathrm{N}$ & $\mathrm{N}$ & $\mathrm{N}$ & $\mathrm{B}=7 \mathrm{ft}, \mathrm{H}=7 \mathrm{ft}$ & $\mathrm{N}$ & $\mathrm{Y}$ & $\mathrm{Y}$ \\
\hline 3 & $\mathrm{~B}=8 \mathrm{ft}, \mathrm{H}=12 \mathrm{ft}$ & $\mathrm{Y}$ & $\mathrm{Y}$ & $\mathrm{Y}$ & $\mathrm{B}=8 \mathrm{ft}, \mathrm{H}=12 \mathrm{ft}$ & $\mathrm{Y}$ & $\mathrm{Y}$ & $\mathrm{Y}$ \\
\hline \multicolumn{9}{|c|}{ Face batter 12:1 } \\
\hline Case & $\mathbf{W}[\mathbf{f t}]$ & 12 & 24 & 48 & W [ft] & 12 & 24 & 48 \\
\hline $\mathbf{1}$ & $\mathrm{B}=7 \mathrm{ft}, \mathrm{H}=12 \mathrm{ft}$ & $\mathrm{N}$ & $\mathrm{N}$ & $\mathrm{N}$ & $\mathrm{B}=7 \mathrm{ft}, \mathrm{H}=12 \mathrm{ft}$ & $\mathrm{N}$ & $\mathrm{N}$ & $\mathrm{N}$ \\
\hline 2 & $\mathrm{~B}=7 \mathrm{ft}, \mathrm{H}=7 \mathrm{ft}$ & $\mathrm{Y}$ & $\mathrm{Y}$ & $\mathrm{Y}$ & $\mathrm{B}=7 \mathrm{ft}, \mathrm{H}=7 \mathrm{ft}$ & $\mathrm{Y}$ & $\mathrm{Y}$ & $\mathrm{Y}$ \\
\hline 3 & $\mathrm{~B}=8 \mathrm{ft}, \mathrm{H}=12 \mathrm{ft}$ & $\mathrm{Y}$ & $\mathrm{Y}$ & $\mathrm{Y}$ & $\mathrm{B}=8 \mathrm{ft}, \mathrm{H}=12 \mathrm{ft}$ & $\mathrm{Y}$ & $\mathrm{Y}$ & $\mathrm{Y}$ \\
\hline
\end{tabular}

Table 6-4: Stability analysis for sliding and overturning failure of a selected set of rockeries. The weight of the retained soil is $\gamma_{\mathrm{s}}=125 \mathrm{pcf}\left(2 \mathrm{okN} / \mathrm{m}^{3}\right)$.

\begin{tabular}{|c|c|c|c|c|c|c|c|c|}
\hline & \multicolumn{4}{|c|}{ SLIDING } & \multicolumn{4}{|c|}{ OVERTURNING } \\
\hline & \multicolumn{8}{|c|}{ Face batter 4:1 } \\
\hline Case & $\mathbf{W}[\mathbf{f t}]$ & 12 & 24 & 48 & $\mathbf{W}[\mathbf{f t}]$ & 12 & 24 & 48 \\
\hline $\mathbf{1}$ & $\mathrm{B}=7 \mathrm{ft}, \mathrm{H}=12 \mathrm{ft}$ & $\mathrm{N}$ & $\mathrm{N}$ & $\mathrm{N}$ & $\mathrm{B}=7 \mathrm{ft}, \mathrm{H}=12 \mathrm{ft}$ & $\mathrm{N}$ & $\mathrm{N}$ & $\mathrm{N}$ \\
\hline 2 & $\mathrm{~B}=7 \mathrm{ft}, \mathrm{H}=7 \mathrm{ft}$ & $\mathrm{N}$ & $\mathrm{N}$ & $\mathrm{N}$ & $\mathrm{B}=7 \mathrm{ft}, \mathrm{H}=7 \mathrm{ft}$ & $\mathrm{N}$ & $\mathrm{N}$ & $\mathrm{N}$ \\
\hline \multirow[t]{3}{*}{3} & $\mathrm{~B}=8 \mathrm{ft}, \mathrm{H}=12 \mathrm{ft}$ & $\mathrm{N}$ & $\mathrm{N}$ & $\mathrm{N}$ & $\mathrm{B}=8 \mathrm{ft}, \mathrm{H}=12 \mathrm{ft}$ & $\mathrm{N}$ & $\mathrm{N}$ & $\mathrm{N}$ \\
\hline & \multicolumn{8}{|c|}{ Face batter 12:1 } \\
\hline & $W[f t]$ & 12 & 24 & 48 & $\mathbf{W}[\mathbf{f t}]$ & 12 & 24 & 48 \\
\hline $\mathbf{1}$ & $\mathrm{B}=7 \mathrm{ft}, \mathrm{H}=12 \mathrm{ft}$ & $\mathrm{N}$ & $\mathrm{N}$ & $\mathrm{N}$ & $\mathrm{B}=7 \mathrm{ft}, \mathrm{H}=12 \mathrm{ft}$ & $\mathrm{N}$ & $\mathrm{N}$ & $\mathrm{N}$ \\
\hline 2 & $\mathrm{~B}=7 \mathrm{ft}, \mathrm{H}=7 \mathrm{ft}$ & $\mathrm{N}$ & $\mathrm{Y}$ & $\mathrm{Y}$ & $\mathrm{B}=7 \mathrm{ft}, \mathrm{H}=7 \mathrm{ft}$ & $\mathrm{Y}$ & $\mathrm{Y}$ & $\bar{Y}$ \\
\hline 3 & $\mathrm{~B}=8 \mathrm{ft}, \mathrm{H}=12 \mathrm{ft}$ & $\mathrm{Y}$ & $\mathrm{Y}$ & $\mathrm{Y}$ & $\mathrm{B}=8 \mathrm{ft}, \mathrm{H}=12 \mathrm{ft}$ & $\mathrm{Y}$ & $\mathrm{Y}$ & $\mathrm{Y}$ \\
\hline
\end{tabular}

Computational Assessment of Hydrodynamic Loads on Rockeries for River Bank Protection 


\subsection{Lateral force coefficient}

One of the goals of the study is to generate design aids for engineers, by developing formulas and charts that can be used in the design of new rockeries or in evaluation of existing dry-stack rockeries in river environments.

A dimensionless hydraulic force coefficient was defined for $i^{\text {th }}$ rockery layer of rocks as

$$
C_{l a t, i}=\frac{2 F_{H D, i}}{\rho v^{2} h_{i}}
$$

where: $F_{H D, i}$ is the hydrodynamic force per $1 \mathrm{~m}, \rho$ is the density of water, $v$ is the mean flow velocity, $h_{i}$ - rockery layer height.

The coefficient was plotted in Figure 6-31 and Figure 6-32 against a non-dimensional parameter $d_{i} / h_{i}$, which is a ratio of the distance between the center of the channel at the water surface level, $C$, and the center of the $i^{\text {th }}$ rockery layer, $C_{r}$, to the rockery layer height. Figure 7-21 presents an example cross section through a model with the dynamic force acting on the $i^{\text {th }}$ layer, as well as the points $C$ and $C_{r}$, distance $d_{i}$, and rock layer height $h_{i}$ marked for reference.

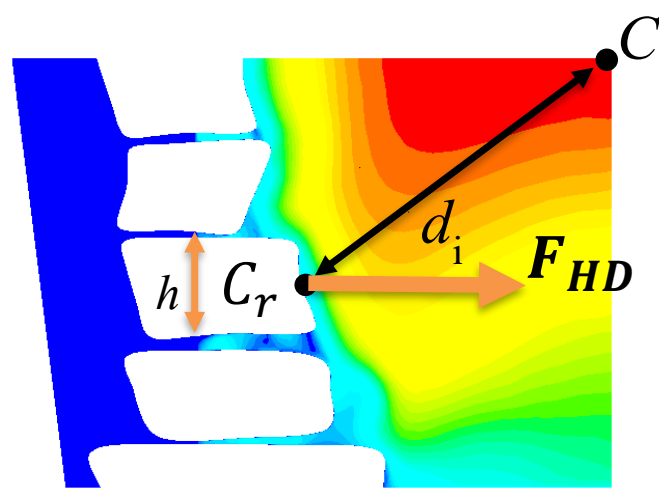

Figure 6-30: An example cross section through a model, $\mathrm{W}=12 \mathrm{ft}, \mathrm{W} / \mathrm{H}=1$. The dynamic force acting on the $i_{\text {th }}$ layer was shown. Points $C$ and $C_{\mathrm{r}}$, as well as distance $d_{i}$, and rock layer height $h_{i}$ were marked for reference. 


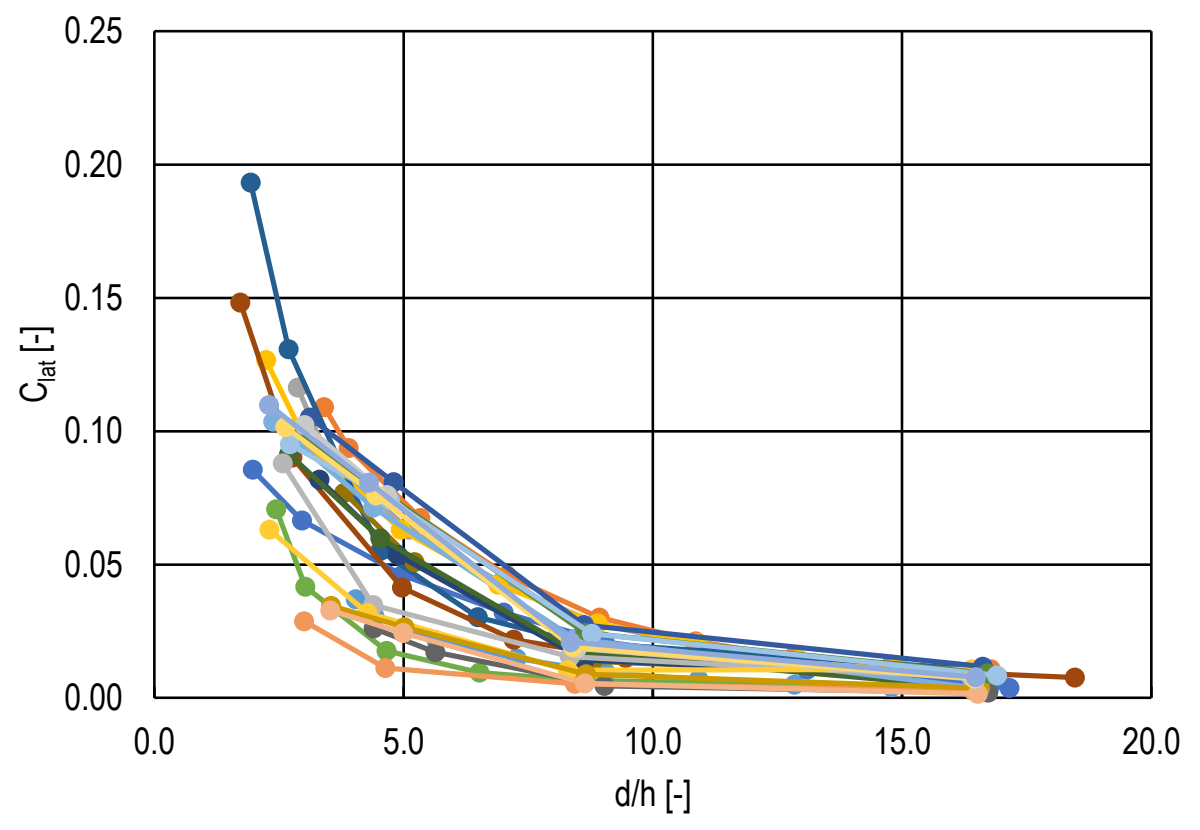

$$
\begin{aligned}
& \longrightarrow \mathrm{L} 1, \mathrm{H} 12 \mathrm{ft}, \mathrm{b} 4: 1-\mathrm{L} 2, \mathrm{H} 12 \mathrm{ft}, \mathrm{b} 4: 1-\mathrm{L} 3, \mathrm{H} 12 \mathrm{ft}, \mathrm{b} 4: 1-\mathrm{L} 4, \mathrm{H} 12 \mathrm{ft}, \mathrm{b} 4: 1 \\
& \longrightarrow \mathrm{L} 5, \mathrm{H} 12 \mathrm{ft}, \mathrm{b} 4: 1-\mathrm{L} 1, \mathrm{H} 7 \mathrm{ft}, \mathrm{b4}: 1 \rightarrow \mathrm{L} 2, \mathrm{H} 7 \mathrm{ft}, \mathrm{b} 4: 1 \rightarrow \mathrm{L} 3, \mathrm{H} 7 \mathrm{ft}, \mathrm{b} 4: 1 \\
& \longrightarrow \mathrm{L} 1, \mathrm{H} 12 \mathrm{ft}, \mathrm{b} 12: 1-\mathrm{L} 2, \mathrm{H} 12 \mathrm{ft}, \mathrm{b} 12: 1 \longrightarrow \mathrm{L} 3, \mathrm{H} 12 \mathrm{ft}, \mathrm{b} 12: 1 \longrightarrow \mathrm{L} 4, \mathrm{H} 12 \mathrm{ft}, \mathrm{b} 12: 1 \\
& -\mathrm{L} 5, \mathrm{H} 12 \mathrm{ft}, \mathrm{b} 12: 1-\mathrm{L} 1, \mathrm{H} 7 \mathrm{ft}, \mathrm{b} 12: 1-\mathrm{L} 2, \mathrm{H} 7 \mathrm{ft}, \mathrm{b} 12: 1-\mathrm{L} 3, \mathrm{H} 7 \mathrm{ft}, \mathrm{b} 12: 1 \\
& \longrightarrow \text { L1,H9ft,b4:1 } \longrightarrow \text { L2,H9ft,b4:1 } \longrightarrow \text { L3,H9ft,b4:1 } \longrightarrow \text { L4,H9ft,b4:1 } \\
& \longrightarrow \text { L1,H9ft,b12:1 }-\mathrm{L} 2, \mathrm{H} 9 \mathrm{ft}, \mathrm{b} 12: 1-\mathrm{L} 3, \mathrm{H} 9 \mathrm{ft}, \mathrm{b} 12: 1 \longrightarrow \mathrm{L} 4, \mathrm{H} 9 \mathrm{ft}, \mathrm{b} 12: 1
\end{aligned}
$$

Figure 6-31: Lateral force coefficient vs. $d / h$ for cases with water level lower than the rockery height (no overtopping) 

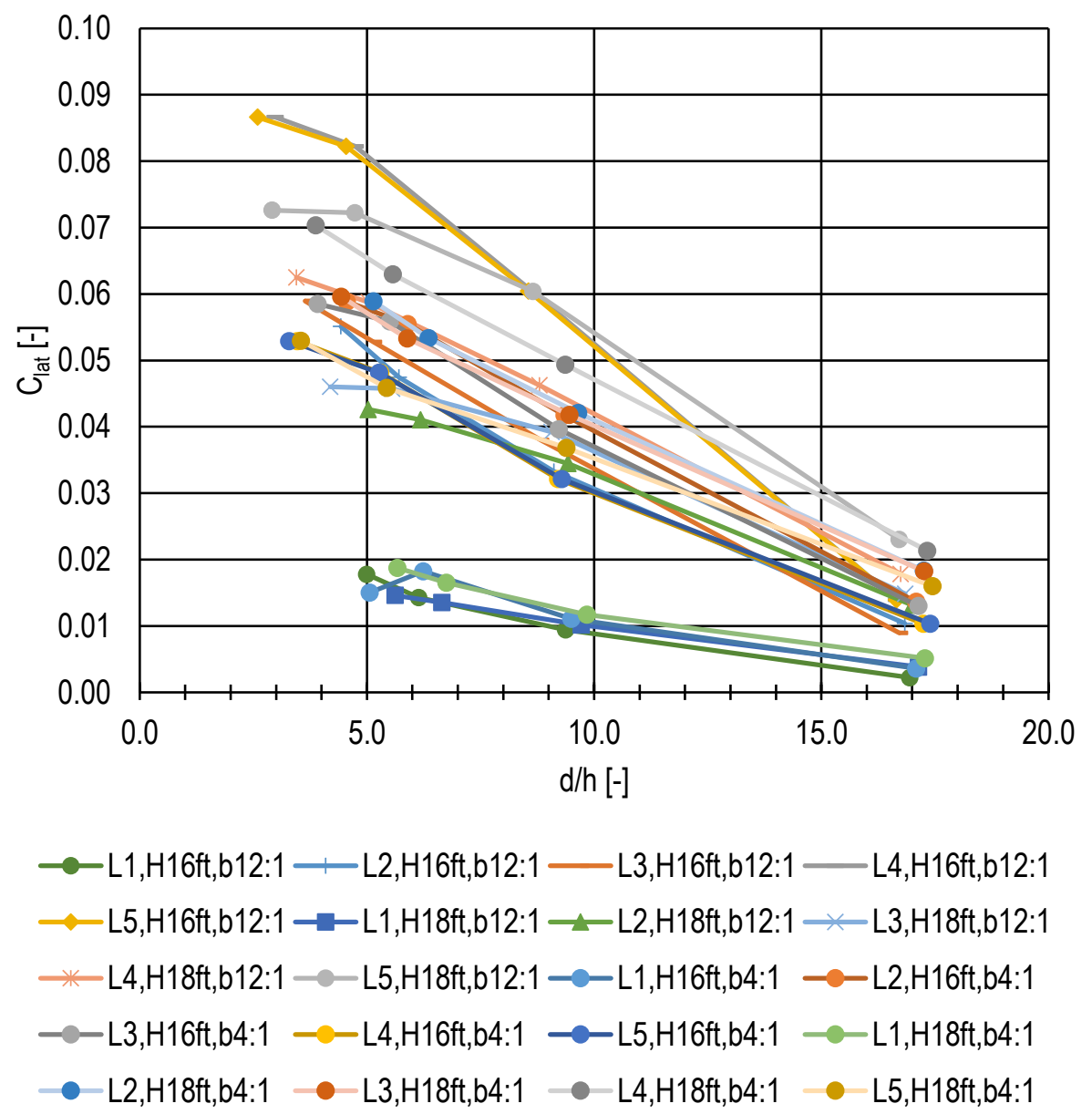

Figure 6-32: Lateral force coefficient vs. $d / h$ for cases with water level higher than the rockery height (overtopping)

Figure 6-33 illustrates an example use of the proposed chart. Let's assume that the forces acting on the rockery layers are the same and equal to the upper limit of the computational results. For a channel width $\mathrm{W}_{\mathrm{B}}=48 \mathrm{ft}$, batter $4: 1$, water depth $\mathrm{H}_{\mathrm{W}}=12 \mathrm{ft}$, distance from the bed to point $C_{r}$ is $\mathrm{Z}=4.6 \mathrm{ft}$, rockery layer height is $h=3 \mathrm{ft}$, and $d=\sqrt{\left(\frac{W_{B}}{2}+\frac{Z}{b}\right)^{2}+\left(H_{W}-Z\right)^{2}}=8.7 \mathrm{ft}$,

$$
C_{\text {lat }}=0.033 \text {. }
$$

The hydrodynamic force per unit rockery length can be calculated according to

$$
F_{H D}=K C_{\text {lat }} \rho v^{2} h / 2,
$$

where $K=1 / 32.2$ for English units, $K=1$ for metric units, water density $\rho=62.4 \mathrm{lb} / \mathrm{ft}$, mean flow velocity $v=18.6 \mathrm{ft} / \mathrm{s}$,

$$
F_{H D}=33.2 \frac{l b f}{f t} .
$$

Computational Assessment of Hydrodynamic Loads on Rockeries for River Bank Protection 

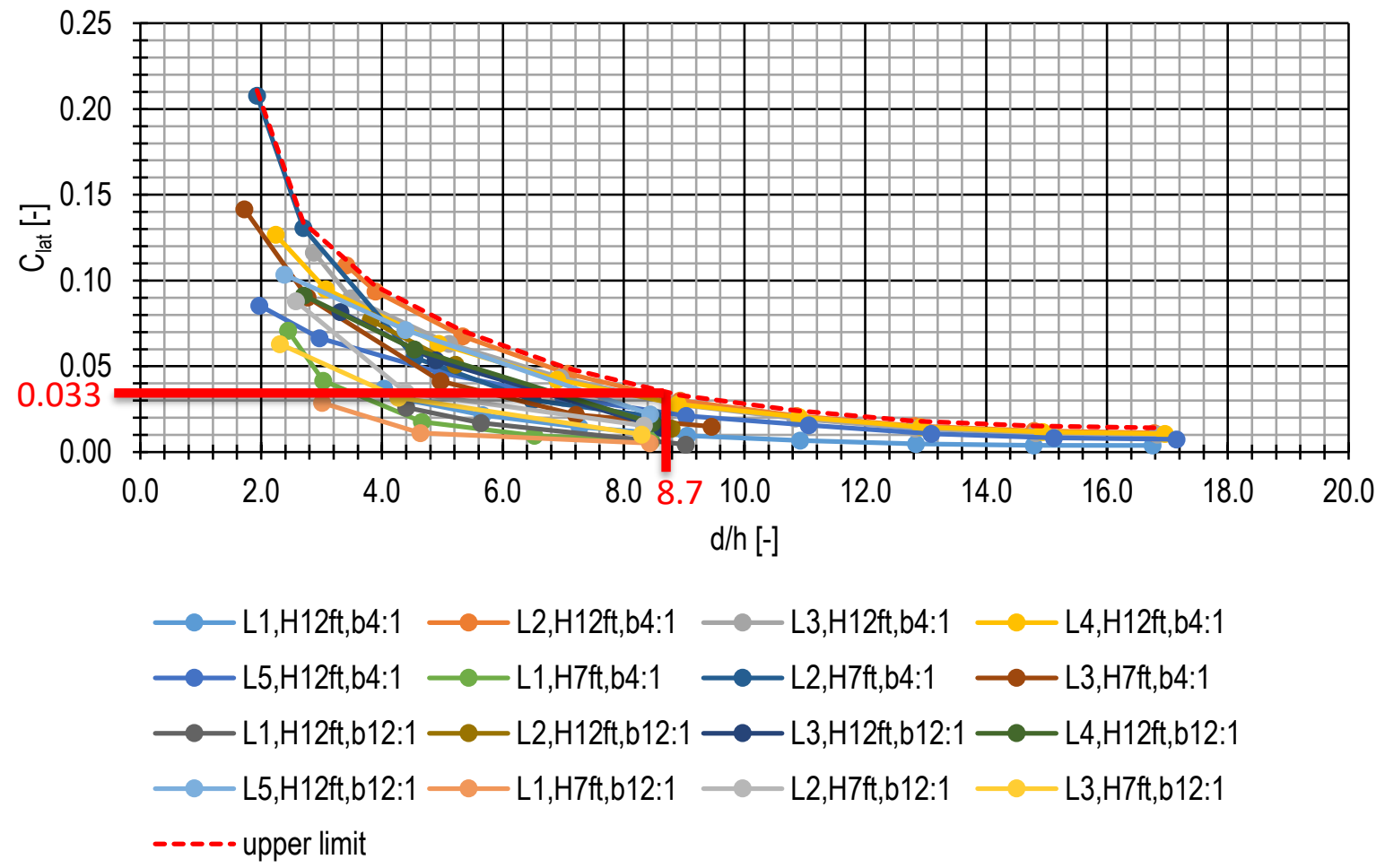

Figure 6-33: Example chart to be used in design of rockeries in river environment

The lateral force coefficient was plotted against $d / h$ in a log-log scale in Figure 6-34. Only the cases with the highest coefficient values were chosen for this plot. Although there is some scatter of points present, but overall a linear trend is clear.

Figure 6-35 presents a point plot of the lateral force coefficient vs. Reynolds number scaled with the ratio of channel width to water height $\left(\mathrm{Re}^{*} \mathrm{~W}_{\mathrm{B}} / \mathrm{H}_{\mathrm{W}}{ }^{*} \mathrm{O}^{-7}\right)$ for all considered flow conditions (with and without overtopping). Also, the values on the horizontal axis were multiplied by 10e-7 to lower the difference in the orders of magnitude between the vertical and horizontal axes. Forces acting on the bottom layers of rocks were omitted from the chart, as they are the lowest. A linear function was fitted to the observations (blue dotted line), and an upper limit was proposed (red dashed line). The lowest ratio of channel width to water height $\left(\mathrm{W}_{\mathrm{B}} / \mathrm{H}_{\mathrm{W}}\right)$ considered in this study was equal 0.5, which represents the geometry of a very narrow channel that does not usually occur in real life situations. The extrapolation of the plot beyond this point would not be reasonable. If, on the other hand, the value of $\mathrm{Re}^{*} \mathrm{~W}_{\mathrm{B}} / \mathrm{H}_{\mathrm{W}}{ }^{*} 10^{-7}$ was higher than 2.5, it is recommended to assume that the coefficient is constant and equal to a small value $\left(C_{\text {lat }}=0.02\right)$.

Computational Assessment of Hydrodynamic Loads on Rockeries for River Bank Protection 


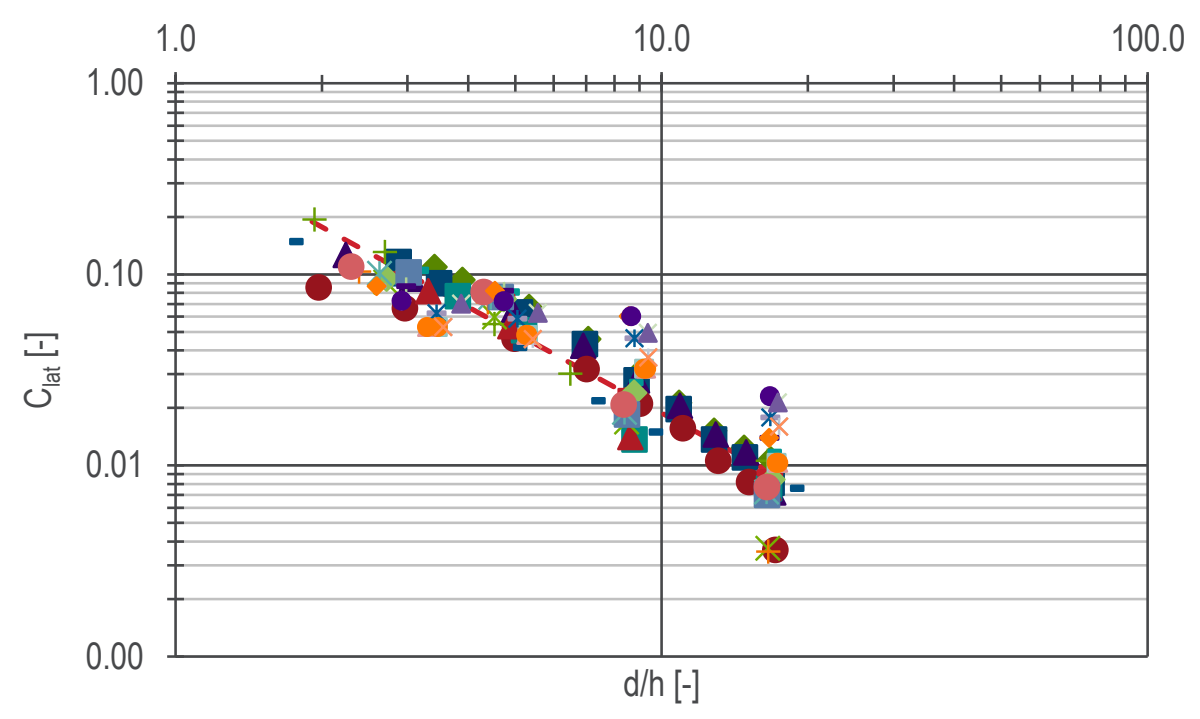

Figure 6-34: Lateral force coefficient $\mathrm{C}_{\text {lat }}$ vs. $d / h$ in log-log scale for cases without overtopping. Forces acting on the bottom layers of rocks were omitted from the chart, as they are the lowest. A linear function fitted from the data points is marked with a red dashed line $\left(\mathrm{C}_{\text {lat }}=-0.012 \mathrm{~d} / \mathrm{h}+0.2128\right)$.

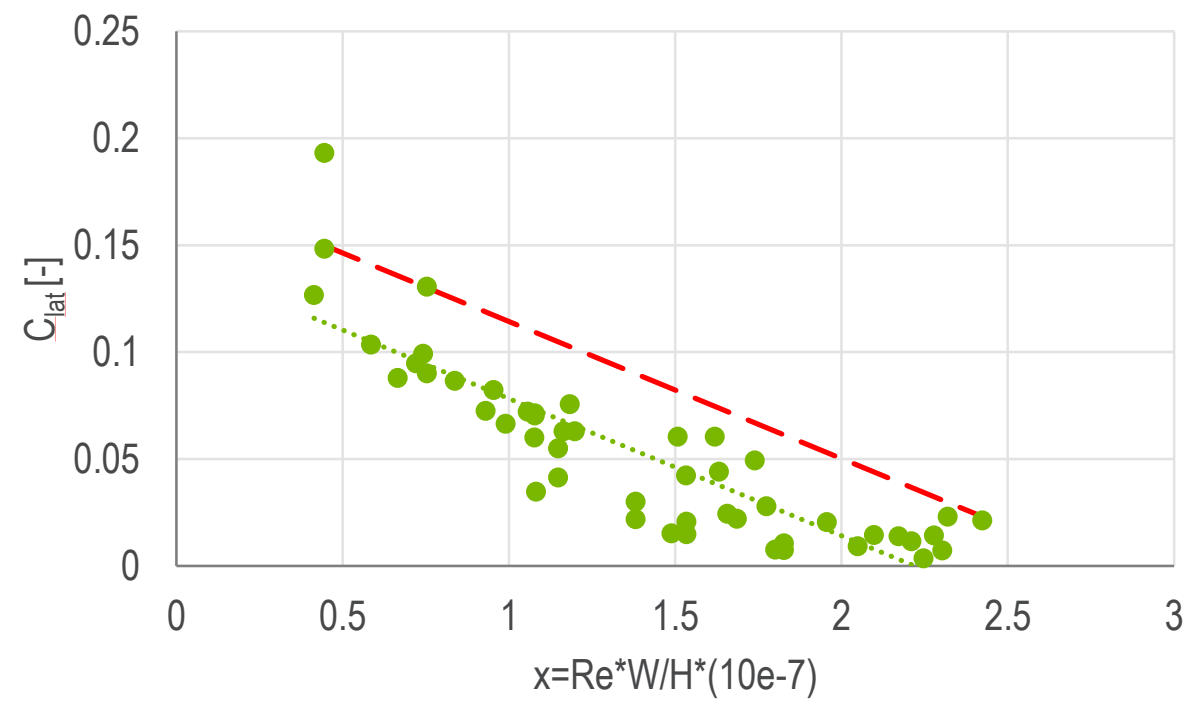

Figure 6-35: Lateral force coefficient vs. Reynolds number scaled with the ratio of channel width to water height (forces acting on the bottom layers of rocks were omitted from the chart, as they are the lowest). The best fit is a linear function $\mathrm{C}_{\text {lat }}=-0.0641 \mathrm{x}+0.1424$ (green dotted line), and the linear upper limit is defined as $\mathrm{C}_{\text {lat }}=-0.0641 \mathrm{x}+0.1784$ (red dashed line). 


\subsection{Selection of representative set of rocks for further analysis}

Let's take a closer look at a set of three rocks of the same shape, one from $2^{\text {nd }}, 3^{\text {rd }}$ and $4^{\text {th }}$ layer. Forces acting on these rocks were among the highest. The $1^{\text {st }}$ and $5^{\text {th }}$ layers were omitted because the rocks are only partially exposed to water flow. Figure 7-24 shows the selected rocks (marked in pink), their location within the rockery and a plot of hydrodynamic forces acting on them in parallel flow conditions. The change of the hydrodynamic force values per rock due to increasing channel width was plotted in Figure 7-25. The trend noticeable in the figure corresponds to the one obtained for the forces averaged over the rockery length for layers of rocks, see Figure 7-14.

Lateral force coefficient for $i^{\text {th }}$ rock was defined as

$$
C_{l a t, i}=\frac{2 F_{H D, i}}{\rho v^{2} A_{r, i}}
$$

where $F_{H D, i}$ - hydrodynamic force acting on a rock, $\rho$ - density of water, $v$ - mean flow velocity, $A_{r, i}$ - frontal area of the $i^{\text {th }}$ rock (area of a vertical cross-section of a rock).

The coefficient was plotted against a non-dimensional parameter $\frac{d_{i}}{\sqrt{A_{r i}}}$, see Figure 7-26. 

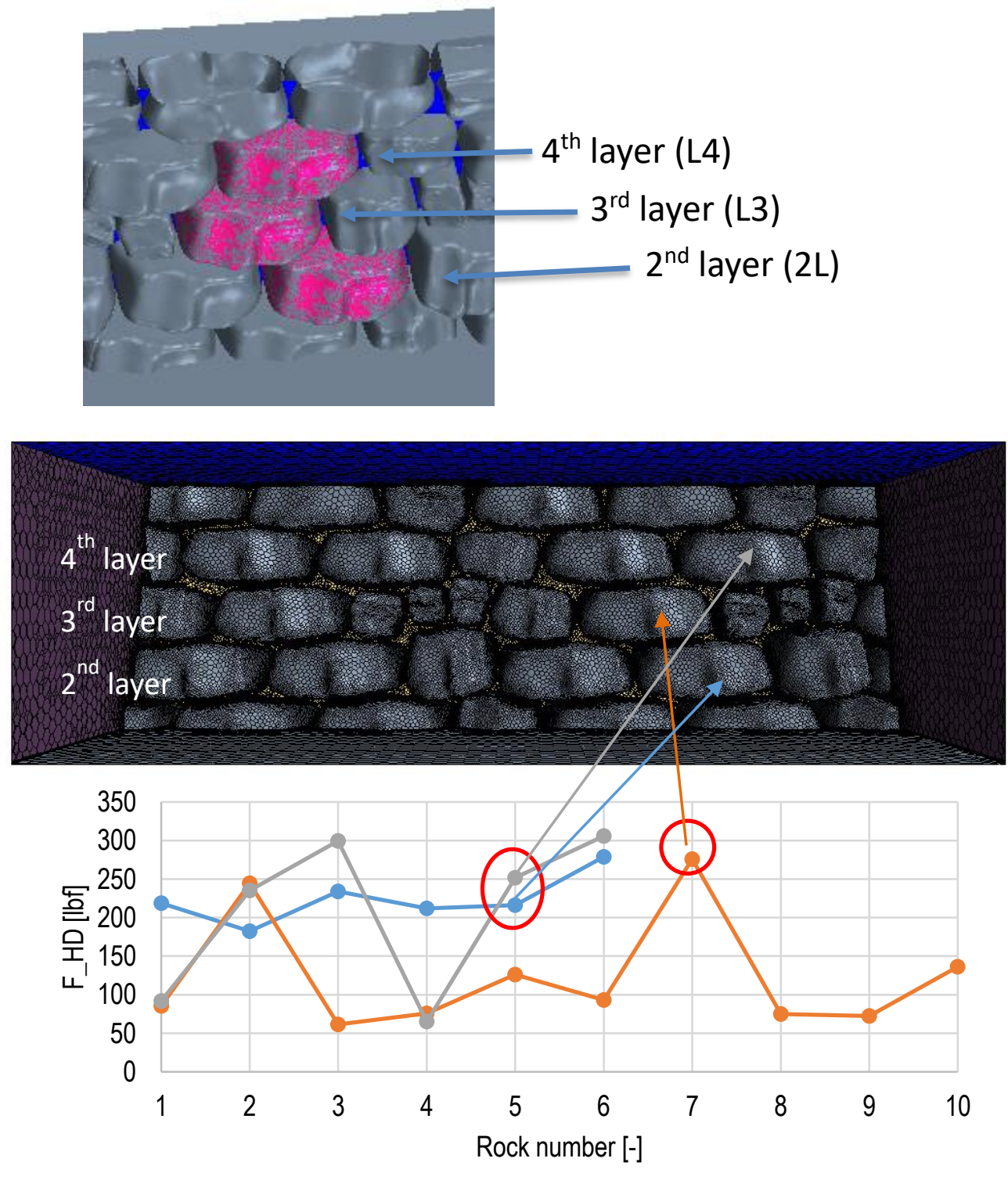

$\multimap$ layer $2 \multimap-$ layer $3 \multimap$ layer 4

Figure 6-36: Cluster of stones selected for analysis 


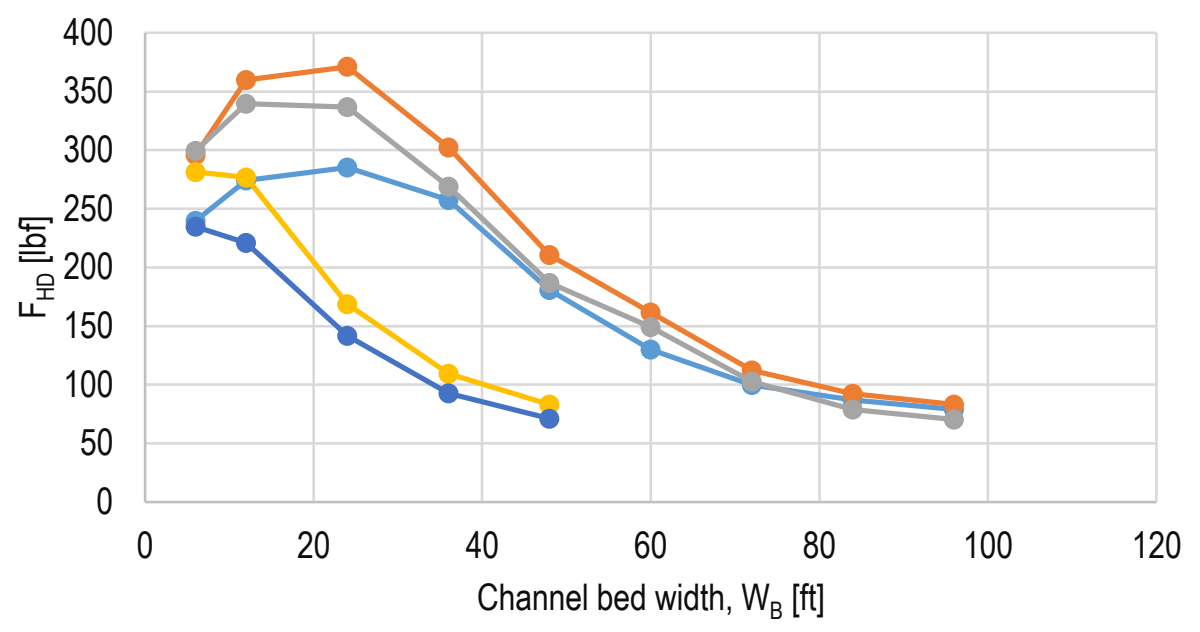

$\longrightarrow \mathrm{L} 2, \mathrm{H}=12 \mathrm{ft} \longrightarrow \mathrm{L} 3, \mathrm{H}=12 \mathrm{ft} \longrightarrow \mathrm{L} 4, \mathrm{H}=12 \mathrm{ft} \longrightarrow \mathrm{L} 2, \mathrm{H}=7 \mathrm{ft} \rightarrow \mathrm{L} 3, \mathrm{H}=7 \mathrm{ft}$

Figure 6-37: Hydrodynamic forces per rock vs. channel width

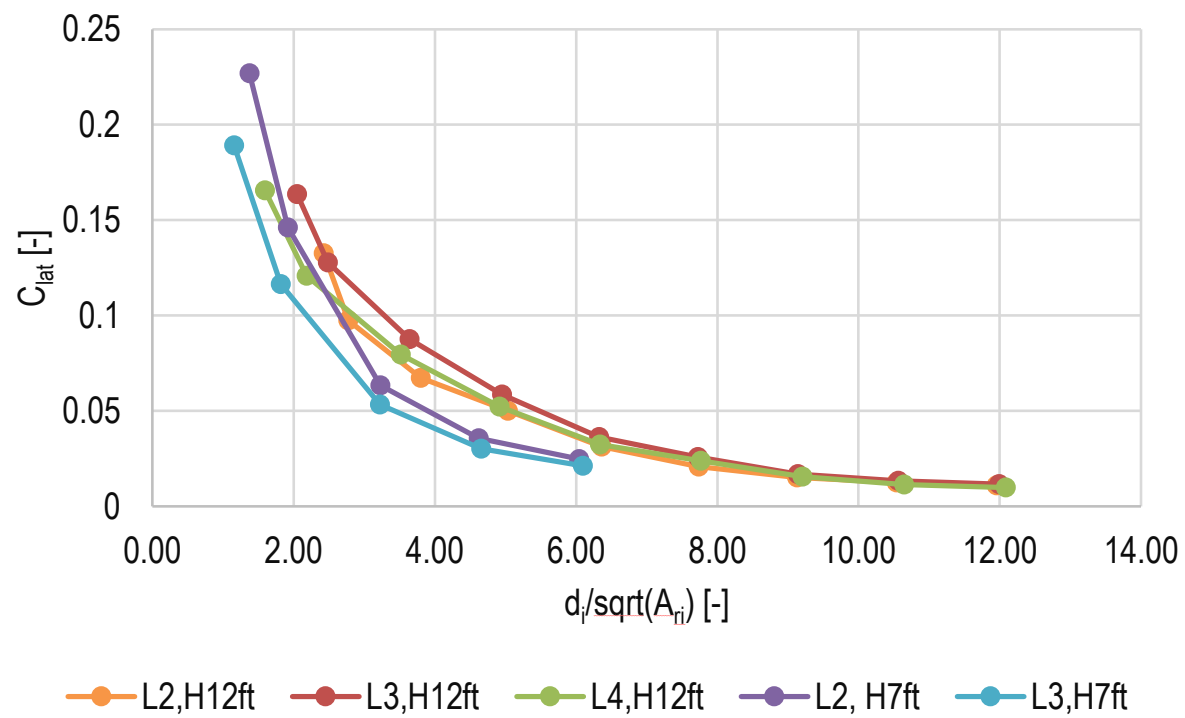

Figure 6-38: Lateral force coefficient per rock vs. a non-dimensional parameter 


\subsection{Channels with bends}

The influence of the angle of attack of the flow on the hydrodynamic forces that could cause a failure of a rockery was analyzed on a set of CFD models of a flow in a channel with a sharp bend. The angle of the bend, $\alpha$, varied from 15 degrees to 60 degrees, with a 15-degree increment. The results were compared to those obtained in a straight channel model, see chapter 4. An example geometry of a channel with a bend was shown in Figure 6-39. Flow direction was shown, as well as the inlet surface (marked in red) and outlet surface (marked in brown). In a straight channel it was possible to average the hydrodynamic forces over the length of a rockery. In this case, this approach is not possible because the flow is more complex than in a straight channel and results in a non-uniform distribution of loads. For this reason, a cluster of representative rocks, presented in chapter 6.4, was selected for the analysis. The geometry of the rockery is repetitive, and therefore this cluster of stones can be found several times along the length of the channel (see Figure 6-39). This arrangement allows tracking of the changes in flow characteristics and their influence on the forces exerted by the flow on the rockery.

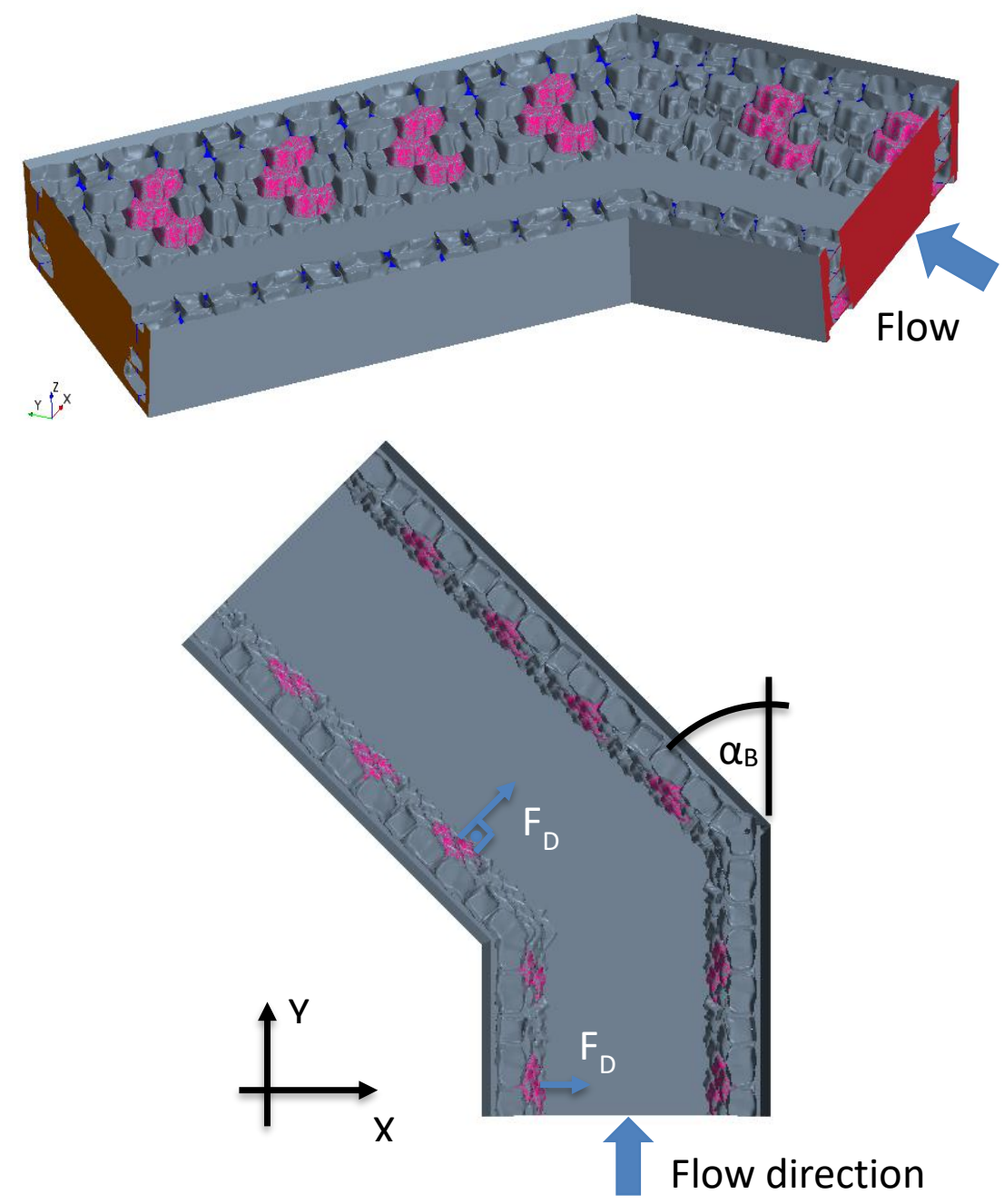

Figure 6-39: Geometry of an example channel with a sharp bend ( $\alpha$ is the bend angle). The clusters of representative stones were marked in pink. The direction of the hydrodynamic forces was shown. 
The velocity inlet boundary condition was set using the velocity and turbulence distribution profiles from the model of a straight channel with cyclic boundary conditions. This procedure yields a fully developed velocity profile at the inlet of the simulation domain and provides the equivalent of a much longer channel than that shown in 6.1 leading into the bend. At the downstream end of the model, a pressure outlet boundary condition was applied. All other boundary conditions are the same as in the previously described computational models.

The distribution of the flow velocity magnitude was monitored on three horizontal planes, each crossing one layer of rocks. Figures from Figure 6-40 to Figure 6-42 show velocity magnitude contour plots at various angles of the bend: 15 degrees, 30 degrees, 45 degrees, and 60 degrees at the $2^{\text {nd }}, 3^{\text {rd }}$, and $4^{\text {th }}$ layer of rocks respectively. Figure 6-43, Figure 6-44, and Figure 6-45 combine the resultant loads for rocks in the $2^{\text {nd }}, 3^{\text {rd }}$, and $4^{\text {th }}$ layer. The plots are divided into two, to account for the rocks on the left (L) and right (R) side of the channel.

With a goal to relate the results from a bent channel to the straight channel case, a ratio of the force in a channel with a bend to the force in a straight channel was introduced.

$$
r_{F}=\frac{F_{D \_} b}{F_{D_{-} s}},
$$

where $F_{D_{-} b}$ is the force in a bent channel, $F_{D_{-} S}$ is the force in a straight channel.

Cumulative plots of the force ratio for the rocks in the layers from 2 to 4 , at varying angle of the bend, are shown in Figure 6-46, Figure 6-47, and Figure 6-48. Table 6-5 summarizes the results by combining the maximum values of the ratio at varying angle of attack. The dependence of the ratio on the angle of attack is very close to linear, see Figure 6-49.

The forces acting on the first set of rocks, located close to the inlet in the straight part of the channel, do not differ much from the loads obtained from the straight channel model described in chapter 4 . The feedback from the downstream flow causes a small decrease of the forces on the left side of the channel, and an equally small increase of forces on the right side. The forces on the other clusters differ due to the increase of angle of attack depending on the location along the channel and layer number. Overall, they are lower on the rocks of the left side rockery than on the right side. This is consistent with a higher velocity on the outside of the bend just downstream of the bend as shown in the velocity color plots. Along flow paths where the velocity is higher parallel to the rockery, the dynamic pressure increases, and that decreases the pressure on the rockery yielding a net force out into the stream. The maximum increase in forces on the left side occurs for the third cluster (3L); the force increases approximately by a factor of two at each layer.

The flow along the channel with a 15-degree bend is very similar to the flow in a straight channel. The separation from the corner rocks at the bend does not affect the flow significantly in this case and the dynamic loads do not differ by more than approximately $100 \%$. With an increase of the angle, this influence is more pronounced. The flow separates and the recirculation zone just downstream of the separation point on the left side of the channel effectively reduces the cross section area of the flow yielding a higher velocity flow that reaches the maximum for the biggest considered angle of attack. The forces acting on the $2^{\text {nd }}$ layer increase the most, by a factor of 5.7 when the angle $\alpha_{B}$ is 60 degrees. The forces on the $3^{\text {rd }}$ layer increase 4.6 times, and those acting on the $4^{\text {th }}$ layer increase 5.5 times, at $\alpha_{B}=60 \mathrm{deg}$.

Computational Assessment of Hydrodynamic Loads on Rockeries for River Bank Protection 
(a)

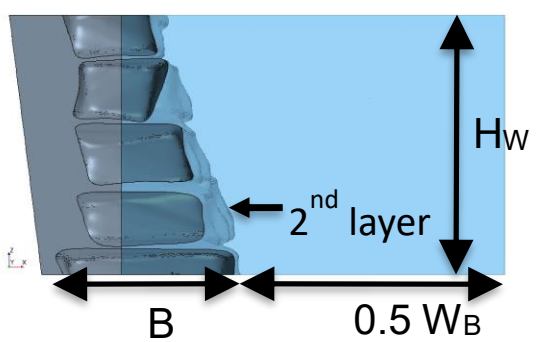

(b)

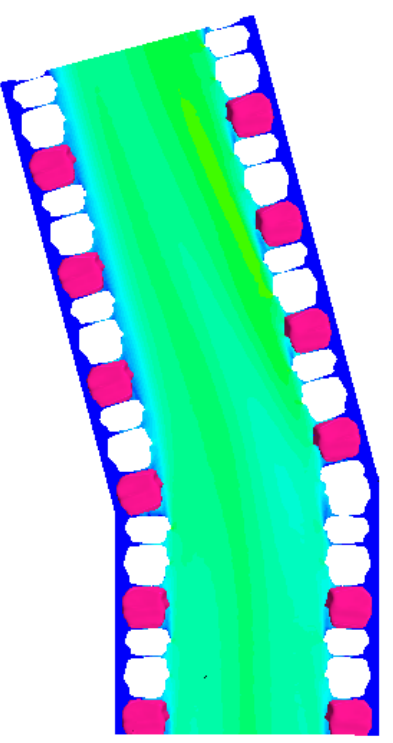

(c)

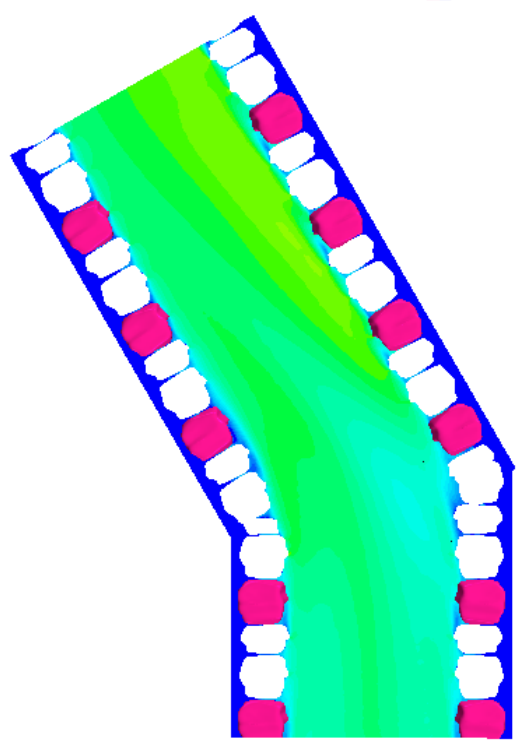

(e)

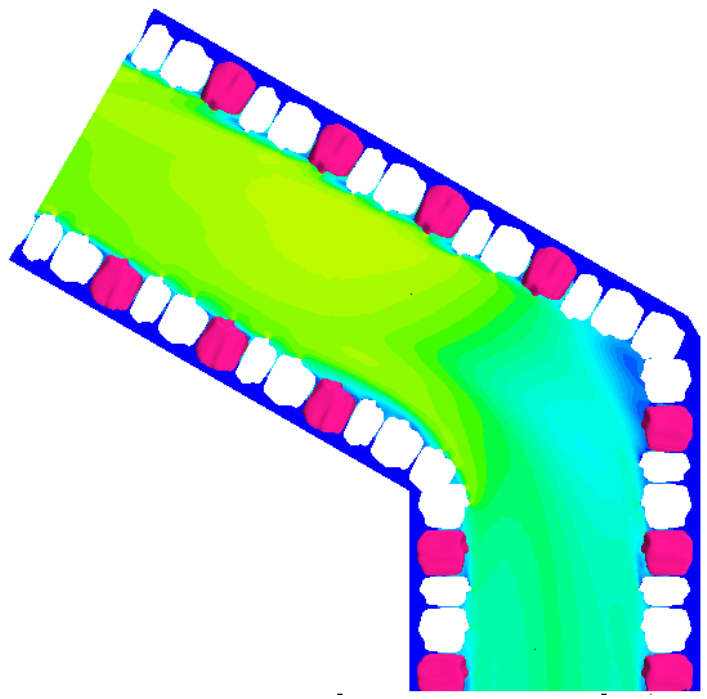

0

$6.76 \quad 13.52$

itude $[\mathrm{ft} / \mathrm{sec}]$

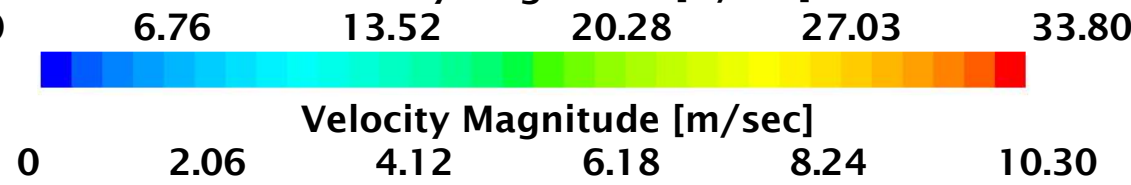

Figure 6-40: Velocity magnitude at the level of the 2nd layer of rocks (a) at various angles of the bend, (b) 15 degrees, (c) 30 degrees, (d) 45 degrees, (e) 60 degrees.

Computational Assessment of Hydrodynamic Loads on Rockeries for River Bank Protection 
(a)

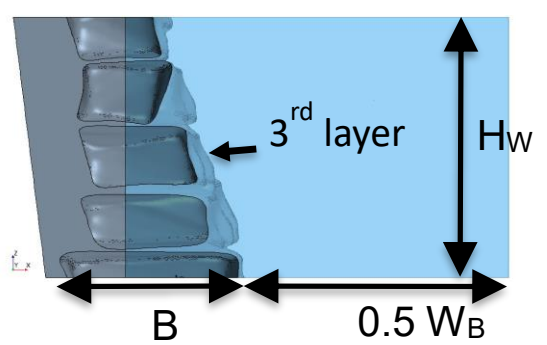

(b)

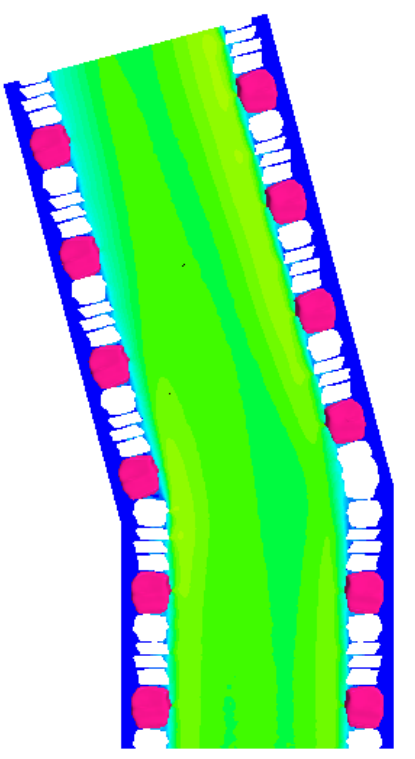

(c)

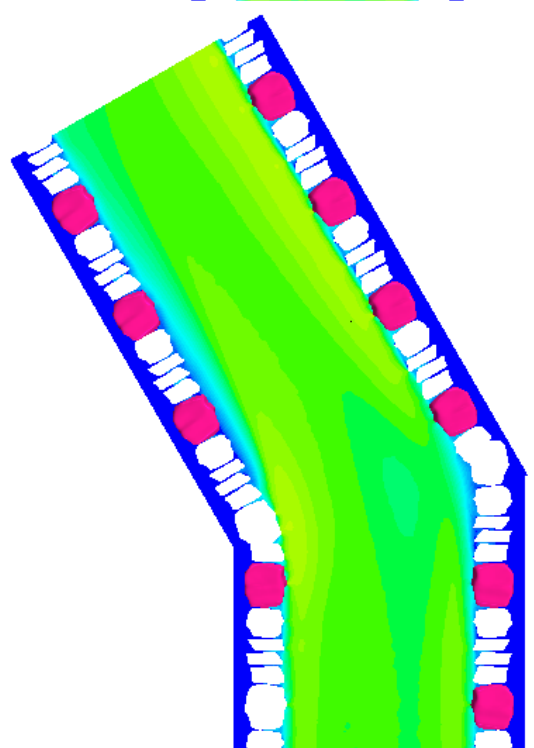

(e)

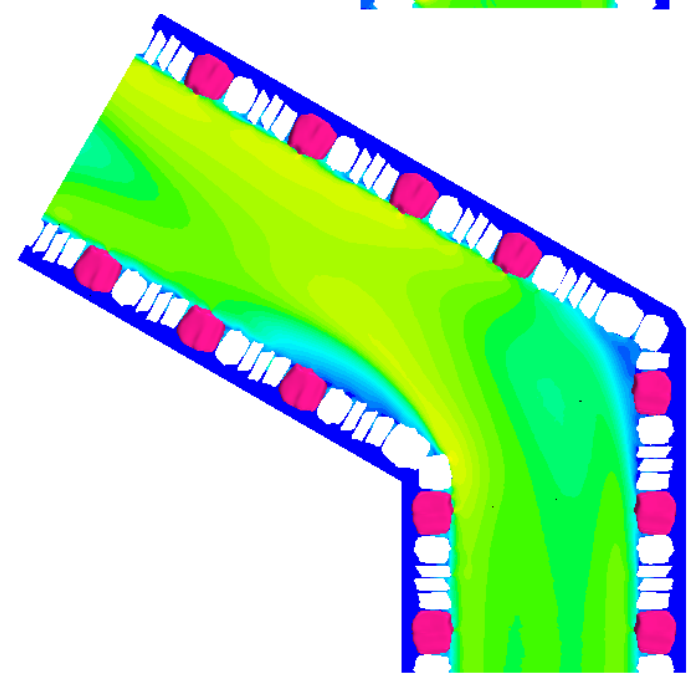

(d)

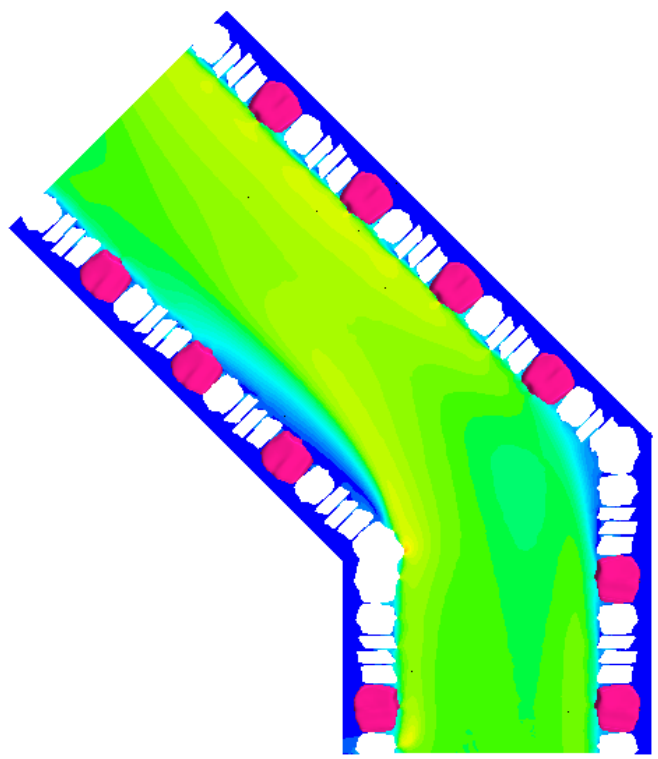

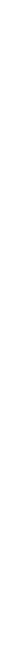

. 
(a)

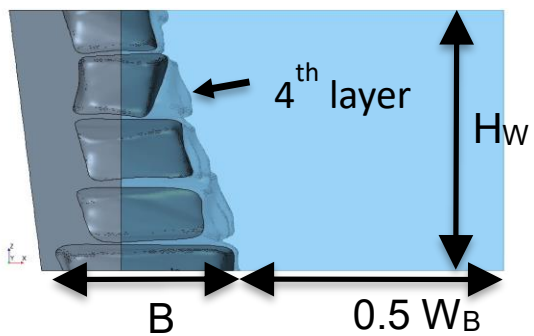

(b)

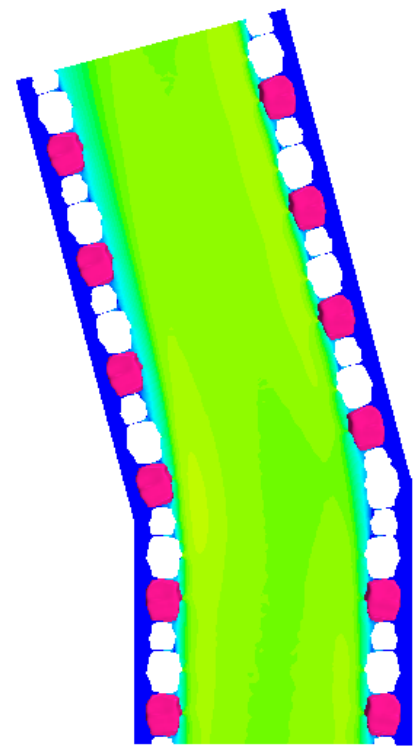

(c)

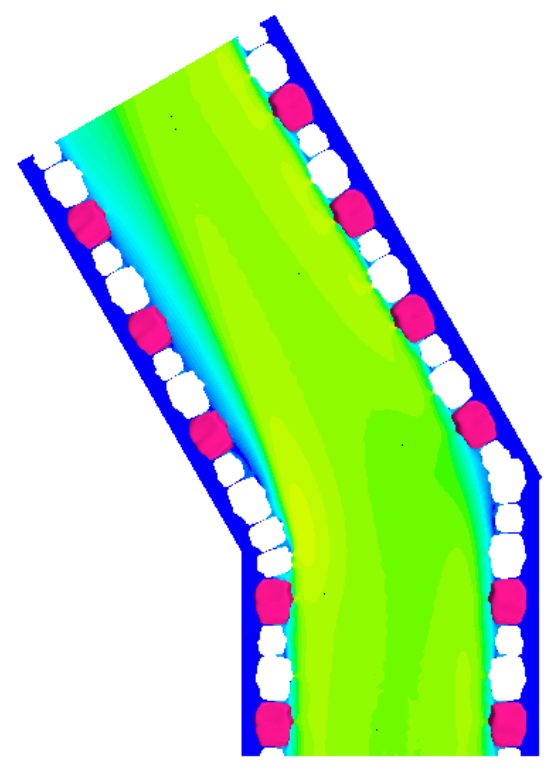

(d)

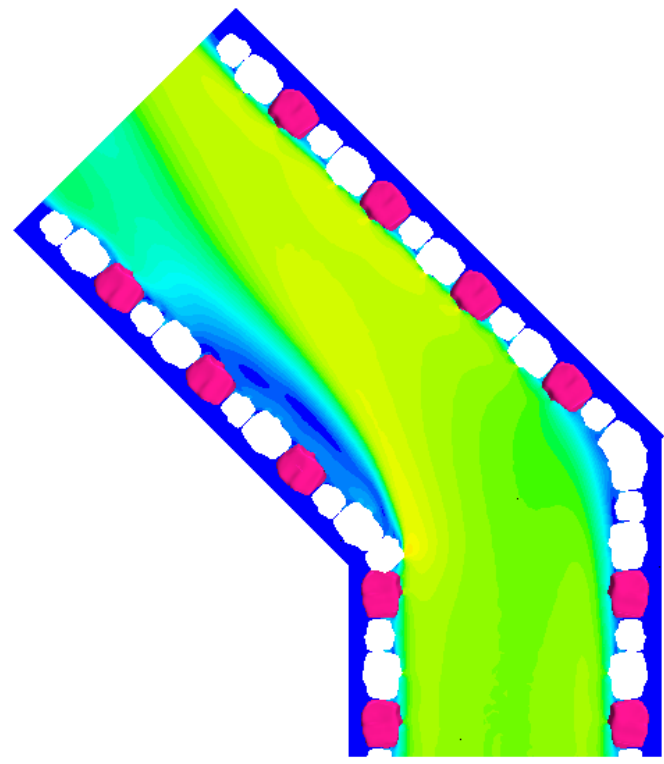

(e)

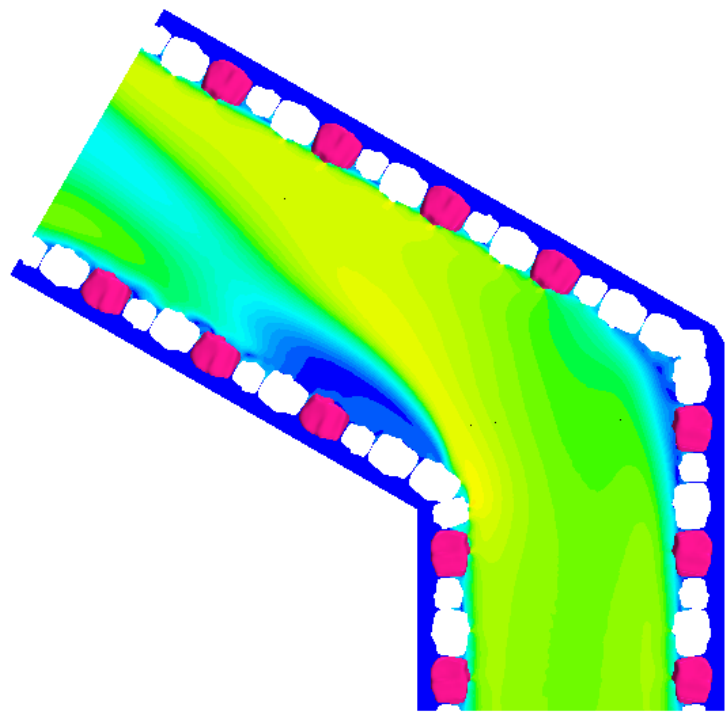

0

Velocity Magnitude [ft/sec]

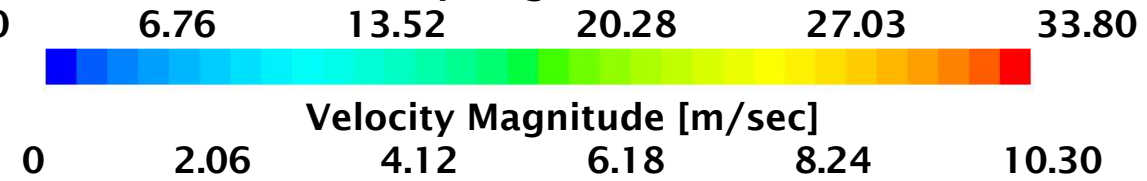

Figure 6-42: Velocity magnitude at the level of the 4th layer of rocks (a) at various angles of the bend, (b) 15 degrees, (c) 30 degrees, (d) 45 degrees, (e) 60 degrees 
(a)

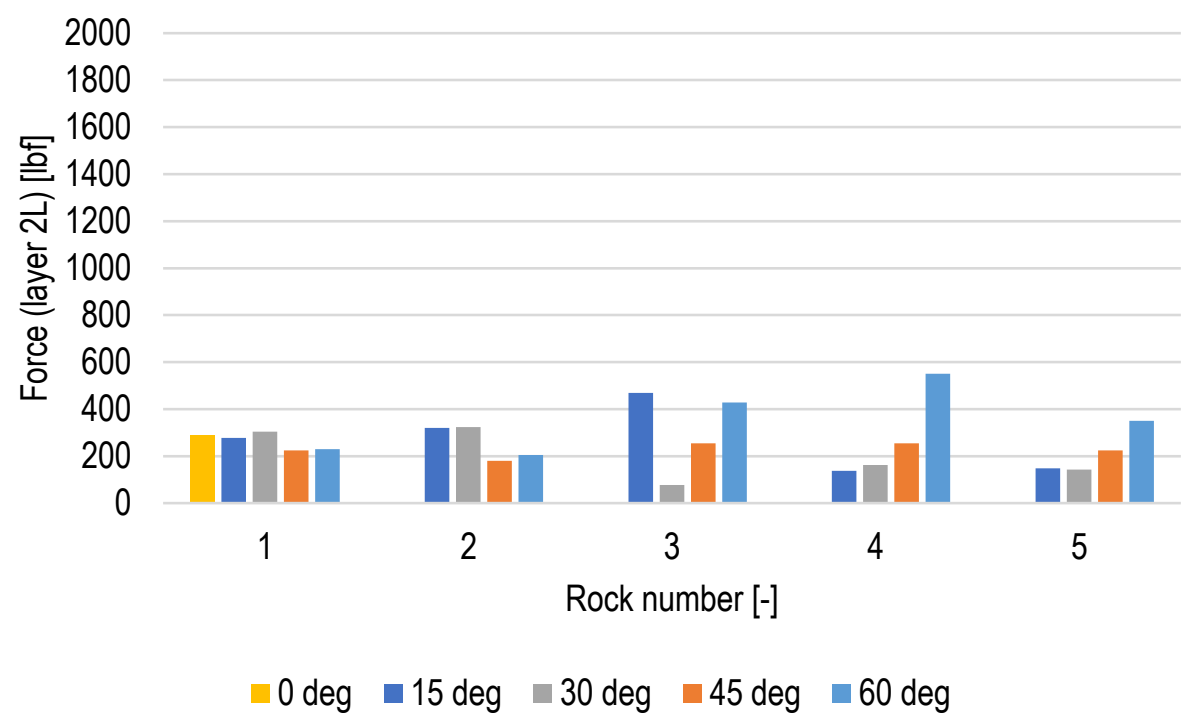

(b)

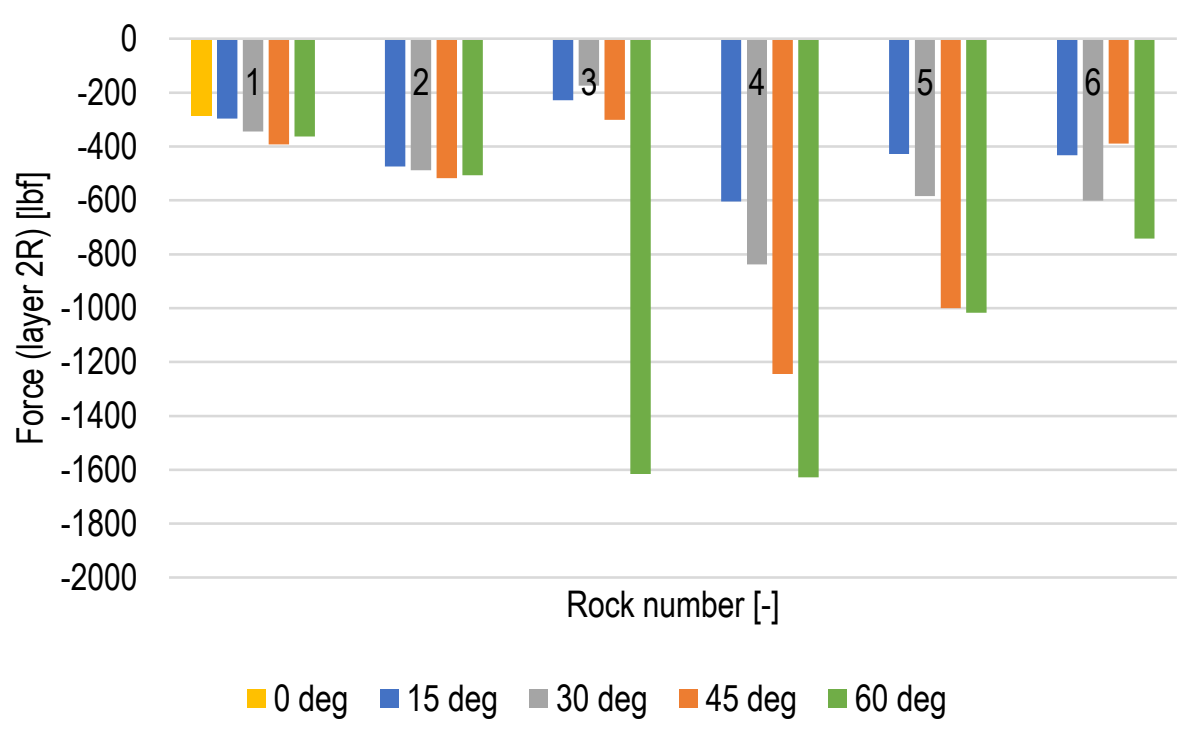

Figure 6-43: Hydrodynamic forces on clusters of rocks in the $2^{\text {nd }}$ layer at varying angle of the channel bend. Rocks located in the rockery (a) on the left side, and (b) on the right side of the channel. 
(a)

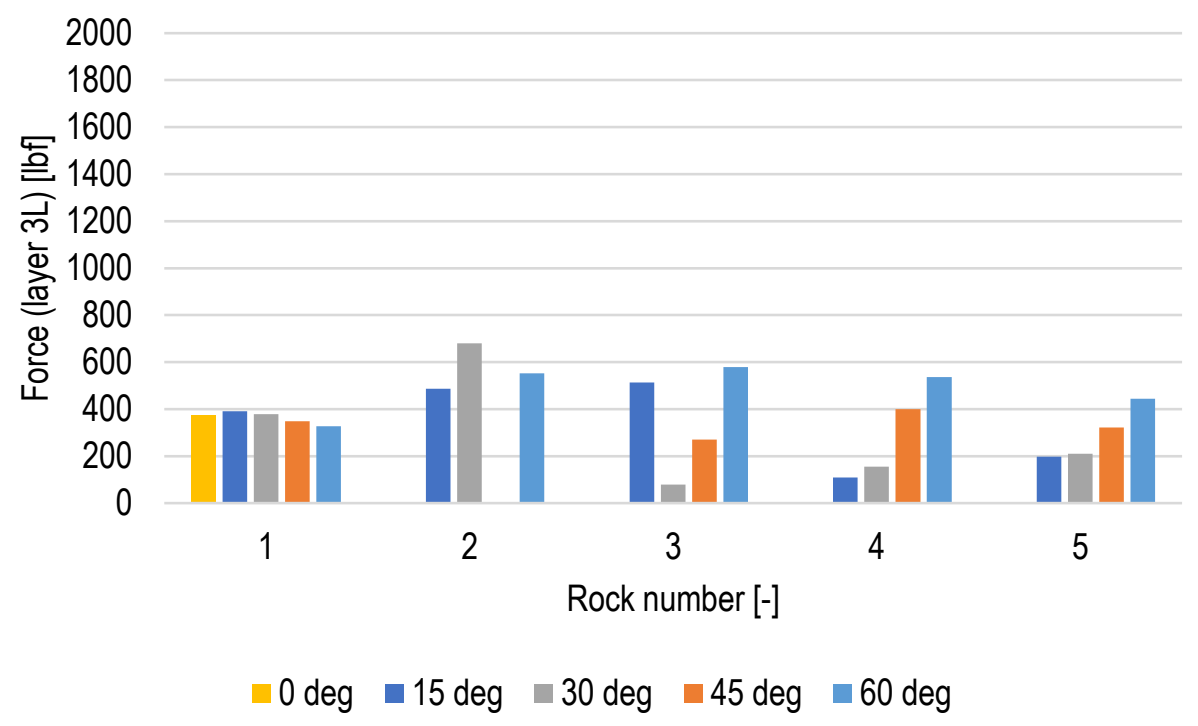

(b)

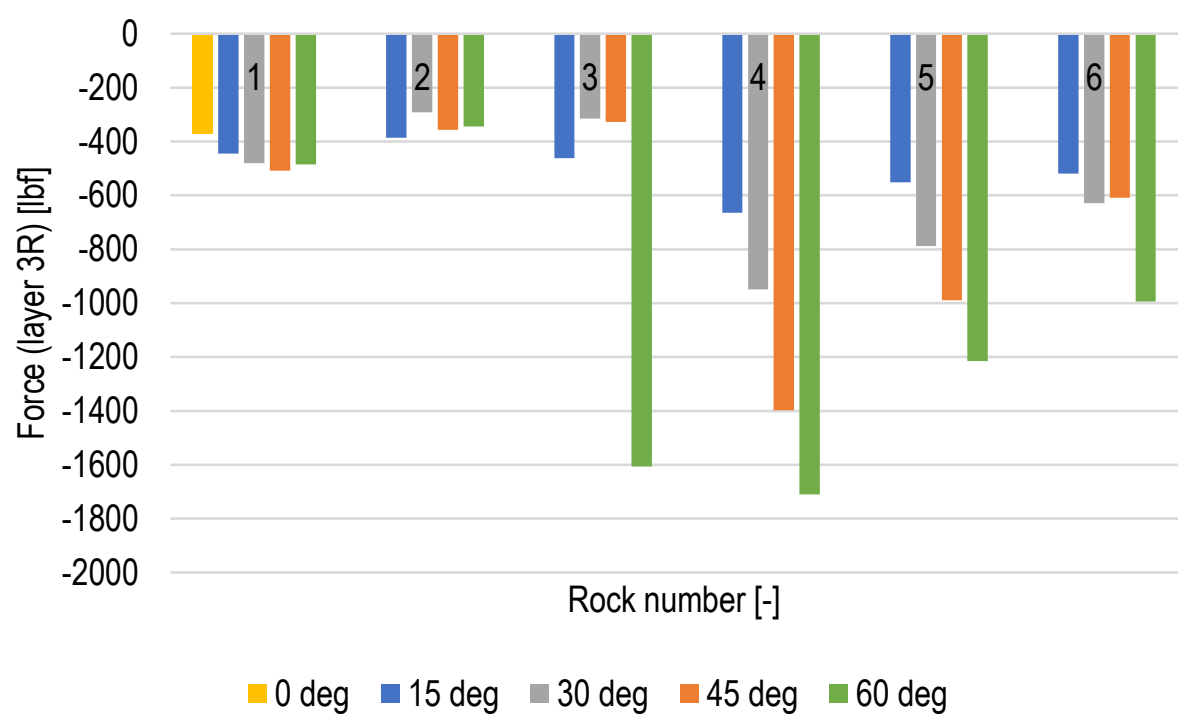

Figure 6-44: Hydrodynamic forces on clusters of rocks in the 3rd layer at varying angle of the channel bend. Rocks located in the rockery (a) on the left side, and (b) on the right side of the channel. 
(a)

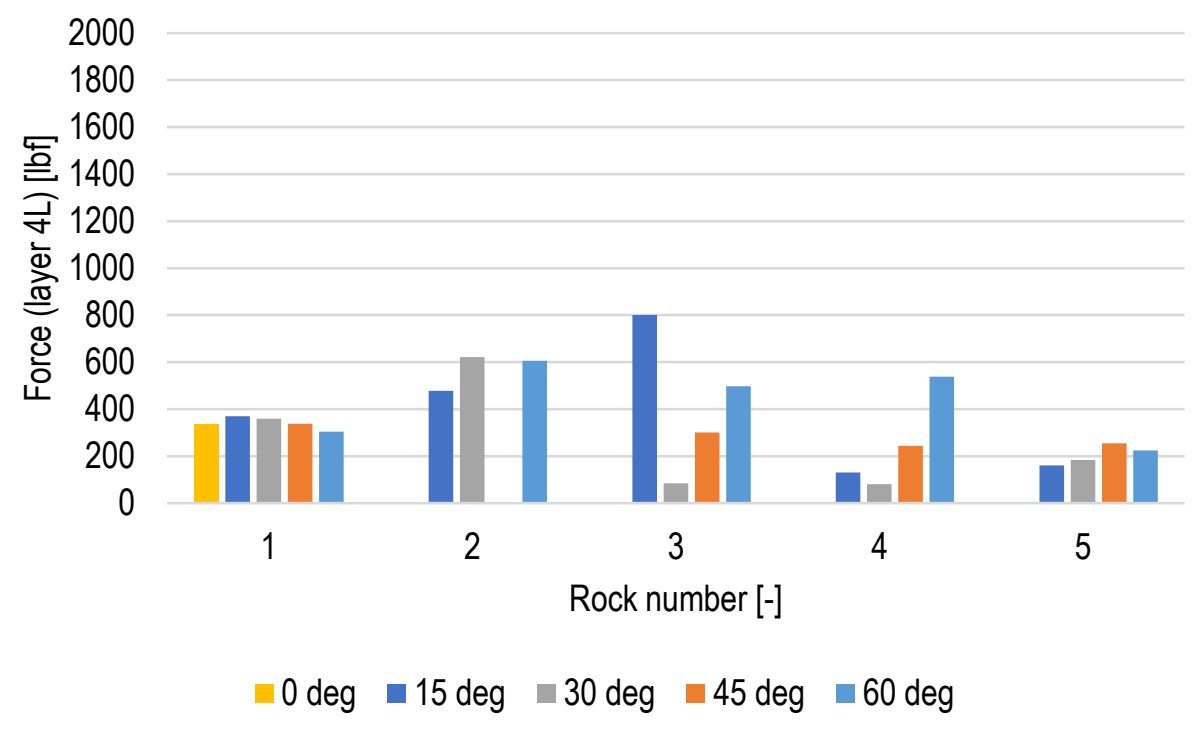

(b)

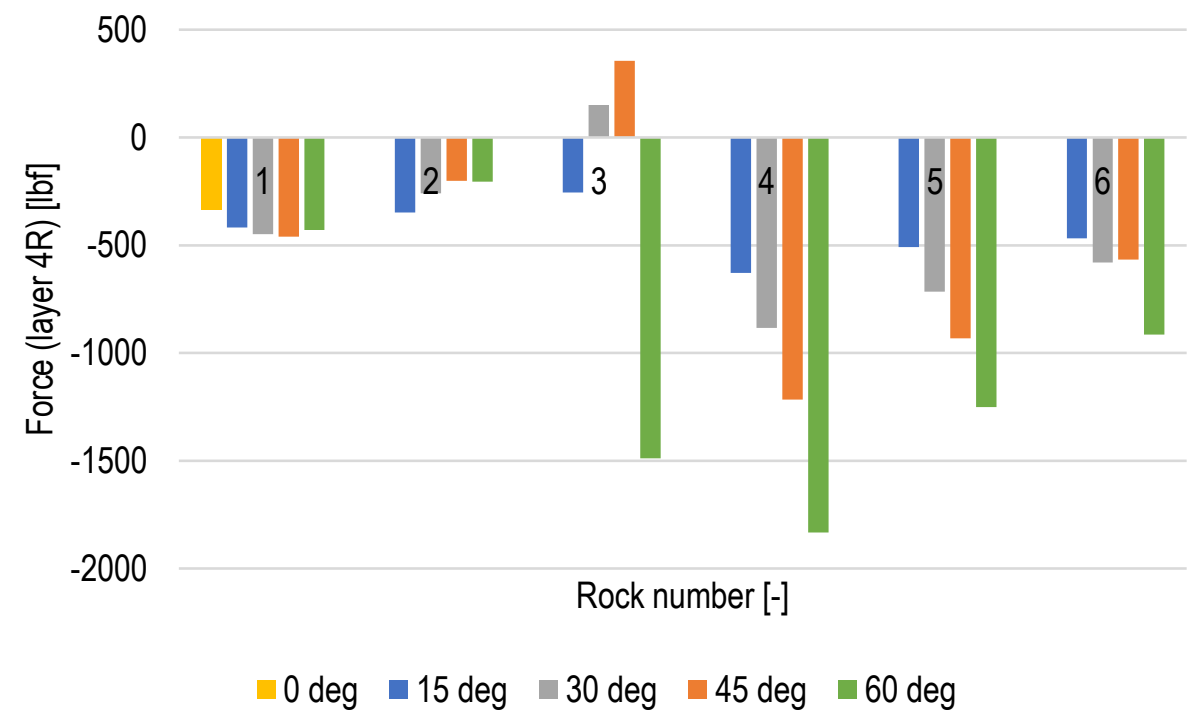

Figure 6-45: Hydrodynamic forces on clusters of rocks in the 4th layer at varying angle of the channel bend. Rocks located in the rockery (a) on the left side, and (b) on the right side of the channel 


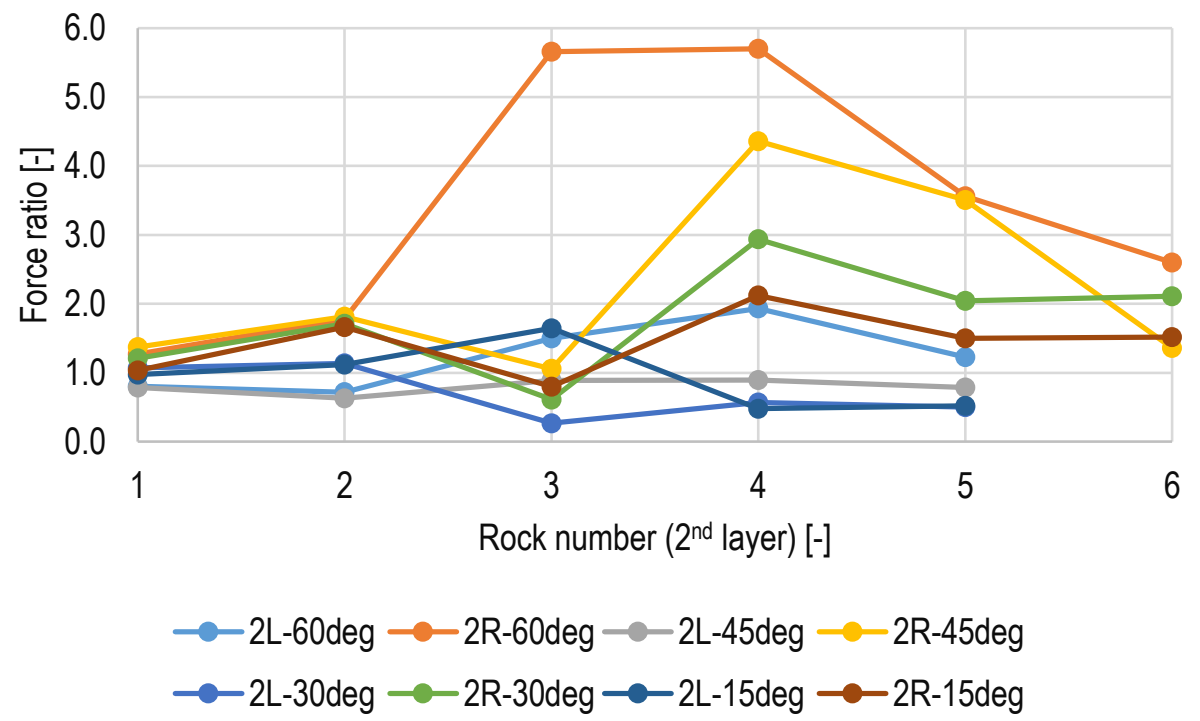

Figure 6-46: Cumulative plot of the force ratio for the rocks in the 2nd layer at varying angle of the bend

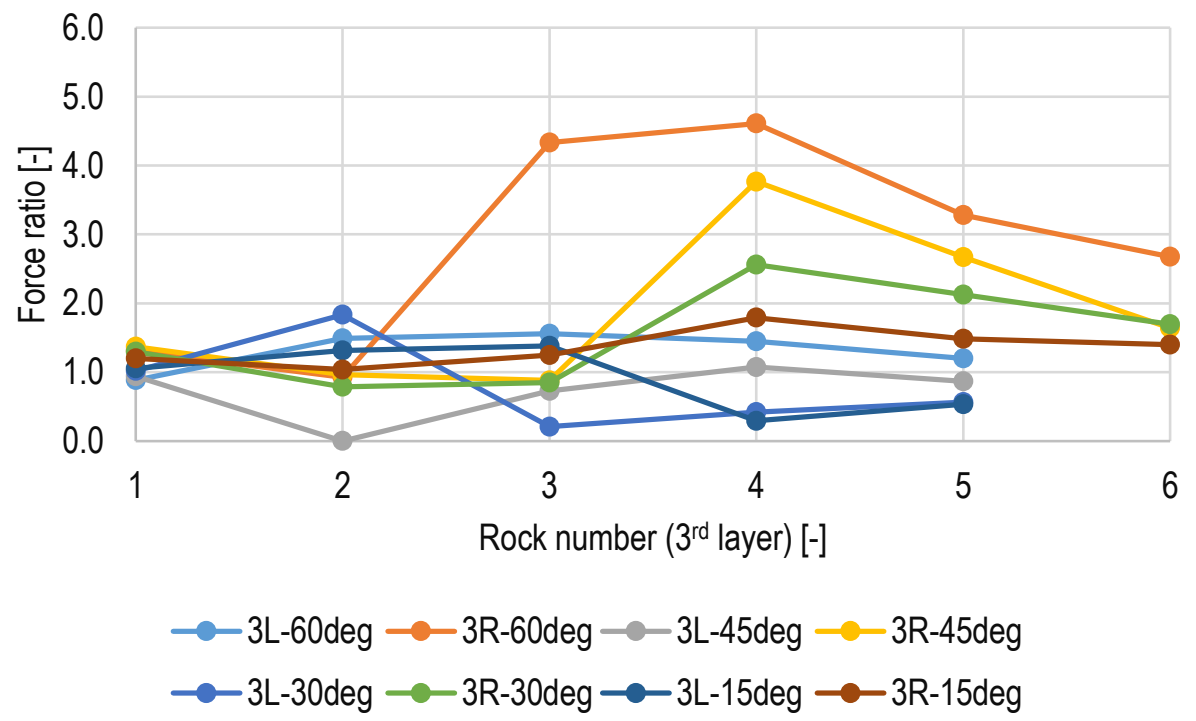

Figure 6-47: Cumulative plot of the force ratio for the rocks in the 3rd layer at varying angle of the bend 


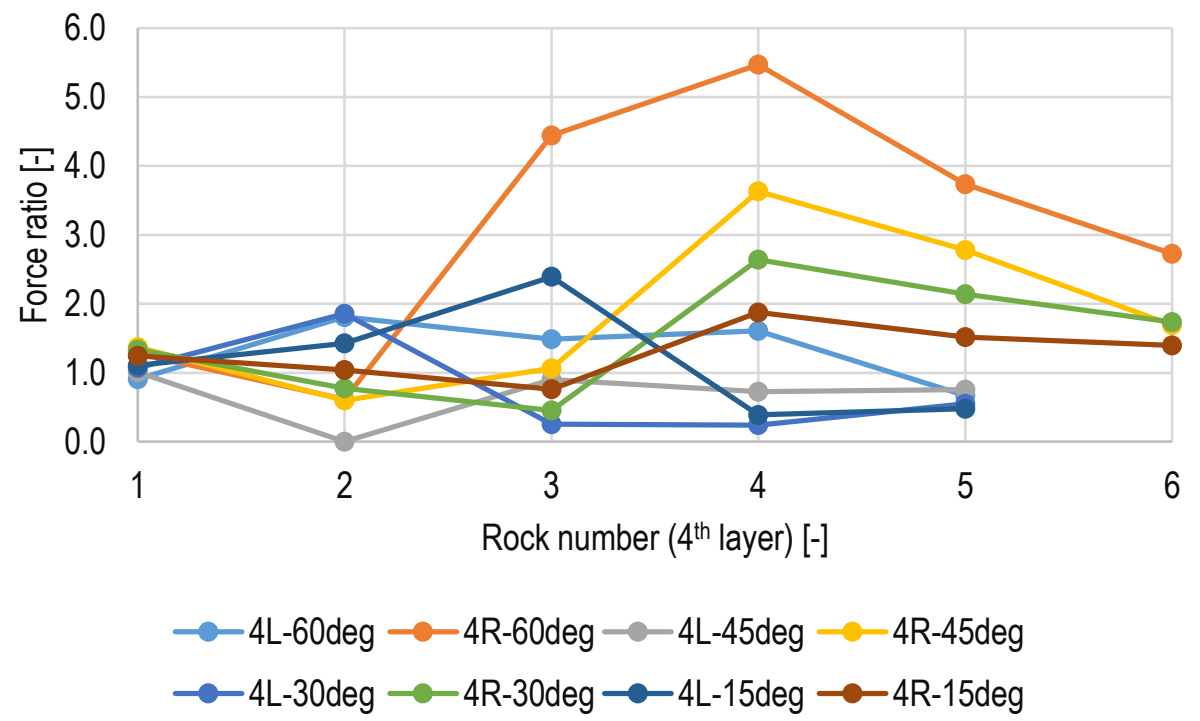

Figure 6-48: Cumulative plot of the force ratio for the rocks in the 4th layer at varying angle of the bend

Table 6-5: Maximum force ratio vs. the angle of the channel bend

\begin{tabular}{|c|c|c|c|}
\hline \multirow{2}{*}{ Angle [deg] } & \multicolumn{3}{|c|}{ Force ratio [-] } \\
\cline { 2 - 4 } & $\begin{array}{c}\text { Layer 2, rock } \\
\text { cluster 4 }\end{array}$ & $\begin{array}{c}\text { Layer 3, rock } \\
\text { cluster 4 }\end{array}$ & $\begin{array}{c}\text { Layer 4, rock } \\
\text { cluster 4 }\end{array}$ \\
\hline $\mathbf{6 0}$ & $5 \cdot 7$ & 4.6 & 5.5 \\
\hline $\mathbf{4 5}$ & 4.4 & 3.8 & 3.6 \\
\hline $\mathbf{3 0}$ & 2.9 & 2.6 & 2.6 \\
\hline $\mathbf{1 5}$ & 2.1 & 1.8 & 1.9 \\
\hline $\mathbf{0}$ & 1 & 1 & 1 \\
\hline
\end{tabular}




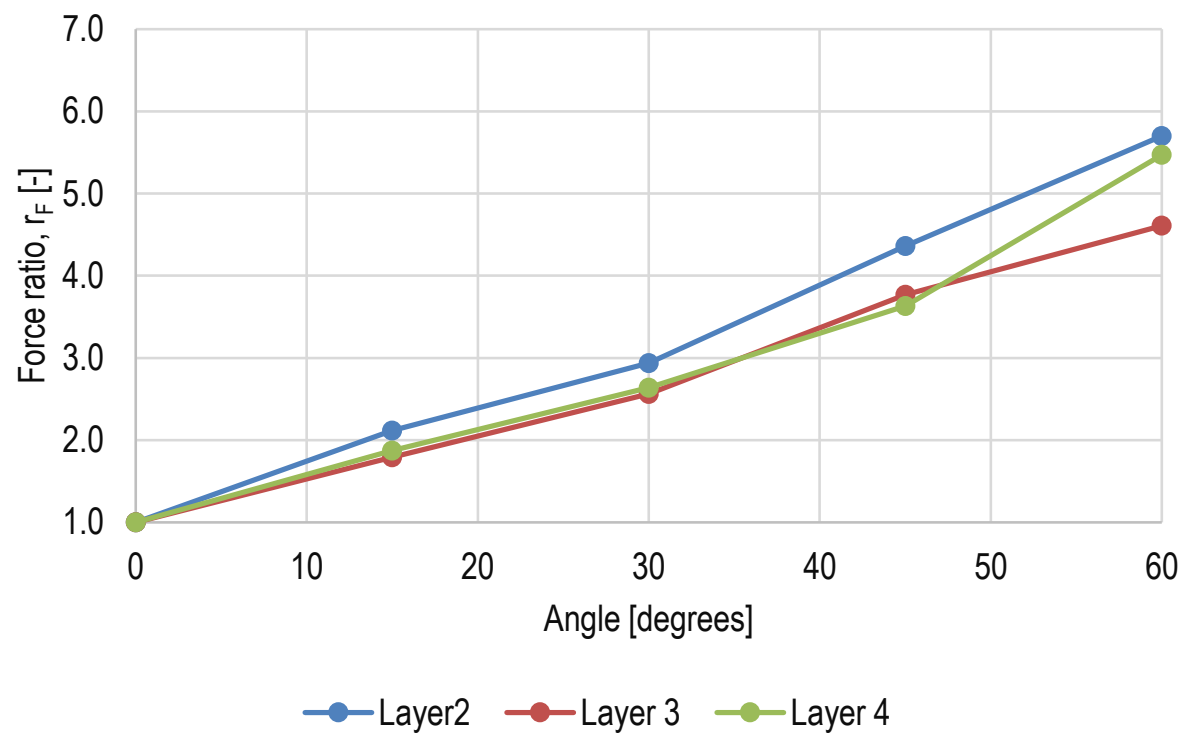

Figure 6-49: Force ratio vs. angle of the bend

\subsection{Numerical example of rockery failure criteria. Channel with a bend}

A rockery with the geotechnical and hydraulic parameters described in chapter 6.2 was constructed on both sides of a channel with a 60 degree bend, see Figure 6-50. It was established in chapter 6.5 that the maximum increase of the hydrodynamic forces, as compared to a straight channel, was by a factor of 5.7. Under the conservative assumption that all loads increase by the same factor, the sum $\sum_{i} F_{H D_{i}}$ increases 5.7 times. The ratios of resisting forces to sliding forces, and resisting moments to overturning moments are as follows:

- straight channel:

$$
\frac{F_{\mu}}{F_{H}}=1.03<1.5, \frac{M_{R}}{M_{O}}=1.48<2.0,
$$

- channel with a sharp bend:

$$
\frac{F_{\mu}}{F_{H}}=0.83<1.0, \frac{M_{R}}{M_{O}}=1.19<2.0 .
$$

The ratios of forces and moments drop, and the sliding failure criterion was not met, which means that the rockery is not stable under these conditions. 

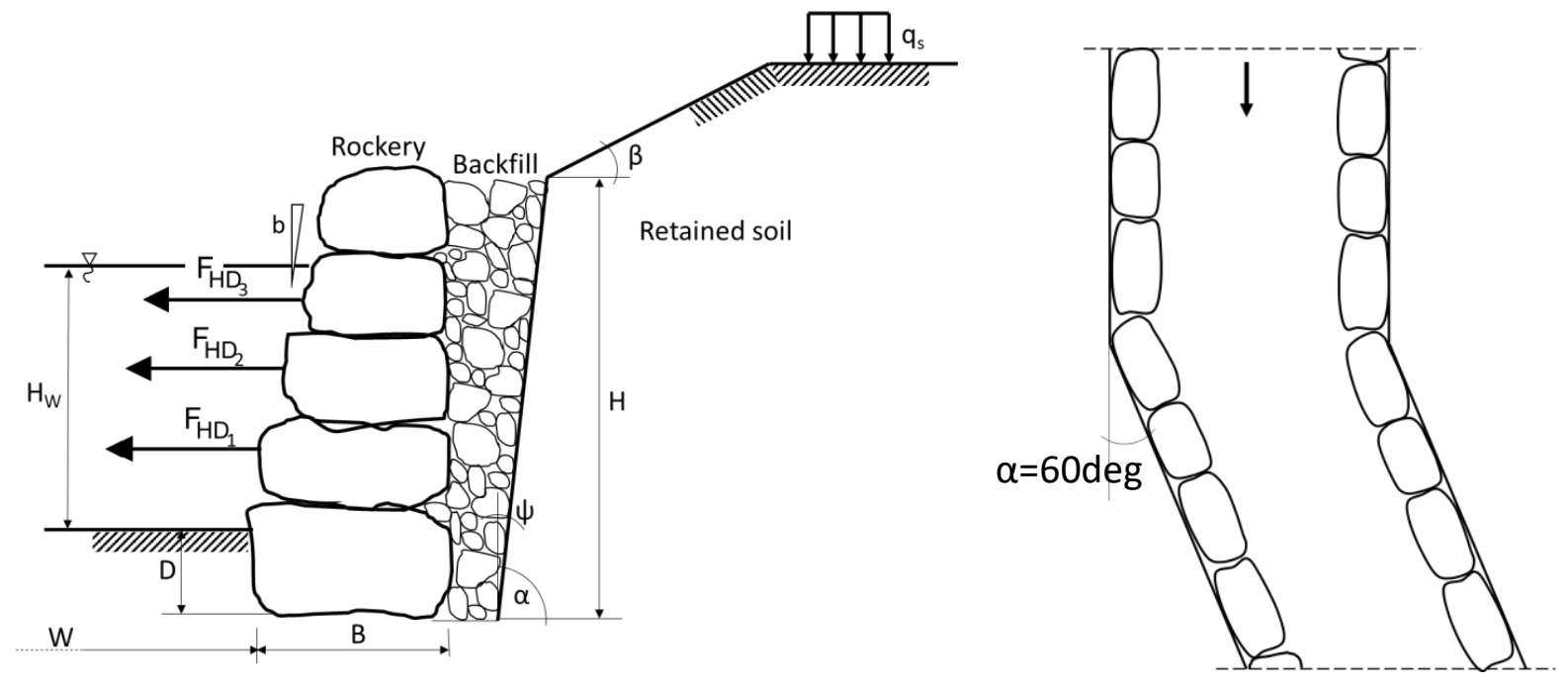

Figure 6-50: Numerical example - channel with a bend

\section{Summary}

Application of rockeries to channel bank protection has been of interest to engineers in the recent years. The existing design and construction guidelines refer to earth retaining and protecting structures, without the influence of flowing water. The design equations include various loads acting on a rockery, i.e. gravity force, lateral earth pressure, surcharge pressure, buoyancy, and contact/friction forces are the main forces acting on the rocks in a dry-stack rockery. The dynamic pressure distribution resulting from the water flow is unknown and has to be established experimentally, or, as presented in this report, with the use of computational fluid dynamics (CFD) analysis. The main goal of the study was to compute these additional, dynamic forces exerted on a structure in a riverine environment and to assess their influence on overall rockery stability.

A general approach to rockery stability analysis was presented that considers two failure types, sliding and overturning. The test case matrix covered computer simulations of various rockery and channel geometries as well as hydraulic conditions. The geometrical parameters taken into account are: rockery height, outside face batter angle of the rockery, rockery base width, river bed width, and the hydraulic parameters were: flow depth, flow velocity, and hydraulic angle of attack. Flow conditions representing water level lower than the rockery height, as well as overtopping of the structure, were considered.

The analysis showed that to ensure stability of a rockery in river environment, hydraulic static and dynamic forces should be accounted for in the design process. The hydrodynamic forces vary as a function of position in the rockery, size of the rocks, and the flow conditions. In the considered cases, these forces added a few percent to the total force. In most cases these hydrodynamic additional forces didn't influence the overall stability of the rockery, and the ratio of resisting to driving forces was higher than one. Nevertheless, calculations presented in chapter 6.2 showed, that under certain conditions the stability criteria were met by a very small margin, and when a 
channel with a sharp bend was considered, as described in chapter 6.6, it was found that the increase in hydrodynamic forces resulted in the resisting forces being lower than the driving forces, which made the rockery unstable. An increase in the other loads acting on the structure, such as the weight of the backfill or surcharge loads, may also lead to unsafe conditions. These considerations are outside of the scope of the present study. The resisting force component from the weight of the rocks changes in a riverine environment when they are submerged. In water, the weight of the rocks is effectively decreased by the buoyancy force, and this reduction can have a significant effect on the stability of a rockery.

Non-dimensional plots of a lateral force coefficient were developed with the goal to generate design aids for engineers. The proposed charts and formulas make it possible to make use of the CFD simulation results in a straightforward stability assessment procedure that does not involve running CFD software, and could be easily carried out by field engineers. An example design problem was provided.

Currently the recommendations for rockery design are limited to the considered cases, which cover two face batter slopes, two rockery base widths, five values of water depth, several channel bed widths with parallel flow, and one type of channel bend with varying angle of the bend. To obtain a broader and more detailed set of data covering effects of parameter variation on the hydrodynamic forces on rockeries, an expanded test case matrix should be considered to cover a wider range of structures and conditions.

\section{Acknowledgements}

The funding for this project came from the Hydraulics Research Program at the Turner-Fairbank Highway Research Center, through Interagency Agreement Number DTFH61-14-X-300002 between DOT and DOE, and the work was performed under DOE's contract with UChicago Argonne, LLC, contract no. DE-ACo2-06-CH11357. 


\section{References}

[1] Rockery Wall, Plan No. CK-R.52, City of Kirkland, Washington

[2] Prescriptive Standards for Design, Installation and Inspection of Rockeries, City of Sparks, Nevada

[3] Rockery Wall Construction. South Nevada Local Standard, SNBO Structural Committee, 2005

[4] WSDOT, Retaining Walls and Steep Reinforced Slopes, WSDOT Design Manual M 2201.05, 2009

[5] Mohoney J., Retaining Wall Design Guide, FHWA-FLP-94-006, 1994

[6] Mack D. A., Sanders S. H., Millhone W.L., Fippin R. L., Kennedy D. G., Rockery Design and Construction Guidelines, FHWA-CFL/TD-06-006, 2006

[7] Bojanowski C., Lottes S., Bergendahl B., CFD Modeling of Rockery Walls in the River Environment, 2014 National Hydraulic Engineering Conference, August 22, 2014, Iowa City, IA

[8] Sitek M., Lottes S., Bojanowski C., Hydrodynamic loads on rockeries for bank protection, 2018 Transportation Research Board Meeting, January 7-11, 2018, Washington DC

[9] Star-CCM+ v.12.06 documentation

[10] American Association of State Highway Transportation Officials (AASHTO), Standard Specifications for Highway Bridges, 17th Edition, Code HB-17, 2002 


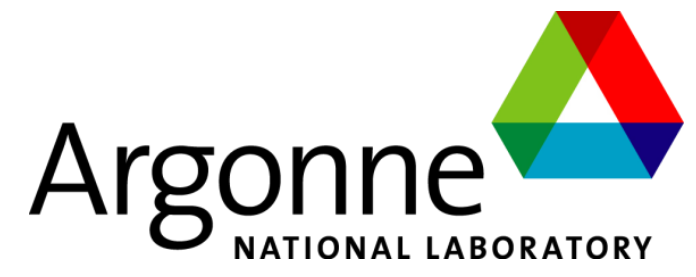

Nuclear Science and Engineering Division

Argonne National Laboratory

9700 South Cass Avenue

Argonne, IL 60439-4815

www.anl.gov

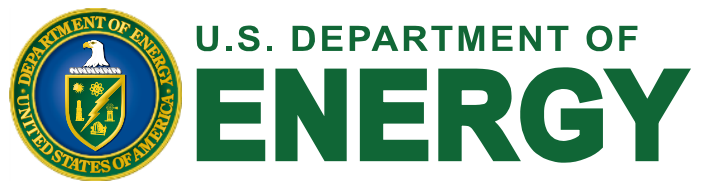

Argonne National Laboratory is a U.S. Department of Energy laboratory managed by UChicago Argonne, LLC

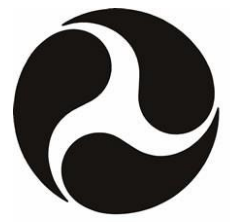

U.S. Department of Transportation

\section{Federal Highway Administration}

